\title{
MINIMAL REALISM ABOUT ORDINARY OBJECTS
}

\author{
By
}

Chrissy van Hulst

A thesis submitted to the Victoria University of Wellington in fulfilment of the requirements for the degree of Masters of Arts in Philosophy

Victoria University of Wellington

2018 


\section{ACKNOWLEDGEMENT}

I would first like to thank my thesis advisor Stuart Brock. The door to Prof. Brock's office was always open whenever I ran into a trouble spot or had a question about my research or writing. He consistently allowed this paper to be my own work, but steered me in the right the direction whenever he thought I needed it.

I would also like to thank all my friends who were there for both emotional support and helped me talk through some of the philosophical issues contained in this thesis. In particular, I would like to thank Mat Logan, Agata Orłowicz, and Johnny McDonald. 


\begin{abstract}
In 2015 Daniel Korman published an incredibly important book called Objects: Nothing out of the ordinary, in which he defends a position known as conservatism about ordinary objects. He contrasts this position with two other positions - eliminativism and permissivism - and provides comprehensive arguments against these two positions. Korman takes eliminativism to be the view that ordinary objects do not exist. Even though this is indeed one of the claims eliminativists make, by itself it is not a good description of what eliminativism entails. For eliminativism, as ordinarily conceived, contains three main claims: i) the anti-realist claim that certain entities do not exist, ii) the claim that we are making an error when we assert that those entities do exist, and iii) the prescriptive claim that we should eliminate talking and thinking about those entities. These three claims together entail eliminativism. Korman, however, identifies eliminativism merely with the first anti-realist claim. Since Korman's focus is on the anti-realist claim, this thesis departs from Korman's tripartite division and instead frames the debate in terms of Minimal Realism and Minimal Anti-Realism about ordinary objects. Minimal Realism is simply the view that ordinary objects exist, and includes views such as conservatism and permissivism. Minimal Anti-Realism, by contrast, is the view that ordinary objects do not exist, such as eliminativism as Korman defines it. By refocussing the debate in terms of Minimal Realism and Minimal Anti-Realism, it becomes apparent that there are a variety of Minimal Realist positions which claim that ordinary objects do indeed exist, but which have been left out by Korman. My goal is to supplement Korman's arguments with literature published since the publication of his book, and to show how Minimal Realism responds to the arguments for eliminativism. In particular, I focus on the Debunking Argument, the Argument from Arbitrariness, the Overdetermination Argument, the Argument from Vagueness, the Argument from Material Constitution, and the Problem of the Many. After setting out these arguments, I discuss some recent objections, and show how Minimal Realism can respond to the proposed arguments and objections.
\end{abstract}


CHAPTER 1 THE DEBUNKING ARGUMENT

$\begin{array}{ll}1.1 \text { EXPLANATION OF THE ARGUMENT } & 14\end{array}$

1.2 OBJECTIONS TO THE DEBUNKING ARGUMENT 1

$\begin{array}{ll}1.3 \text { RESPONSES TO THE OBJECTIONS } & 19\end{array}$

1.4 THE ONTOLOGICAL CONCEPTUALIST'S RESPONSE 39

CHAPTER 2 THE ARGUMENT FROM ARBITRARINESS 46

2.1 EXPLANATION OF THE ARGUMENT 46

2.2 OBJECTIONS TO THE ARGUMENT FROM ARBITRARINESS

2.3 THE ONTOLOGICAL CONCEPTUALIST'S RESPONSE

CHAPTER 3 THE OVERDETERMINATION ARGUMENT

3.1 EXPLANATION OF THE ARGUMENT

3.2 OBJECTIONS TO THE OVERDETERMINATION ARGUMENT

3.3 THE ONTOLOGICAL CONCEPTUALIST'S RESPONSE 82

CHAPTER 4 THE ARGUMENT FROM VAGUENESS

4.1 EXPLANATION OF THE ARGUMENT

4.2 OBJECTIONS TO THE ARGUMENT FROM VAGUENESS 90

4.3 THE ONTOLOGICAL CONCEPTUALIST'S RESPONSE 108

CHAPTER 5 THE ARGUMENT FROM MATERIAL CONSTITUTION 113

5.1 EXPLANATION OF THE ARGUMENT 113

5.2 OBJECTIONS TO THE ARGUMENT FROM MATERIAL CONSTITUTION 115

5.3 THE ONTOLOGICAL CONCEPTUALIST'S RESPONSE $\quad 129$

CHAPTER 6 PROBLEM OF THE MANY 133

6.1 EXPLANATION OF THE ARGUMENT 133

6.2 OBJECTIONS TO THE PROBLEM OF THE MANY 134

6.3 THE ONTOLOGICAL CONCEPTUALIST'S RESPONSE 138

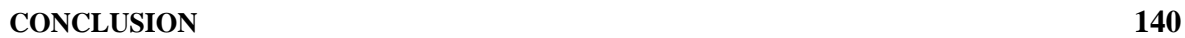




\section{INTRODUCTION}

In 2015, Daniel Korman published an important book called Objects: Nothing out of the ordinary. The book defends conservatism about ordinary objects. According to conservatism, ordinary objects, such as tables, chairs, stars, and planets, exist. Moreover, extraordinary objects such as the 'object' composed of a tree and a dog, don't exist. Korman's monograph is a seminal work in metaphysics, partly because his articulation of conservatism is so clear and his defence is cogent. The monograph comprehensibly covers the range of positions in the field of mereology. He looks closely at motivations for adopting each of the alternative positions and clearly explains the problems associated with them. The book has had an astonishing influence on people working within the field and has captured the attention even of philosophers who don't traditionally work in this area. ${ }^{1}$

My goal in this thesis is twofold. It takes as a starting point Korman's 2015 Objects: Nothing out of the ordinary. My first goal is to look at some of the literature for eliminativism published since the publication of this book. I only look at the recent literature because my concern is to respond to the arguments concerning eliminativism. My second goal is to propose that Minimal Realist views can address the arguments for eliminativism.

Korman sets out the main positions regarding ordinary objects. Korman's exposition of these positions is excellent and he presents the main arguments for and against them clearly and concisely. His coverage is comprehensive and includes the relevant literature up until the date of publication. I explain and evaluate these arguments in the following chapters and look at some of the recent literature regarding these arguments. I then explain how a Minimal Realist view can answer these arguments.

\footnotetext{
${ }^{1}$ For reviews of Korman's book see Envine 2016; Sanson (forthcoming); Olivero 2016.
} 
The three main positions regarding ordinary objects are eliminativism, permissivism, and conservatism. Korman describes eliminativism as the view that a wide range of ordinary objects don't exist. Two main varieties of eliminativism are nihilistic and non-nihilistic eliminativism, but my focus is on nihilistic eliminativism. Nihilism is the thesis that a plurality of objects doesn't compose a further object. According to nihilistic eliminativism, ordinary objects don't exist, because they are composite objects and pluralities of objects never compose a further object. $^{2}$ What there is instead, are many microscopic atoms. An atom is a fundamental entity; they could be those entities talked about in science or they could be the mereological simples talked about in philosophy. ${ }^{3}$ According to nihilistic eliminativism, some of these atoms are arranged table-wise but they don't compose a table. ${ }^{4}$ The difference between an object being composed of something and an object being made up of something is that an object is made up of the matter it's constituted by, whereas an object is composed of something when the composite object is a further object.

Eliminativism, as Korman conceives it, denies the existence of ordinary objects such as tables; what there is instead are atoms arranged table-wise. Some argue this view is incoherent or trivially false, because having atoms arranged table-wise just is what it is for there to be tables. However, this is not necessarily true, for this idea relies on the Composition as Identity thesis, which states that if an object is composed of certain parts, then that object is identical to those parts taken collectively. ${ }^{5}$ However, the Composition as Identity thesis is controversial, because atoms still exist after tables are destroyed while tables don't. The atoms still exist, but they are not arranged table-wise anymore. Thus, atoms arranged table-wise have different modal profiles

\footnotetext{
${ }^{2}$ However, not all eliminativists argue that composition never occurs. Such eliminativists argue that nihilism is false and make an exception for the existence of certain classes of composites. In particular, they often make an exception for people and/or other organisms. See Van Inwagen 1990; Merricks 2001.

${ }^{3}$ Nihilism is compatible with existence monism which is the view that there's only one object, usually the cosmos, which has no parts despite appearances. Nihilism is also compatible with the extreme nihilist view that there are no objects at all. See Le Bihan 2015. I won't focus on these two subclasses of nihilistic eliminativism since the other version is much more popular.

${ }^{4}$ Korman 2015: 19-21; Korman 2016: 4.

${ }^{5}$ Korman 2015; 21-22.
} 
than tables, which means they cannot be identical. ${ }^{6}$ In this thesis I assume the Composition as Identity thesis is false.

Korman describes permissivism as the view that both ordinary objects and extraordinary objects exist. Extraordinary objects are objects composed of any two or more objects, and any two objects compose a further object. For example, a trog is an object that is composed of a dog and a tree. The main varieties of permissivism are universalism, diachronic universalism, and the doctrine of plenitude, but this thesis focuses on universalism. ${ }^{7}$ Universalism is the thesis that composition is unrestricted; for any plurality of objects there's a further object composed of those objects. When there are some atoms arranged table-wise, there's also a further object composed of those atoms, i.e. a table. It also means that whenever there's a plurality of objects that we don't usually think of as composing a further object, such as a dog and a tree, there $i s$ an object composed of a dog and a tree, i.e. a trog. ${ }^{8}$

Conservatism is the view that ordinary objects exist while extraordinary objects don't. Korman defines the term 'object' as a material object, which is made up of matter, has a location, and can move through space and persist through time. ${ }^{9}$ Conservatism only concerns the question of which objects exist, and remains neutral regarding other questions, and could endorse different views about the nature of ordinary objects. ${ }^{10}$ Most importantly, conservatism remains neutral regarding the identity and persistence-conditions of ordinary objects, and the mind(in)dependence of ordinary objects. Identity-conditions of ordinary objects are conditions that make an object the object it is. Persistence-conditions of ordinary objects are those conditions that account for an object persisting through time. ${ }^{11}$ Conservatism also remains neutral regarding the mind-(in)dependence of ordinary objects. Conservatists can endorse mind-dependent views

\footnotetext{
${ }^{6}$ Korman 2015: 21-22.

${ }^{7}$ Korman 2015: 13-14; Korman 2016: 6.

${ }^{8}$ Korman 2015: 14; Korman 2016: 6.

${ }^{9}$ Korman 2015: 25.

${ }^{10}$ Korman 2015: 23.

${ }^{11}$ Korman 2015: 23.
} 
about ordinary objects, meaning the existence of objects is in some way dependent on human beings. ${ }^{12}$

Korman's tripartite division between eliminativism, permissivism, and conservatism is great. However, this thesis doesn't follow Korman's tripartite division, but instead frames the debate in terms of Minimal Realism and Minimal Anti-Realism. Minimal Realism is the view that ordinary objects exist (either mind-independently or mind-dependently), and thus includes conservatism and permissivism. Minimal Anti-Realism is the view that ordinary objects don't exist, and thus includes eliminativism as Korman sets it out. I frame the debate in terms of Minimal Realism and Anti-Realism, because Korman takes eliminativism to be the view that ordinary objects don't exist simpliciter. However, eliminativism as ordinarily conceived consists of three main claims: (i) the anti-realist claim that certain entities don't exist, (ii) the claim that we are making an error when we assert those entities exist, and (iii) the prescriptive claim that we should eliminate talking and thinking about those entities. Any one of these claims by themselves don't entail eliminativism; only taken together do they constitute eliminativism. The anti-realist claim by itself doesn't constitute eliminativism. For example, many people don't believe unicorns exist, but this doesn't mean people are eliminativists about unicorns, because we are not in error about such beliefs nor should we eliminate talking about unicorns. Furthermore, even the first two claims taken together don't entail eliminativism, since many philosophical views - such as fictionalism, projectivism, and non-cognitivism - accept the anti-realist claim and the error claim, but don't accept we should stop talking about the entities they deem not to exist. A genuine eliminativist view, therefore, should embrace all three claims. Korman, however, identifies eliminativism merely with the anti-realist claim. That is, he defines eliminativism as the view that ordinary objects don't exist, and the arguments he proposes focus on the claim that ordinary objects don't exist. ${ }^{13}$

Since Korman focuses on the anti-realist claim, this thesis frames the debate in terms of Minimal Realism and Minimal Anti-Realism. Construing the debate this way mirrors a well-known

\footnotetext{
${ }^{12}$ See Goodman 1978 and Einheuser 2006 for anti-realist views.

${ }^{13}$ Korman 2015: 19.
} 
distinction between realism and anti-realism about ordinary objects. Realism about ordinary objects is often taken to be the view that ordinary objects exist, and furthermore, that they exist mind-independently. Anti-realism about ordinary objects is often taken to be the view that ordinary objects don't exist, and furthermore, that even if they exist in some sense, this existence is mind-dependent. Although realism often implies a mind-independent view about ordinary objects and anti-realism sometimes implies a mind-dependent view about ordinary objects, I want to be clear that I take Minimal Realism about ordinary objects to be the view that ordinary objects exist regardless of their mind-(in)dependence. So, both mind-dependent and mindindependent views about ordinary objects fall under Minimal Realism. By contrast, I take Minimal Anti-Realism about ordinary objects to be the view that ordinary objects simply don't exist. However, I still often talk in terms of Korman's eliminativist's terminology.

Korman proposes a conservatist view and attempts to undermine the arguments for eliminativism and permissivism. In doing so, he tacitly endorses the view that ordinary objects have an intrinsic essence. The term 'intrinsic' is controversial and there are many ways to interpret it. ${ }^{14}$ However, for the purpose of this thesis, a property is intrinsic to an object when that property doesn't depend for its existence on anything external to that object. The term 'essence' is controversial as well. I take the essence of an object to be the property or set of properties whose possession is a necessary and sufficient condition to make the object as the object it is. ${ }^{15}$ Korman tacitly endorses the view that objects have intrinsic essences; objects have an intrinsic property making it the object it is. However, Korman doesn't discuss, or at least he doesn't discuss at length, what this means. This omission is justified because his focus is not on essences, however, if an explication of the essence of an object influences the answer to the arguments for eliminativism, then an explication of essence should be included.

Instead of talking about essences, however, I talk about the identity and identity-conditions of ordinary objects. There are different interpretations of identity and identity-conditions. Identityconditions can be the conditions under which an object counts as one object, they can be the

\footnotetext{
${ }^{14}$ See Humberstone 1996 for an examination of the terms intrinsic and extrinsic.

${ }^{15}$ Fine 1994; Bird and Tobin 2017.
} 
conditions under which an objects remains the same over time, ${ }^{16}$ or they can be the conditions that make an object the object it is. These three interpretations are related, but I take identityconditions to be those conditions that make an object as the object it is.

There's an important relationship between essence and identity-conditions. In the literature on identity-conditions, there are many terms that denote my interpretation. These terms include essences, essential properties, necessary properties, boundaries, sameness-conditions, and modal properties. I talk about identity-conditions as opposed to these other terms because I think what underlies these different terms is the question about what makes an object the object as it is. For instance, many discussions involving essential properties can be phrased in terms of identityconditions, for when philosophers talk about essential properties of ordinary objects, they are talking about what makes an object the object it is. ${ }^{17}$ Similarly regarding necessary properties, e.g. many discussions about necessary properties of ordinary objects involve the properties an object must have for it to be the object it is. Likewise, persistence-conditions and samenessconditions can also be framed in terms of identity-conditions. To determine whether an object persists through time, one must look at the identity-conditions at two different times and determine whether the identity-conditions are the same (or similar enough) at those times. Likewise for sameness-conditions; to determine whether two objects are the same, one must look at the identity-conditions of those objects, and determine whether or not the two objects have the same identity-conditions. Overall, it seems that discussions involving those terms can be rephrased in terms of identity-conditions.

So this thesis focuses on identity-conditions. I argue ordinary objects don't have their identityconditions intrinsically but instead have them in virtue of the concepts we employ to pick them out. Identity-conditions are grounded in our concepts, and concepts impose identity-conditions on ordinary objects. So ordinary objects do have identity-conditions, but they are not intrinsic to objects and instead are grounded in our concepts. I endorse a Conservatist Minimal Realist view I call Ontological Conceptualism. Ontological Conceptualism is the view that what exists partly

\footnotetext{
${ }^{16}$ Moltman 2007.

${ }^{17}$ Lowe 2008: 10 explicitly states that he takes 'identity' to mean individual essence.
} 
depends on the concepts we use. So the existence of ordinary objects we perceive partly depends on the concepts we employ. ${ }^{18}$ Not only are identity-conditions grounded in our concepts, but an object's modal and mereological profiles are grounded in our concepts as well, because an object's modal and mereological profile depend on, or are determined by, the object's identityconditions. ${ }^{19}$ Since identity-conditions determine the modal and mereological profiles of ordinary objects, modal and mereological profiles are also grounded in our concepts.

An Ontological Conceptualist account must explain what the world contributes to what objects exist, how our concepts contribute to what objects exist, and must explain the nature of the objects jointly determined by the world and our concepts. ${ }^{20}$

To say identity-conditions are grounded in our concepts is not to say that no properties of an object depend on the mind-independent world. For example, the matter tables are made up of is not determined by our concepts. But our concept TABLE may determine that tables are necessarily composed of the matter they are made up of. ${ }^{21}$ Had we employed different concepts, the matter would still exist, but they would not be objects or they would have been different objects. Thus, the mind-independent world contributes the matter - the atoms - but it doesn't provide the identity-conditions. ${ }^{22}$ I remain neutral regarding what the mind-independent world is like. I remain neutral regarding the nature of the world, and merely maintain that identity-

\footnotetext{
${ }^{18}$ Alternatively, Ontological Conceptualism about macroscopic ordinary objects could also be interpreted as the claim that how we perceive or experience these objects depends on our concepts and how we use them. The claim that objects depend on our concepts and the claim that our experience of those objects depend on our concepts are importantly different. However, since Korman uses ordinary perception, experience, and intuitions as one of the most important underlying arguments against eliminativism, this distinction is not that important for the purpose of this thesis.

${ }^{19}$ The term Ontological Conceptualism is borrowed from Einheuser 2011.

${ }^{20}$ Einheuser 2003: 23; 2011: 303.

${ }^{21}$ Einheuser 2011: 304.

${ }^{22}$ Einheuser 2006: 461, 480-481fn4. The term 'substratum' is often used to denote the underlying structure of the world. For the Ontological Conceptualist, the substratum does not have to be like Kantian things-in-themselves, or a mysterious stuff or dough which we can only access through a conceptual or perceptual veil which misrepresents what the world in itself is like. Instead, Ontological Conceptualism merely takes some features of reality to be grounded in our concepts and can take for granted those aspects of reality which don't depend for their existence on our concepts.
} 
conditions are not intrinsic to the mind-independent world, but are instead grounded in our concepts.

The next question is how our conceptual practices impose identity-conditions onto ordinary objects. I provide a mechanism - categorization - by which concepts impose identity-conditions onto the mind-independent world.

Categorization is a neurological process that transforms incoming sensory stimulation into meaningful information. By categorizing sensory information, the stream of sensory information is divided up into meaningful objects. ${ }^{23}$ One result of categorization is the way we experience something - the way we experience something as something. Due to categorizing, we perceive objects as objects, and we perceive particular objects as the objects they are. Thus, categorization determines what objects are, what their identity-conditions are, and what kind they fall under.

Categorization uses the conceptual system in categorizing sensory information. The conceptual system comprises our conceptual knowledge about objects. Conceptual knowledge enables recognition of objects and enables us to make inferences about them. This knowledge exists in the form of concepts. Concepts have been defined in several ways; for example, as "the mental representation of a class or individual," 24 or as "the meaning of objects, events, and abstract ideas. ${ }^{25}$ When conceptual knowledge about objects combines with sensory information, the experience of those objects as the objects they are, emerges. This means that the experience of the objects we perceive results from conceptualization of sensory information from the mindindependent world during categorization. Conceptualization is the process that combines conceptual knowledge with sensory information, and is part of the categorization process.

\footnotetext{
${ }^{23}$ Lindquist 2013: 361.

${ }^{24}$ Smith 1989 as cited in Goldstein 2015: 246.

${ }^{25}$ Kiefer and Pulvermuller 2012 as cited in Goldstein 2015: 246.
} 
Categorization, then, is the process from conceptualization to the experience of objects and the experience of objects as the objects they are. ${ }^{26}$

I argue categorization imposes identity-conditions on objects. We perceive objects as the objects they are as a result of categorization. Human beings naturally have a preference for order and stability - both consciously and subconsciously - and our brain functions to achieve this stability. Categorization creates this stability by making sensory information meaningful in the sense that without it, both the mind-independent world and our internal milieu would be a bombardment of information that we are unable to make sense of.

I take the term 'object' to mean a conceptualized entity. We conceptualize entities through categorization resulting in conceptualized objects. I argue ordinary objects are conceptualized objects while extraordinary objects are unconceptualized objects. Through categorization, we experience the world as containing ordinary objects. We experience the world as containing conceptualized objects. Since we don't categorize the extraordinary objects permissivists talk about, we don't experience the world as containing unconceptualized objects.

I argue we should only admit conceptualized objects in our ontology and exclude unconceptualized objects. I take human beings, including their conceptual activities, to be part of the world. If conceptual activities are part of the world, then the world doesn't merely contain atoms arranged in a certain way, but the world also contains conceptualized objects. Thus, Ontological Conceptualism is a Minimal Realist view and not an Anti-Realist view. I take conceptualized objects to exist, and since I defined an object as a conceptualized entity, the only objects that exist are ordinary objects. Extraordinary objects are not objects in my sense of the word, since they are by definition unconceptualized. And since they are not objects to begin with they don't exist. Hence my view is a Conservatist Minimal Realist position. Conservatist because I only take ordinary objects to exist, and it's Minimal Realist because I take those objects to exist.

${ }^{26}$ Barrett 2006: 20-21; 2011: 362-364; 2009a: 9; 2009b: 1289-1290. 
In the following chapters I set out the arguments for eliminativism: the Debunking Argument, the Argument from Arbitrariness, the Overdetermination Argument, the Argument from Vagueness, the Argument from Material Constitution, and the Problem of the Many. I devote one chapter to each of these arguments. After explaining each argument, I discuss some objections and responses included in Korman's book, and provide some objections and responses published after the publication of his book. Finally, I explain how a Conservatist Minimal Realist view, such as Ontological Conceptualism, addresses the argument and objections.

The Debunking Argument claims there's no explanatory causal connection between the existence of objects and the beliefs we have about the existence of objects, and therefore, we shouldn't believe ordinary objects exist. The main objections are Causal Connection Objections, such as the Perceptual Connection, the Intuition Connection, and the Apprehension Connection, which all propose an explanatory causal connection between the existence of objects and the beliefs we have about those objects. Responses to these objections argue the connection in question is deviant. I consider responses by Osborne, who provides empirical evidence to substantiate the claim that the connection is deviant, and Rose and Schaffer, who conducted a study to show our intuitions regarding the existence of objects are teleologically infused, and for that reason we shouldn't rely on those intuitions. Korman and Carmichael reply to Rose and Schaffer and state objections to how those studies were conducted. Bowers, by contrast, accepts Rose and Schaffer's results, but instead of rejecting those intuitions, he takes them as a reason to accept a teleological account of ordinary objects. Lastly, I discuss the Ontological Conceptualist's response to the Debunking Argument and the proposed objections and responses.

The Argument from Arbitrariness claims there's no ontologically significant difference between ordinary objects and extraordinary objects, so if we accept that ordinary objects exist, then we should also accept extraordinary objects exist (or deny both exist). The main objections are the objection from Extraordinary Restrictive Modal Profiles and the objection from Extraordinary Liberal Modal Profiles. Both claim there's an ontologically significant difference between 
ordinary objects and extraordinary objects. I discuss these objections and some of the proposed responses. Lastly, I discuss the Ontological Conceptualist's response to the Argument from Arbitrariness and the proposed objections and responses.

The Overdetermination Argument claims that events caused by ordinary objects are also caused by the atoms they are made up of, leading to unacceptable overdetermination. I discuss four objections. The first objection is that there are unproblematic cases of overdetermination, such as object-event overdetermination, so overdetermination in terms of objects and their atoms is unproblematic as well. Merricks responds to this objection and argues there are important differences between these two cases. The second objection is that overdetermination is only problematic when two causes are sufficiently independent from one another. Since ordinary objects and their parts are not sufficiently independent from each other, there's no problematic overdetermination. The third objection is that overdetermination is only problematic when both causes exist. However, Merricks argues we don't have reason to believe ordinary objects exist. If ordinary objects don't exist, then there's no overdetermination. Sider and Korman reply to Merricks' argument. Next, I set out a recent response by Bernstein who argues the distinction between problematic and unproblematic overdetermination doesn't undermine eliminativism but also argues this distinction doesn't support conservatism either. The fourth objection is a recent argument by Le Bihan who argues eliminativism about ordinary objects entails eliminativism about physical particles. Lastly, I set out how the Ontological Conservatist responds to the Overdetermination Argument and the proposed objections and responses.

The Argument from Vagueness claims that if some pluralities of objects compose something and others don't, then this leads to unacceptable vagueness; it is vague whether some plurality of objects composes something. I discuss four objections to the Argument from Vagueness. The first objection is the Epistemicist Objection that there can be exact cut-offs in sorites series, and I set out a recently proposed response by Kurtsal Steen. The second objection is that there can be borderline cases of composition and accept this commits one to existential indeterminacy. This can be done in two ways. Firstly, one can deny an expression in a numerical sentence must be vague if it's indeterminate which objects exist. Secondly, one can deny no expression in a 
numerical sentence is vague. Merricks recently proposed a third objection, and argues that if vagueness is a feature of language, then there cannot be vagueness if there's no language. Wasserman recently proposed a fourth objection and argues borderline cases result from indeterministic metaphysical laws. Lastly, I discuss the Ontological Conceptualist's response to the Argument from Vagueness and the proposed objections and responses.

The Argument from Material Constitution claims ordinary objects are unacceptably co-located with the atoms they are made up off. The idea is that ordinary objects are made up of the matter constituting them. The relationship between ordinary objects and what constitutes them leads to a tension between our intuitions about the identity of objects and our intuitions about the persistence-conditions of objects. The main objections against the Argument from Material Constitution are monist objections and pluralist objections. According to monist objections, Athena is identical to Lumpy. I discuss one monist objection; the Inconstancy Objection and Barker and Jago responses to it. The Pluralist objection claims Athena is distinct from Lumpy. The argument against the Pluralist objection is the Grounding Problem. I discuss four replies to the Grounding Problem. The Sortal Reply claims Athena and Lumpy are different because they fall under different sortals. The Spatial Arrangements Reply claims the differences are grounded in the way their parts are arranged. A recent reply by Jago claims the differences are grounded in the identity of objects. Another recent reply by Campdelacrue claims the differences are grounded in the primary kind an object belongs to. Lastly, I discuss the Ontological Conceptualist's response to the Argument from Material Constitution and the proposed objections and responses.

The Problem of the Many claims if we admit one ordinary object into our ontology, this leads to admitting an unacceptably many number of objects into our ontology, because it isn't clear exactly which atoms it's made up of. I discuss two objections to the Problem of the Many. The first objection is Constitutionalism and the second objection is Manyism. I then discuss two responses to Manyism. The first response to Manyism appeals to supervaluationism while the second response to appeals to Almost-Identity. Next, I discuss a recent reply to Almost-Identity 
proposed by Sutton. Lastly, I discuss how the Ontological Conceptualist can respond to the Problem of the Many and the proposed objections and responses. 


\section{CHAPTER 1 THE DEBUNKING ARGUMENT FOR ELIMINATIVISM}

\subsection{EXPLANATION OF THE ARGUMENT}

The first argument for eliminativism is the Debunking Argument. Debunking arguments attempt to show a belief or set of beliefs lack justification and for that reason undermine those beliefs. The two main types of debunking arguments are best-explanation debunking arguments and process debunking arguments. Best-explanation debunking arguments attempt to show a belief lacks justification if the best explanation for that belief doesn't involve the truth of that belief, whereas process debunking arguments attempt to show a belief lacks justification if the process by which someone arrives at their belief is epistemically unreliable. ${ }^{27}$ The idea behind the Debunking Argument is that there's no explanatory causal connection between facts about the existence of ordinary objects (object-facts) and the beliefs we have about the existence of those objects (object-beliefs) or the process by which we came to those object-beliefs is somehow deviant. The argument runs as follows:

DA1: There's no explanatory causal connection between our object-beliefs and the object-facts.

DA2: If there's no explanatory causal connection between our object-beliefs and the object-facts, then we shouldn't believe ordinary objects exist.

DA3: Therefore, we shouldn't believe ordinary objects exist. ${ }^{28}$

The first premise is plausible. The idea is that our beliefs regarding the existence of objects is, at least partly, the result of biological and cultural factors. For example, the reason we tend to believe in trees but not trogs isn't because trees exist and trogs don't exist, but instead we tend to

\footnotetext{
${ }^{27}$ Hricko and Leben forthcoming: 2-3.
}

${ }^{28}$ Korman 2015: 5. 
believe in trees but not trogs because of the conventions we use regarding these objects. According to these conventions, we don't regard something as an object unless it's connected or unified in a certain way. Thus, the conventions which regulate composition likely result from us perceiving some qualities as being co-instantiated by a single object, while we perceive others as not co-instantiated by a single object. Our ability to perceive some but not other qualities as being co-instantiated by a single object is probably innate, and evolved because it's adaptive for human beings to perceive the world as divided into the objects we take there to be. So it's plausible the reason for why we divide up the world the way we do, has nothing to do with how the world is actually divided up. If this is true, then there's no satisfactory explanatory connection between our beliefs about which objects exist and which objects actually exist. ${ }^{29}$

A satisfactory explanatory connection could either be an alethic explanation or a doxastic explanation. An alethic explanation is an explanation of object-beliefs in terms of object-facts; e.g. facts about trees explain the belief that trees exist. A doxastic explanation, by contrast, is an explanation of object-facts in terms of object-beliefs; e.g. beliefs about trees explain facts about the existence of trees. According to Korman, it's not plausible there's a doxastic explanation of object-facts in terms of object-beliefs; for it isn't plausible that facts about the existence of objects depend on our beliefs about the existence of objects. If ordinary objects such as trees do indeed exist, this is not because we believe in trees nor is it because we perceive or experience trees. The existence of trees is independent from our beliefs about trees. ${ }^{30}$ Moreover, according to the debunker, it isn't plausible there's an alethic explanation from object-facts to objectsbeliefs either. Such an explanation would state how facts about ordinary objects cause our beliefs about those objects, but since our object-beliefs result from biological and cultural factors rather than what objects actually exist, such explanation won’t be satisfactory. ${ }^{31}$

The second premise is plausible since if there's no explanatory causal connection between our object-beliefs and object-facts, then it's a coincidence our object-beliefs match the object-facts.

\footnotetext{
${ }^{29}$ Korman 2015: 4-5, 92-93; See also Benovsky (2015: par. 2); Elder (2011: 66); Merricks (2001: 72-76); Osborne (2016); Sattig (2015: 25-26); Sider 2001: 156-157); Rea (2002: ch.2); van Inwagen (1990: 6-12).

${ }^{30}$ Korman 2015: 92, Ch. 8.4.

${ }^{31}$ Korman 2015: 93.
} 
Since there's no rational grounds for believing in such a coincidence, we shouldn't believe ordinary objects exist. ${ }^{32}$

The Debunking Argument for eliminativism is aimed at those views about ordinary objects that hold ordinary objects are mind-independent. Mind-dependent views that hold object-facts are determined by, or somehow result from, object-beliefs, argue there is an explanatory causal connection between object-beliefs and object-facts; namely an alethic explanation. ${ }^{33}$

\subsection{OBJECTIONS TO THE DEBUNKING ARGUMENT}

The three objections to the Debunking Argument, which are all directed at the first premise, propose three different explanatory causal connections between our object-beliefs and the objectfacts. ${ }^{34}$ An explanatory causal connection is a connection between our object-beliefs and objectfacts in terms of a causal relation. All three connections are in terms of a causal connection where object-facts explain object-beliefs by positing a causal relation between the two. This causal connection can be cashed out in three ways. First, the connection can be based on perception or experience, i.e. object-beliefs are connected to object-facts because our perception or experience about the existence of objects cause the beliefs we have about those objects. Second, the connection can be based on intuition, i.e. object-beliefs are connected to object-facts, because our intuitions about the existence of objects causes the beliefs we have about those objects. Third, the connection can be cashed out in terms of apprehension; we have the object beliefs we have because we apprehend facts about the existence of objects.

\section{THE PERCEPTUAL CONNECTION OBJECTION}

\footnotetext{
${ }^{32}$ Korman 2015: 5, 94.

${ }^{33}$ Korman 2015: 94.

${ }^{34}$ For an objection to DA2 See Benacerraf 1973.
} 
The first objection to the Debunking Argument is the Perceptual Connection objection. The first explanatory causal connection is a causal connection between object-facts and object-beliefs in terms of our perception or experience of object-facts. This connection proposes that the existence of ordinary objects causes our perception or experience of those objects, which in turn causes our beliefs about the existence of ordinary objects. Thus, the existence of a tree causes the experience of a tree, which in turn causes the belief about the existence of that tree. Therefore, DA1 is false - there is an explanatory causal connection between our object-beliefs and the object-facts. ${ }^{35}$

\section{THE INTUITION CONNECTION OBJECTION}

The second objection to the Debunking Argument is the Intuition Connection objection. The second explanatory connection is a causal connection between object-facts and object-beliefs in terms of our intuitions about object-facts. This connection proposes that the existence of ordinary objects causes our intuitions about those objects, which in turn causes our beliefs about the existence of ordinary objects. Thus, the existence of trees causes our intuitions about trees, which in turn causes the belief of the existence of trees. Therefore, DA1 is false - there is an explanatory connection between our object-beliefs and the object-facts.

\section{THE APPREHENSION CONNECTION OBJECTION}

The third objection to the Debunking Argument is the Apprehension Connection objection. The third explanatory connection is a causal connection between object-facts and object-beliefs in terms of our apprehension of object-facts. This connection proposes that the existence of ordinary objects causes our apprehension of those objects, which in turn causes our beliefs about the existence of ordinary objects. Thus, the existence of a tree causes the apprehension of a tree,

${ }^{35}$ Korman 2015: 105. See also Baker 2007: 46; Joyce 2006: 182; Street 2006: 160 fn.35; FitzPatrick 2015: par. 1. 
which in turn causes the belief about the existence of that tree. Therefore, DA1 is false - there $i s$ an explanatory connection between our object-beliefs and the object-facts.

According to Korman, beliefs about ordinary objects result from apprehending facts about coinstantiation, composition, and kind membership (CCK-facts). In other words, we have the beliefs we do because we apprehend facts about perceived properties instantiated by a single object (co-instantiation), facts about when something composes an object (composition), and facts about the kind an object belongs to (kind-membership). Our ability to apprehend such facts, together with our perception of atoms arranged $\mathrm{x}$-wise, and background knowledge about occluded properties, explains why we experience some objects but not others. ${ }^{36}$

Korman doesn't explain how the apprehension of CCK-facts works nor does he attempt to explain the accuracy of our object-beliefs. Instead, he merely shows we are justified in believing there's an explanation of object-beliefs in terms of object-facts. When Korman talks about apprehending CCK-facts, this is merely a substitute term for whatever it is by which CCK-facts nondeviantly influence beliefs about ordinary objects. ${ }^{37}$

This seem circular to me, because Korman posits an explanation which is supposed to explain object-beliefs in terms of object-facts nondeviantly by positing a capacity which is by definition nondeviant. Furthermore, Korman must explain what apprehension actually is. Setting aside the explanation of the capacity to apprehend, it's not clear what apprehension itself means. Korman merely contrasts apprehending with intuiting in the following way: apprehending something and intuiting it differ from one another, for apprehension is a nonoccurrent mental state, which sometimes gives rise to intuitions and experiences which are occurrent mental states. ${ }^{38}$ Given that Korman doesn't say anything else about it, I think what he means by apprehension is the understanding or grasping of certain facts. If Korman meant apprehension to be understanding or

\footnotetext{
${ }^{36}$ Korman 2015: 111.

${ }^{37}$ Korman 2015: 112.

${ }^{38}$ Korman 2015: 114.
} 
grasping certain facts, then this is some sort of cognitive perception. However, if this is what Korman meant by apprehension, then he needs to give an argument for why cognitive perception is a nondeviant way to get at the object-facts. Although Korman doesn't address this concern directly, he does mention the accuracy of perception or experience. According to Korman, the justification for believing we apprehend CCK-facts stems from an inference to the best explanation of the accuracy of our perceptions and experiences. He assumes our perceptual experience represents objects accurately and non-coincidentally, i.e. our experiences represent objects accurately because these objects actually exist and not because we are just lucky to have accurate experiences. The idea is that the apprehension of CCK-facts influences our experiences of ordinary objects, which is why it can account for the accuracy of those experiences. Since we don't have a better explanation yet, it's rational to believe we apprehend CCK-facts. ${ }^{39}$ However, proponents of the Debunking Argument don't think this is the best explanation of the accuracy of our perception. For the idea behind the Debunking Argument is that the reason we experience the world the way we do results from biological and cultural factors.

\subsection{RESPONSES TO THE OBJECTIONS}

In this section, I discuss two recent responses to these causal connections. These responses generalize to all three objections and for that reason are discussed together. The response to the causal connections is that the causal chain leading from the object-facts to our object-beliefs is deviant; we have the object-beliefs we have due to factors irrelevant to what objects actually exist. Osborne substantiates this claim by providing empirical evidence regarding our visualcognitive system. I then focus on recent empirical studies by Rose and Schaffer (2017) that show our intuitions regarding the existence of objects are teleologically infused, which means they are infused with function, and therefore, we shouldn't rely on those intuitions.

THE DEVIANT CAUSAL CONNECTION RESPONSE (KORMAN AND OSBORNE)

\footnotetext{
${ }^{39}$ Korman 2015: 113.
} 
The first response points out that the causal connections in question are deviant. If the causal connection is deviant, then this undermines the justification of said causal connection. ${ }^{40}$ So there's a causal connection between our object-beliefs and the object-facts, but this causal connection is of the wrong kind, and therefore it cannot justify DA1.

The idea is that our object-beliefs are due to biological and cultural factors, and because of this, the causal chain is deviant, since biological and cultural factors don't necessarily track the truth. We regard some pluralities of objects as composing a further object and other pluralities of objects as not composing a further object because of the conventions we use. These conventions regulate compositions and likely result from us perceiving some, but not other, qualities as being co-instantiated by a single object, and this ability to perceive qualities being co-instantiated is probably innate and evolved because it would be adaptive to perceive the world divided into the objects we perceive. For example, suppose we come across a distribution of atoms arranged xwise. Our perceptual and cognitive processes process the sensory inputs resulting from the atoms arranged $\mathrm{x}$-wise and result in an experience representing some qualities as being unified in a single object while other qualities are unified in a different object. For instance, when we come across atoms arranged leaf-wise, trunk-wise, and dog-wise, we have an experience representing the atoms arranged leaf-wise and trunk-wise as being unified in a one object (a tree), while we experience the atoms arranged dog-wise as being unified in a different object (a dog). The reason we experience a tree and a dog as two different objects, as opposed to experiencing them as one object (a trog), isn't because there are two separate objects, but rather because of biological and cultural factors. It's still possible the experience of the tree is caused by a tree, but because the causal chain leading from the tree to the experience of the tree is deviant, one should suspend the belief that the experience of the tree is caused by the actual tree, and therefore we should also suspend the belief that the experienced tree actually exists. ${ }^{41}$

\footnotetext{
${ }^{40}$ Korman 2015: 106.

${ }^{41}$ Korman 2015: 106.
} 
One might reply there's no evidence that we have the beliefs we have due to biological and cultural factors. Osborne remedies this situation and provides empirical support to substantiate the claim that we have the beliefs we have due to biological factors, and thus provides evidence for DA1.

The empirical support Osborne presents focuses on a number of biological factors, such as the nature of the human visual-cognitive system. This empirical support is by no means new, but has been largely overlooked. In addition to providing empirical support, he also argues that once we understand how the evidence supports the Debunking Argument, we can see it undermines the causal connections, and therefore it undermines the claim that object-beliefs are appropriately connected to object-facts. ${ }^{42}$

The empirical evidence Osborne presents supports DA1 that there's no appropriate explanatory causal connection between our object-beliefs and the object-facts. Osborne argues the causal chain from object-facts to object-beliefs is deviant; our object-beliefs are caused and explained by irrelevant factors. ${ }^{43}$

The first body of empirical evidence Osborne considers concerns the nature of the human visual system, how it affects our perceptual experiences, and the representations of the mindindependent world that our brain constructs. Particularly, Osborne outlines the inverse optics problem, capacity limits, and visual heuristics as three different, but interrelated, explanations for why we have the object-beliefs we have. ${ }^{44}$

The inverse optics problem arises from the fact that the brain reconstructs and represents the three-dimensional world from two-dimensional images projected onto the retina. The problem is that any two-dimensional image under-constrains the three-dimensional interpretation of it, since

\footnotetext{
${ }^{42}$ Osborne 2016: 3.

${ }^{43}$ Osborne 2016: 4-5.

${ }^{44}$ Osborne 2016: 7-8.
} 
an infinite number of three-dimensional realities could lie behind any two-dimensional image. Since information is lost when the brain interprets these two-dimensional images, the inverse optics problem is unsolvable. Not only is information lost when interpreting two-dimensional images, but our processing systems are also limited by processing capacity. That is, even if we could interpret the two-dimensional image perfectly, information is still lost because we can only process so much information at any one time. These capacity limits are most likely due to our brains having evolved to solve certain problems - especially those pertaining to our survival - at the expense of other problems. ${ }^{45}$ Since our brain has limited capacities to process information, the visual system uses heuristics, which are educated guesses based on imperfect and incomplete information. The visual systems uses these heuristics when constructing three-dimensional interpretations from two-dimensional images. These heuristics get it right most of the time, but are subject to biases and illusions. If our visual system is based on heuristics, then the fact that the world seems a certain way to us is at least partially based on the nature of our visual system as opposed to how the world really is. Although the mere fact that our visual system uses heuristics doesn't necessarily imply that the visual system is unreliable, inaccurate, or prone to error, it does imply that visual perception is not in contact with reality directly or unmediated, and that the visual system is often just as concerned with efficiency, biological viability, and practical reliability as it is with representational accuracy and epistemic reliability. ${ }^{46}$

The second body of empirical evidence Osborne considers concerns object segregation, object recognition, and binding. This empirical evidence is relevant in explaining why it is that we have the object-beliefs we have. Object segregation and object recognition are two tasks the visual system undertakes. They are processes by which the visual system constructs representations of the mind-independent world as divided into various objects. They represent the boundaries between objects (segregation) and allow us to recognize those objects and categorize them by sorting them into conceptual categories (recognition). The visual system uses heuristics in accomplishing these tasks and is thus subject to biases and illusions. ${ }^{47}$ Another task the visual system undertakes is binding, which is the process by which the visual system determines which

\footnotetext{
${ }^{45}$ Osborne 2016: 8.

${ }^{46}$ Osborne 2016: 8.

${ }^{47}$ Osborne 2016: 9.
} 
qualities we perceive as being co-instantiated by a single object. There are numerous studies within psychology of the various factors which systematically affect object segregation, object recognition, and binding. ${ }^{48}$ These studies show that factors such as similarity, familiarity, and proximity affect object recognition, segregation, and binding; they show why we perceive there to be some kinds of objects and not others. For example, we perceptually group things like tablelegs and table-tops into what we take to be a single, unified object (a table) because they occupy the same region of space, they are familiar, and they share a functional relationship. By contrast, we don't perceive there to be trogs because we don't perceptually group dogs and trees together, since most of the time they occupy distinct regions in space, they are not particularly similar in their qualities, and don't share an obvious functional relationship. ${ }^{49}$ So visual representations of the mind-independent world don't result from a direct and unmediated process. Rather, information is received, broken down, and put back together again. So again, the visual system is often just as concerned with providing information beneficial for our survival as it is with representational accuracy and epistemic reliability. ${ }^{50}$

The important point to substantiate DA1 is that familiarity, functional relations, similarity, and other factors affect, our ability to perceive and cognize objects, but these factors are irrelevant in determining which objects exist. For example, just because an object is more familiar to us, share a functional relationship, are similar, or are adaptively useful, doesn't make it more likely that those objects actually exist. Nevertheless, those factors are vital to our ability to perceive and cognize objects, and thereby affect object-beliefs and intuitions about the existence of objects. Thus, the factors that cause object-beliefs are not properly connected to object-facts and often have little or nothing to do with those facts; the explanatory connection is deviant. As a result, object-facts don't explain object-beliefs, but instead these other irrelevant facts explain our object-beliefs. Therefore, if our object-beliefs are based on our perceptual experiences, and the content of our perceptual experiences are based on representational systems and factors that are not connected in a non-deviant manner with object-facts, then DA1 is true. ${ }^{51}$

\footnotetext{
${ }^{48}$ Osborne 2016: 10. See Biederman 1987.

${ }^{49}$ Osborne 2016: 10.

${ }^{50}$ Osborne 2016: 9.

${ }^{51}$ Osborne 2016: 10-11.
} 
The empirical evidence Osborne considers undermines the causal connections because the empirical evidence shows the causal chain leading from object-facts to object-beliefs is deviant. Particularly, it undermines the Perceptual Connection because the factors which influence our object-beliefs affect our perception of object-facts. It undermines the Intuition Connection because the factors that influence object-beliefs affect the intuitions we have about object-facts. And more controversially, it undermines the Apprehension Connection, because the factors that influence our object-beliefs also affect cognitive perceptions, such as apprehensions.

The third body of empirical evidence Osborne considers are evolutionary pressures on object perception. Studies in evolutionary biology concerning the evolution of the visual system are relevant since they explain why our visual system works the way it does. Our visual system evolved the way it did because it's beneficial for us to perceive and cognize objects within the constraints of biological feasibility. Dividing the world into certain objects, such as those that harm or nourish, is evolutionarily advantageous, while dividing the world into other objects, such as trogs, is not evolutionarily advantageous. ${ }^{52}$

For example, the visual system must strike a balance between the capacity, processing, and physical limitations discussed above, and the amount of information to include in visual representations of the world necessary for survival. ${ }^{53}$ Taking capacity limits and evolutionary pressures into account, certain representations are more viable and valuable for adaptive fitness than other representations, so the accuracy of those representations is sacrified for efficiency and survival. And for that reason there are evolutionary pressures to perceive those objects useful for survival while there are no evolutionary pressures to perceive objects not useful for survival. ${ }^{54}$ Thus, evolutionary considerations support DA1 because it shows the reason why we have the

\footnotetext{
${ }^{52}$ Osborne 2016: 11.

${ }^{53}$ Osborne 2016: 11-12.

${ }^{54}$ Osborne 2016: 12.
} 
object-beliefs we have is due to evolutionary pressures to perceive those kinds of objects which are useful for survival, even if those objects don't actually exist. ${ }^{55}$

The fourth body of empirical evidence Osborne considers comes from developmental psychology. This evidence is more speculative, but it directly concerns intuitions we have about which kinds of objects exist. ${ }^{56}$ These studies provide support that intuitions about essences stem from an implicit belief set which arises early in development. The reason why certain philosophical theories seem so intuitive results from a cognitive bias rather than what the world is actually like. For example, one study shows children base their judgments about essences and kind membership on inductive inferences rather than perceptual similarity. This shows we have an implicit belief in something like a metaphysical essence that exists within objects and that grounds identity and persistence-conditions. ${ }^{57}$ Another study showed children have implicit belief sets about the nature of ordinary objects. This belief set consists of beliefs about object unity, object boundaries, and object segregation. They are beliefs about the nature of what it means for an object to be one object as opposed to several distinct objects and about the nature of what it means for an object to be the object it is. These findings look structurally similar to the previous study about essence and kind-membership. The latter study concerns children as young as four months, so they presumably form those belief sets before they develop the ability to undertake conceptual cognition and before they reliably intuit object-facts. Given the structural similarity between these two studies, this supports the claim that intuitions about which objects exist, might also stem from an implicit belief set and a cognitive bias. ${ }^{58}$

The idea is that intuitions arise from, and are shaped by, implicit beliefs and cognitive biases, so the reason something is intuitive results from cognitive biases as opposed to what the mindindependent world is actually like. ${ }^{59}$ Therefore, this would be another case of a deviant causal

\footnotetext{
${ }^{55}$ Osborne 2016: 12.

${ }^{56}$ Osborne 2016: 13-14.

${ }^{57}$ Osborne 2016: 14.

${ }^{58}$ Osborne 2016: 14.

${ }^{59}$ Osborne 2016: 14.
} 
chain, since the intuitions about which objects exist are not caused or explained by what objects actually exist. $^{60}$

However, Osborne merely shows there's evidence that some intuitions or apprehensions are prone to cognitive biases, not that they are all unreliable. ${ }^{61}$ Osborne concedes this objection, at least to a point, since he hasn't shown conclusively that all intuitions are unreliable. It's certainly possible that intuition (or apprehension) provides an appropriate explanatory connection between object-facts and object-beliefs, but simply postulating such an ability by itself isn't enough, since it's possible to postulate many different explanations that are consistent with the data. Korman must provide an argument for why apprehensions exist. The argument that postulating such an ability is consistent with common-sense isn't enough, especially if other explanations have further evidence supporting them. ${ }^{62}$ Science provides evidence on how information is collected, processed, and used in cognitive tasks, whereas we don't have evidence for how this works in terms of intuitions or apprehensions. This is especially important if intuitions or apprehensions are supposed to provide information about non-empirical entities such as essences, as Korman wants us to believe. ${ }^{63}$

Moreover, recent studies have shown that many intuitions are prone to cognitive and cultural biases. Although they don't show intuitions in general are unreliable, the diversity of the studies shows intuitions in a wide variety of situations are prone to cognitive and cultural biases. This variety concerns different kinds of biases, such as language, gender, race, culture, age; variety in different areas, such as epistemology, metaphysics, philosophy of mind, etc.; and variety in terms of folk intuitions and the intuitions of philosophers. Given these studies cover a wide variety of situations, it's likely that intuitions being unreliable is not a topic-specific phenomenon, but rather a characteristic of intuitions in general. ${ }^{64}$

\footnotetext{
${ }^{60}$ Osborne 2016: 14.

${ }^{61}$ Osborne 2016: 17. See Korman 2015.

${ }^{62}$ Osborne 2016: 17.

${ }^{63}$ Osborne 2016: 18.

${ }^{64}$ Machery 2017: Ch. 2. See also Sytsma and Buckwalter 2016.
} 
In short, Osborne provides evidence from psychology and evolutionary biology to support DA1. There's no explanatory causal connection between object-beliefs and object-facts. Instead, object-beliefs result from factors irrelevant to object-facts. Therefore, the evidence supports the claim that the causal chain from object-facts to object-beliefs is deviant; there's a causal connection between object-facts and object-beliefs, but this connection is of the wrong kind, and therefore our object-beliefs are not caused or explained in an appropriate manner by those objectfacts. $^{65}$

\section{THE DEVIANT CAUSAL CONNECTION RESPONSE (ROSE AND SCHAFFER)}

The second response to the causal connection objections concerns recent empirical studies which show intuitions or apprehensions are objectionably teleological in nature and therefore we shouldn't rely on them when answering questions about composition and kind-membership. Specifically, since explanatory connections between our object-beliefs and object-facts are based on intuition and apprehension, the teleological nature of intuitions makes the causal chain from object-facts to object-beliefs deviant.

Rose and Schaffer argue that ordinary people think pluralities of objects compose a further object when that plurality has a function; in other words, folk mereology is teleological. Since folk teleological mereology is linked to an objectionable teleological view of nature, it's therefore fit for debunking. ${ }^{66}$ The argument runs as follows:

P1: The Influence Thesis: Whether some objects have a collective function has a substantial influence on folk intuitions about whether those objects compose something.

P2: The Debunking Thesis: If so, then we shouldn't rely on folk intuitions about whether some objects compose something.

\footnotetext{
${ }^{65}$ Osborne 2016: 15.

${ }^{66}$ Rose and Schaffer 2017: 239.
} 
P3: The Liberation Thesis: If so, then we shouldn't reject theories of composition on the basis of intuitions about whether some objects compose something.

P4: Conclusion: So, we shouldn't reject theories of composition on the basis of intuitions about whether some objects compose something. ${ }^{67}$

So the argument claims there is an explanatory casual connection between object-beliefs and object-facts, but again, this connection is of the wrong kind; it's deviant or unreliable, and thereby undermines the justification of those causal connections, and therefore cannot justify DA1.

Rose and Schaffer use empirical evidence from experimental philosophy to answer the Special Composition Question, which is the question concerning the conditions under which a plurality of objects composes a further object. To find out how ordinary people would answer the Special Composition Question, Rose and Schaffer conducted a series of studies. They designed surveys which describe various cases about composition modelled on van Inwagen's cases. ${ }^{68}$

The first study is based on van Inwagen's handshake case. ${ }^{69}$ Van Inwagen asks us to imagine two people shaking hands (thereby coming into contact) and to imagine the hands being glued together (thereby being fastened). We are asked to consider whether the two hands compose a new object that came into existence when the hands came in contact or became fastened. If contact or fastening is the folk theory, then one would expect the answer to be 'yes', since the hands are either in contact or fastened. If nihilism or eliminativism is the folk theory, then one would expect the answer to be 'no', since the hands would not compose a further object and nothing new has come into existence. If universalism or permissivism is the folk theory, then one would expect the answer be 'no' as well, since the two hands already were a sum so nothing new came into existence.

\footnotetext{
${ }^{67}$ Korman and Carmichael 2017: 187-188.

${ }^{68}$ Rose and Schaffer 2017: 248.

${ }^{69}$ Van Inwagen 1990: 57-59.
} 
Rose and Schaffer have two goals. First, to test van Inwagen's prediction that the folk answer 'no' to this question. Second, to test whether they can flip intuitions by manipulating function. Results show participants answer 'no' when the handshake case is presented without function, e.g. just two people shaking hands, but answer 'yes' when the case includes function, e.g. shaking hands with the function of posing for a work of art. ${ }^{70}$ Not only did adding a function produce a significant effect on intuitions, but adding a function flips intuitions regarding composition. That is, instead of saying 'no', participants answer 'yes' once function is added. Rose and Schaffer conclude that because these results are not predicted by any of the theories on composition, the study is a counterexample to both nihilism/eliminativism and universalism/permissivism. Moreover, these studies hints at an underlying pattern, where the function of objects influences intuitions about composition. ${ }^{71}$

The second study considers questions about composition and function regarding unfamiliar artefacts (gollywags). They asked participants to consider two artificial objects called gollywags. They designed different scenarios where the gollywags were either in contact (by placing them right next to each other), fused (by gluing them together), in contact with function (by placing them right next to each other and providing a function of the two gollywags collectively), or fusion with function (by gluing them together and providing a function of the two gollywags collectively). ${ }^{72}$ A similar pattern to the handshake case emerged. Participants tend to answer 'no' to cases without function, and 'yes' to cases with function. There's no effect of contact versus fusion, which means it isn't the way in which the two objects were joined together, but that function is the main factor. Rose and Schaffer conclude that function influences intuitions about composition. Moreover, as with the handshake case, they provide a counterexample to both nihilism/eliminativism and universalism/permissivism. ${ }^{73}$

\footnotetext{
${ }^{70}$ Rose and Schaffer 2017:249-250.

${ }^{71}$ Rose and Schaffer 2017: 250.

72 Rose and Schaffer 2017: 250-252.

${ }^{73}$ Rose and Schaffer 2017: 252.
} 
The third study considers questions about composition and function regarding organisms. The survey asked participants to consider two mice which are fused together (glued). In one scenario, the two mice together don't have a function, while in another scenario they do have a function (the ability to detect bombs). Again, results show participants judge that without function the two mice don't compose a new object, while participants judge that with function the two mice do compose a new object. ${ }^{74}$

The fourth study considers questions about composition and function regarding natural objects such as rocks. Several different scenarios are presented. The base scenario is a story about Jones who lives on a mountain and is woken up by a series of loud noises caused by a small avalanche. He wakes up, looks outside, and sees some rocks strewn across his lawn resulting from the avalanche. The other scenarios are identical to the base scenario but with additional information. In one scenario, the array of rocks is given a label, e.g. a 'rock garden'. In another scenario, function is included, e.g. the rocks are arranged in that way to function as a rock garden. In another scenario, the array of rocks is given a label and a function, e.g. the label 'rock garden' which functions as a rock garden. ${ }^{75}$ The results of these different scenarios show the same pattern as the previous studies. That is, participants tend to answer 'no' - the rocks don't compose a further object - to those scenarios that don't include function, and 'yes' - the rocks do compose a further object - to those scenarios that do include function. Moreover, labelling the rocks as a 'rock garden' didn't produce an effect, which indicates function is the main factor. Therefore, this study shows teleology influences folk intuitions even in situations where ordinary objects are concerned. $^{76}$

Separately from these four studies, Rose and Schaffer also conducted studies to test whether it matters that the function in question is successfully carried out. Results show that success of function matters. ${ }^{77}$ That is, if the function is thwarted in any way, participants answer 'no' to the

\footnotetext{
${ }^{74}$ Rose and Schaffer 2017: 254.

${ }^{75}$ Rose and Schaffer 2017: 255-256.

${ }^{76}$ Rose and Schaffer 2017: 256.

${ }^{77}$ Rose and Schaffer 2017: 258.
} 
question of whether or not two distinct objects compose a further object, and answer 'yes' - they do compose a further object - when the function is fulfilled. ${ }^{78}$

Taking these studies collectively, it seems the folk have a restricted and teleologically-laden view on composition. The range of cases discussed shows a significant effect of function on folk judgments about composition. ${ }^{79}$ Based on these results, Rose and Schaffer propose an account of teleologically restricted composition where composition occurs when the plurality of objects has a function or purpose. ${ }^{80}$ When the plurality of individuals is for something then it is something. But when the plurality of individuals isn't for something, then it's not something i.e. it is nothing. ${ }^{81}$

Rose and Schaffer argue if folk mereology is teleological, then we shouldn't judge the accuracy of theories such as nihilism/eliminativism and universalism/permissivism by how well they coincide with common-sense intuitions. Since folk mereology is teleological, these studies provide an argument against the causal connection between object-beliefs and object-facts. ${ }^{82}$ If Rose and Schaffer are correct that intuitions and apprehensions are infused with objectionable teleology, then the connection in question is deviant and thus isn't an appropriate explanatory connection, so DA1 is false.

\section{KORMAN AND CARMICHAEL'S REPLY TO ROSE AND SCHAFFER}

Korman and Carmichael reply to Rose and Schaffer and state some objections to the way the studies were conducted. Particularly, they give objections to the Influence Thesis, the Debunking Thesis, and the Liberation Thesis.

\footnotetext{
${ }^{78}$ Rose and Schaffer 2017: 256-257.

${ }^{79}$ Rose and Schaffer 2017: 256.

${ }^{80}$ Rose and Schaffer 2017: 259.

${ }^{81}$ Rose and Schaffer 2017: 247-248.

${ }^{82}$ Rose and Schaffer 2017: 261.
} 
Korman and Carmichael propose two main objections to the Influence Thesis. Whether some objects have a collective function has a substantial influence on folk intuitions about whether those objects compose something. ${ }^{83}$ The first objection is that Rose and Schaffer divided the cases into 'with-function' and 'no-function'. This distinction is supposed to be the basis for the different folk intuitions. However, aside from function, creative intention is possibly a further difference between the cases which could be the basis of the different folk intuitions. The idea is that there are two ways of thinking about objects. In terms of function (like Rose and Schaffer), and in terms of human creative intentions. These two ways of thinking about it are related, e.g. if one thinks something is intentionally created, it's plausible it has a function associated with that intention. Function and creative intention can come apart though. Imagine a child intentionally stacking her toys in the shape of a (very loose) pyramid. If asked what the pyramid is for, she'll likely say it's not for anything. So the pyramid results from her creative intentions but has no function. Accordingly, the basis for the different folk intuitions might not result from the attribution of function to objects, but instead from creative intentions associated with objects. In the 'with-function' cases, participants associate creative intentions with the objects, for they all involve sortal-specific creative intentions, e.g. in the handshake-with-function case the intention is to make a model, in the gollywag-with-function case the intention is to make a back support, and in the avalanche-with-function the intention is to make a rock garden. Furthermore, the 'nofunction' cases don't involve sortal-specific creative intention. ${ }^{84}$ Psychological studies show that creative intentions actually fits better with folk intuitions about artefacts. According to these studies, we have the intuition an object belongs to a particular kind when we know that that object exists as a result of an intention to make it. ${ }^{85}$

I have two points to make. First, although the data is consistent with alternative accounts, such as creative intentions, and although creative intentions are consistent with folk intuitions about artefacts, this is merely an alternative explanation and doesn't actually undermine Rose and

\footnotetext{
${ }^{83}$ Rose and Schaffer actually propose many more objections, but they all concerned the way the studies were conducted so I decided to leave them out.

${ }^{84}$ Korman and Carmichael 2017: 189-190.

${ }^{85}$ Korman and Carmichael 2017: 190. See Bloom 1996.
} 
Schaffer's claims. To establish which of these two explanations is better, further studies are needed. Second, the creative intentions account fits very well with artefacts, since artefacts are created with intention. However, Korman and Carmichael must show that this account works for natural objects, such as trees and rocks, as well.

The second objection to the Influence Thesis is that the creative intentions account is more charitable to people's intuitions. If it's true that people are influenced by teleological notions, then they have a mistaken view about the relevance of function in composition. Assuming people don't have such widespread mistaken belief, the creative intentions account is more charitable. ${ }^{86}$

However, if the creative intentions account is supposed to work for natural objects as well, then the folk would have a widespread mistaken belief that objects only compose a further object when that object has creative intentions behind it. And this is just as mistaken as attributing function to natural objects. For example, if the folk don't consider a tree as a tree unless it has some creative intention associated with, then this is just as bad as them not considering a tree as a tree unless it has some function. The creative intention account might work really well for artefacts, but again, it doesn't seem to work for natural objects. Or at least it doesn't fair better than the functional account.

Korman and Carmichael object to Rose and Schaffer's Debunking Thesis that we shouldn't rely on folk intuitions about whether some objects compose something. The Debunking Thesis is motivated by the idea that we shouldn't rely on teleology when it comes to composition. Using teleological notions for artefacts isn't problematic, since artefacts have functions. However, Rose and Schaffer extend this reasoning to natural objects. Korman and Carmichael argue that all the cases merely involve artefacts, e.g. a model, a back support, a bomb detector, and a rock garden. Even the cases that were supposed to involve natural objects, such as rocks, actually involve

${ }^{86}$ Korman and Carmichael 2017: 191. 
artefacts, such as a rock garden. Therefore, Rose and Schaffer only show teleological intuitions about artefacts, and not teleological intuitions about natural objects. ${ }^{87}$

Korman and Carmichael also object to the Liberation Thesis, which is meant to liberate theories of composition from intuitions, both from folk intuitions and the intuitions of philosophers. One could argue that although we shouldn't take into account folk intuitions, intuitions of philosophers can be relied on. ${ }^{88}$

However, as stated earlier, intuitions of philosophers are prone to the same cognitive and cultural biases as ordinary folk. Even if we grant philosophers don't share folk intuitions, another objection arises. Disagreement between philosopher's intuitions and folk intuitions is a defeater for the beliefs of philosophers in the sense that folk intuitions trump intuitions of philosophers, because philosophers are more likely to have thought about, and researched questions regarding composition. So their intuitions are more likely to be influenced by arguments. One response is to grant that disagreement between folk and philosopher's intuitions is usually a defeater, and grant that folk intuitions should trump the intuitions of philosophers, but since we have already debunked folk intuitions, having different intuitions to the folk shouldn't matter here. ${ }^{89}$

\section{BOWER'S REPLY TO ROSE AND SCHAFFER}

Bowers proposes another reply to Rose and Schaffer. Bowers accepts the results from Rose and Schaffer's studies but instead of rejecting folk intuitions, Bowers embraces them and takes it as a reason to accept a teleological account of ordinary objects. ${ }^{90}$ Teleology is the general feature of having a purpose, a function, or a goal. If something can be explained by talking about its

\footnotetext{
${ }^{87}$ Korman and Carmichael 2017: 195-196.

${ }^{88}$ Korman and Carmichael 2017: 198-199.

${ }^{89}$ Korman and Carmichael 2017: 199.

${ }^{90}$ Bowers (unpublished): 4 and $4 \mathrm{fn} .3$.
} 
function, then it has teleology. ${ }^{91}$ Bowers argues a plurality of objects composes a further object when that plurality has a function and the plurality is arranged in such a way as to perform that function. $^{92}$

Accordingly, ordinary objects are goal-directed systems, whose parts are arranged to perform some function. ${ }^{93}$ For example, the function of a broom is to sweep. To achieve this function the parts that make up the broom are put together in a certain way. These parts compose something because there's a function for which they are put together. Function distinguishes a broom from a collection of parts which are merely arranged broom-wise (for example, a collection of wood, vines, and grass which are coincidentally shaped like a broom). Although the parts are arranged broom-wise, they are not brooms, because the wood, vines, and grass are not arranged for a function. Not only does this collection of parts fail to be a broom, it fails to be any composite object, since it doesn't have any function. Let's call the parts arranged broom-wise a swampbroom. The teleological answer also provides an explanation for why a swamp-broom could become an object once we use it as an actual broom. By using the swamp-broom as a broom, it thereby acquires a function and thus becomes a broom. ${ }^{94}$

Bowers argues we should adopt folk teleological mereology because it can solve the problems associated with nihilism/eliminativism and universalism/permissivism.

Universalism/permissivism take there to be extraordinary objects, such as trogs. This is objectionable because we don't usually take extraordinary objects to exist. Folk teleological mereology, by contrast, doesn't accept the existence of extraordinary objects but does accept the existence of ordinary objects. Extraordinary objects don't exist, because their parts don't collectively have a function. For example, trogs don't exist, because their parts (the tree and the

\footnotetext{
${ }^{91}$ Bowers (unpublished): 5.

${ }^{92}$ Bowers (unpublished): 1-2.

${ }^{93}$ Bowers (unpublished): 1.

${ }^{94}$ Bowers (unpublished): 1-3.
} 
dog), taken together, don't perform a function. Ordinary objects, by contrast, do exist because their parts, taken together, do perform a function. ${ }^{95}$

Nihilism/eliminativism claims that ordinary objects, such as tables and trees, don't exist. This is objectionable because it doesn't accept the existence of objects we usually take to exist. Folk teleological mereology, by contrast, does accept the existence of ordinary objects. It accepts the existence of ordinary objects, because they are put together in such a way that they have a function. For example, tables exist, because the parts of a table are put together in such a way that they have a function, e.g. for people to eat at. Similarly, trees exist, because the parts of a tree are put together in such a way that they perform a function, e.g. trees provide food and habitats for animals, they improve air and soil quality, etc. ${ }^{96}$

Focussing on ordinary natural objects as opposed to mere artefacts, the teleology of ecological functions is understood in three stages. First, Bowers considers the case in which the swampbroom is turned into a broom by using it as a broom. Second, he compares the swamp-broom with the physical portions of reality. Thirdly, he considers environmental harm.

To explain, suppose you find a collection of parts arranged broom-wise lying in a swamp. These parts are distributed in such a way that they have the same shape as an ordinary broom. The parts weren't distributed in that way by anyone - they just happened to be distributed that way - which is why they don't compose a broom. You take it home and start using it to sweep the floor. By using the swamp-broom, it thereby acquires the function of sweeping. Arguably, it won't acquire that function after using it only once, but at some point it does acquire that function. At that point, the parts come to compose a broom. ${ }^{97}$

\footnotetext{
${ }^{95}$ Bowers (unpublished): 8-9.

${ }^{96}$ Bowers (unpublished): 9-11.

${ }^{97}$ Bowers (unpublished): 11-12.
} 
Next, compare the swamp-broom with physical portions of reality. Suppose you live in the wilderness. You are looking for a place to live in the wilderness and you find a collection of solid, sturdy, waterproof materials distributed in such a way that they make a good shelter. The materials were not distributed in that way by anyone - they just happened to be distributed that way, which is why the materials don't compose a 'cave' or a 'house'. You move into this collection of materials and start using it as your dwelling. By using it as a dwelling, it thereby acquires a function - the function of providing a home. Again, this might not happen straight away, but after using it for a while, at some point it does acquire that function. At that point, the materials come to compose a house. ${ }^{98}$

Lastly, consider environmental harm. Human beings harm their environment significantly, especially since the advent of the industrial revolution. The effects include damage to animals, the ozone layer, the soil, water, and air. They are impeded from functioning as life-supporting systems; e.g. pollution harms natural habitats by preventing them from supporting life.

Environmental harm requires a teleological explanation that only natural habitats can provide, since you cannot damage something by removing the ability to support life unless supporting life is one of its functions. Since there's environmental harm that removes its ability to support life, there must be physical portions of the world which have the function of supporting life. Therefore, there must be natural habitats, including rocks, rivers, mountains, trees, stars, and the like. ${ }^{99}$ Thus, folk teleological mereology can account for both artificial and natural objects, which eliminativists fail to recognize.

Bowers discusses two objections to his account. I merely focus on the Empty Habitat Problem. The Empty Habitat Problem claims the existence of habitats, and other ordinary natural objects, requires the existence of inhabitants. If there are no inhabitants, then there cannot composite objects, such as ordinary natural objects. ${ }^{100}$

\footnotetext{
${ }^{98}$ Bowers (unpublished): 12.

${ }^{99}$ Bowers (unpublished): 12-13.

${ }^{100}$ Bowers (unpublished): 18.
} 
Bowers' response to the Empty Habitat Problem is that in a world without inhabitants, there would indeed be no composite objects. It might seem a world without inhabitants still contains composite objects, since we can imagine a world without inhabitants which includes composite objects, so it's certainly conceivable. However, there's actually an independent reason for thinking that without inhabitants there would be no composite objects. At the root of van Inwagen's Special Composition Question is the question of when a plurality of objects composes a further object; it asks when a collection of materials is more than a mere heap of matter. Bowers argues a heap of lifeless matter is the clearest example of an entity that has no function. Composite objects, by contrast, are entities which do have a function. A table, for example, is a good example of an entity that has a function. Bowers argues a world without inhabitants is more like a heap of lifeless matter than a composite object, because a world without inhabitants is a world without function. So a world without inhabitants is more like a heap of lifeless matter. This heap of lifeless matter is much larger than we usually imagine heaps to be, but that's not the point. If a world without inhabitants is a world without function, and if teleology can distinguish between cases of mere heaps and cases of composite objects, then it isn't strange to believe a world without inhabitants is a mere heap of lifeless matter. So there's an independent reason to believe a world without inhabitants $i s$ a mere heap of lifeless matter although much larger than we usually take heaps to be. ${ }^{101}$

\subsection{THE ONTOLOGICAL CONCEPTUALIST'S RESPONSE}

I argue that Conservatist Minimal Realist views about ordinary objects, such as Ontological Conceptualism, can address the Debunking Argument and the objections and responses proposed in this chapter. I argue DA1 is false: it's false that there's no appropriate explanatory causal connection between object-beliefs and object-facts.

The support for DA1 is that we have the object-beliefs we have as a result of biological and cultural factors. The idea is that we regard some pluralities of objects as composing a further

\footnotetext{
${ }^{101}$ Bowers (unpublished): 18-19.
} 
object and other pluralities of objects as not composing a further object, because of the conventions we use. This view, often called Conventionalism, seems plausible to me. I agree composition is regulated by our conventions in the sense that it's regulated by human activities. But 'convention' might not accurately reflect what is going on. I argue the human activities in question are our conceptual practices. So the reason we perceive some but not other qualities as being co-instantiated by a single object is not regulated by convention, but instead is regulated by our conceptual practices. Particularly, they are regulated by the concepts we have about ordinary objects.

Korman said an appropriate explanatory connection could either be an alethic explanation of object-beliefs in terms of object-facts, or it could be a doxastic explanation of object-facts in terms of object-beliefs. Korman dismisses the doxastic explanation because he doesn't think it's plausible that facts about the existence of objects depends on our beliefs about the existence of objects. It's just not plausible that facts about which objects exist depend on which objects we believe exist. However, I argue that object-facts can be explained in terms of object-beliefs. For objects are not objects unless they are conceptualized. That is, an object does not exist unless it's conceptualized. So object-facts concern those objects that are conceptualized. If object-facts concern conceptualized objects, and if conceptualized objects are determined by the concepts we employ, which in turn are influenced by our conceptual knowledge, then object-facts are (partly) determined by our conceptual knowledge. Since our conceptual knowledge consists of objectbeliefs, object-facts are (partly) determined by our object-beliefs. Ontological Conceptualism thus gives a satisfactory explanatory connection of object-facts in terms of object-beliefs. Thus DA1 is false. If DA1 is false, then the conclusion that we shouldn't believe ordinary objects exist, doesn’t follow. Instead, we should believe ordinary objects exist if we take ordinary objects to be conceptualized objects.

However, there's a sense in which DA1 is true. The concepts we have about ordinary objects are influenced by our conceptual knowledge, which in turn is influenced by a wide variety of factors, such as perceptual/cognitive biases and social/cultural factors, that have less to do with the world and have more to do with how our brains works. These factors influence our conceptual 
knowledge, and thus the concepts we employ. This in turn, influences the way we perceive reality, since categorization provides the picture of reality as we perceive it. Thus, the reason we perceive some qualities as being co-instantiated by a single object and other qualities as not being co-instantiated by a single object results from irrelevant factors and not from the objectfacts which supposedly exist mind-independently.

One worry is that if conceptual knowledge really does influence perception to such an extent, then perhaps our conceptual knowledge corresponds to the reality. So conceptual knowledge does not influence perception, but instead, perception influences conceptual knowledge. There's some truth in this; perception does influence conceptual knowledge. It's very likely that it's a two-way system. However, it's more likely perception evolved because it's adaptive for human beings to perceive the world in a certain way; it would be more adaptive to only perceive the relevant bits of the world as opposed to perceiving all of it. The human brain can only process so much information so it restricts perception to those aspects of reality crucial for survival. Take trees for example. It's likely we perceive the matter trees are made up of and general shape of trees, because it's important to perceive trees when it comes to adaptive advantages. But to see the tree as a tree, the brain must use conceptual knowledge and integrate it with the information from the world entering our sense organs. When we perceive a tree as a tree, we have formed a conceptualized object.

So the reason we believe trees exist but trogs don't, is because we have and use the concept TREE, while we don't have and use the concept TROG. And the reason we have and use the concept TREE is because it's adaptive and useful for us to have it. By contrast, having the concept TROG is useless from an evolutionary standpoint and useless in daily life. Perhaps in philosophical circles we, philosophers, have the concept of a trog since we talk about it often. Nevertheless, in ordinary daily life, we don't usually use that concept which is why trogs still go unnoticed for most of us even for those who have a lot of conceptual knowledge about trogs. 
As for the three Causal Connection objections to the Debunking Argument, they are correct in claiming some of our object-beliefs are caused by the object-facts. However, beliefs regarding identity and composition are not caused by object-facts intrinsic to the objects themselves. Instead, facts regarding identity and composition result from our concepts. The reason we intuit certain object-facts, such as facts about identity and composition, isn't because we intuit facts intrinsic to the objects but instead we have those intuitions because they are influenced by our conceptual knowledge. However, this isn't problematic for Ontological Conceptualism because the Ontological Conceptualist takes ordinary objects to be conceptualized objects. So when we intuit facts about objects, we are not intuiting facts intrinsic to those objects but instead we intuit facts about the concepts of those objects. Korman argues the beliefs we have about ordinary objects result from the apprehending of facts about co-instantiation, composition, and kindmembership. I agree our object-beliefs result from knowledge about co-instantiation, composition, and kind-membership. However, this knowledge is really conceptual knowledge. It's part of our concept TREE that certain parts of the tree co-instantiate in a single object and that it's composed of those parts. Since these facts are part of our concept and not the object itself, and because concepts play a role in categorization, which in turn influences how we perceive objects, CCK facts influence how we perceive objects as the objects they are. So Korman's worry about our experiences not accurately representing objects if we don't apprehend CCKfacts is dispensable, since we still accurately perceive objects, that is, we accurately perceive conceptualized objects.

As for the responses to the Causal Connection, Osborne provides some empirical evidence regarding our visual-cognitive system to substantiate the claim that the causal chain from objectfacts to object-beliefs is deviant. This empirical evidence doesn't undermine Ontological Conceptualism, because the only objects that exist are conceptualized objects. And our concepts are indeed influenced by the factors described by Osborne, but this doesn't mean this influence is deviant. The factors which influence our object-beliefs shape the concepts we have of those objects, which in turn, determine which objects exist. 
One worry for Ontological Conceptualism is that it seems it cannot account for misperception. If the existence of objects is determined by the concepts we have, then we can never be wrong about what objects exist. If conceptualized objects result from conceptual knowledge being integrated with information from the mind-independent world, then if our conceptual knowledge is wrong, then we misperceive the mind-independent world. But since Ontological Conceptualists claim we do accurately perceive conceptualized objects, then it seems that no matter how we conceptualize objects, they are always represented accurately since we decided that that's what the object is. My answer is that to a certain extend this is true. It's true to the extent that whatever compositional or identity facts we associate with our concepts, these compositional and identity facts do indeed influence conceptualized objects and are accurate no matter what we take them to be. However, firstly, reality still constraints our concepts, since the only thing that's mind-dependent are compositional and identity facts - so not everything goes. And secondly, if identity and compositional facts are indeed mind-dependent, as I take them to be, then in a sense, it's impossible to misrepresent it, since we determine what they are. Thirdly, our concepts are also constraint by practical use. If we had concepts that couldn't be used for induction (both in daily reasoning and in science), then they would be useless and should be altered to pick out objects better.

Rose and Schaffer's studies, which show ordinary people have a teleological view on composition, fits nicely with Ontological Conceptualism. Because function is a part of concepts of ordinary objects. It's part of our concept TABLE is that it functions as a table, part of our concept TREE is that it functions as a tree, etc. So when asked questions about composition, function plays an important role and influences our judgments about those ordinary objects.

However, Rose and Schaffer argue that because intuitions and apprehensions are infused with objectionable teleology, we shouldn't judge the accuracy of eliminativism and permissivism using those intuitions, because the connection between object-belief and object-fact is deviant. By contrast, Ontological Conceptualism claims composition is grounded in our concepts, which in turn influences which conceptualized objects exist, so we should take intuitions into account when judging the accuracy of eliminativism and permissivism. The idea is that both theories are 
false in a sense; eliminativism claims composition never occurs. But composition does occur; it's just that it's a mind-dependent phenomenon. Permissivism claims composition always occurs. But composition does not always occur, since composition is grounded in our concepts and the objects picked out by our concepts don't always compose a further object.

So Ontological Conceptualism partly agrees with Bower's teleological answer to the Special Composition Question in that a plurality of objects composes a further object when the plurality has a function. The difference is that Ontological Conceptualism doesn't claim a plurality of objects composes a further object when the plurality has a function, but instead claims a plurality of objects composes a further object when the concept we have of that plurality includes a function.

Another objection to Ontological Conceptualism is that if our conceptual practices had been different, then there wouldn't have been mountains in Africa (or any other ordinary objects). The Ontological Conceptualist argues it's indeed true that if our conceptual practices had been different, then there would have been different ordinary objects. If we did not have a concept for mountains, then there wouldn't have been mountains. This doesn't imply that the matter we take mountains to be made up of doesn't exist, but instead that the conceptualized object 'mountain' would not have existed had our conceptual practices been different. For the ontological conceptualist, the matter that composes conceptualized objects is not identical to conceptualized objects. Usually we speak of mountains, and other ordinary objects, as if they are identical with the matter they are made up of. But this is exactly what the Ontological Conceptualist questions. What Ontological Conceptualists mean by a mountain, and other ordinary objects, is not what it's made up of, but instead refers to a conceptualized object. So when Ontological Conceptualists say it's true that if our conceptual practices had been suitably different then there would have been no mountains in Africa, what they mean is that the object conceptualized as a 
mountain would not have existed. It doesn't change the matter mountains are made up of, but it does change how we perceive, experience, and deal with these conceptualized objects. ${ }^{102}$

Another objection to Ontological Conceptualism is that if there were no people (or other suitable creatures), then there would be no ordinary objects. This objection is similar to Bowers' Empty Habitat Objection discussed above, but my response is different to his and is more similar to the No Mountains objection discussed in the previous paragraph. Ontological Conceptualists argue it's indeed true that if there are no people, then there are no ordinary objects. If there are no people, then there are no conceptual practices, and thus there are no conceptualized objects. This is not to say the matter we take objects to be made up of doesn't exist, but instead, conceptualized objects don't exist if there are no humans (or other suitable creatures) to conceptualize the matter they are made up of. So the objection confuses the term objects with conceptualized objects.

In conclusion, Minimal Realist views, such as Ontological Conceptualism, can provide relatively straightforward answer to the Debunking Argument and the proposed objections and responses.

\footnotetext{
${ }^{102}$ The answer to this objection is adapted from Einheuser 2003, 2006 who gave a similar answer to this objection aimed at conventionalism. She also, briefly, discussed a similar answer in her 2011 where she specifically address Ontological Conceptualism.
} 


\section{CHAPTER 2 THE ARGUMENT FROM ARBITRARINESS}

\subsection{EXPLANATION OF THE ARGUMENT}

The second argument for eliminativism is the Argument from Arbitrariness. The idea behind this argument is that there's no ontologically significant difference between ordinary objects and extraordinary objects. ${ }^{103}$ An ontological difference is a difference that gives a satisfactory account for why there are things of one kind (ordinary objects) but not the other (extraordinary objects). There's no satisfactory account that clearly and precisely presents the ontological differences between those kinds of objects, so it's arbitrary to accept the existence of ordinary objects and deny the existence of extraordinary objects. Since extraordinary objects don't exist, ordinary objects don't exist either. Thus, eliminativists deny the existence of both ordinary and extraordinary objects. For example, it would be arbitrary to accept the existence of islands whilst denying the existence of incars. And since there are no incars, there are no islands either. ${ }^{104}$ An incar is an object that is just like a car, but unlike an ordinary car, an incar cannot leave a garage. When an incar leaves a garage, it ceases to exist, and an outcar comes into existence. The argument runs as follows:

AA1: There's no ontologically significant difference between islands and incars.

AA2: If there's no ontologically significant difference between islands and incars, then if there are islands then there are incars.

AA3: There are no incars.

AA4: Therefore, there are no islands. ${ }^{105}$

\footnotetext{
${ }^{103}$ Korman 2015: 6. See Hirsch 1976: par. 2; 1982: 32.

${ }^{104}$ Korman 2015: 6-7, 124-125. See also van Inwagen 1990: 126.

${ }^{105}$ Korman 2015: 125.
} 
The first premise is plausible if islands and incars are both objects of the same kind (or if they are similar enough). The reason eliminativists argue they are of the same kind is that both are objects that cease to exist when the matter that they are made up of undergoes a change. For example, islands cease to exist when they become submerged during high tide, and incars cease to exist when they leave a garage. ${ }^{106}$ The second premise is plausible because if there's no ontologically significant difference between ordinary and extraordinary objects, then there must be a reason for why there are ordinary objects but not extraordinary objects. Thus, if it's true that incars don't exist, then there must be a reason for why islands exist but not incars. Since there's no such reason, islands don't exist either. ${ }^{107}$

Extraordinary objects, such as incars, have extraordinary persistence-conditions, for they cease to exist after they undergo certain changes, e.g. leaving a garage. Some ordinary objects, such as islands, have similar persistence-conditions, and therefore it would be arbitrary to accept the existence of one but not the other. Eliminativists solve the problem by eliminating both.

\subsection{OBJECTIONS TO THE ARGUMENT FROM ARBITRARINESS}

In this section, I discuss two objections: the objection from Extraordinary Restrictive Modal Profiles and the objection from Extraordinary Liberal Modal Profiles. Both these objections claim there is an ontologically significant difference between ordinary objects and extraordinary objects. There are some ordinary objects, such as teenagers and pages, that have very similar persistence-conditions to extraordinary objects. If we restructure the Argument from Arbitrariness in terms of these objects, however, it becomes clear that the Argument from Arbitrariness doesn't work for these objects and it becomes apparent that there's a significant ontological difference after all.

\footnotetext{
${ }^{106}$ Korman 2015: 6.

107 Korman 2015: 6.
} 


\section{EXTRAORDINARY RESTRICTIVE MODAL PROFILES}

The first objection to the Argument from Arbitrariness is the objection from Extraordinary Restrictive Modal Profiles which claims there's an ontologically significant difference between ordinary and extraordinary objects. The difference becomes apparent if we restructure the Argument from Arbitrariness in terms of teenagers and sweenagers. A teenager is usually defined as a person aged 13 to 19 years old and conventionally regarded as an ordinary object. Now contrast teenagers with sweenagers, where a sweenager is an extraordinary object with extraordinary persistence-conditions, namely they come into existence when they turn 13 years old and cease to exist when they turn 14 years old. They have these extraordinary persistenceconditions because we defined sweenagers in this way. A sweenager is co-located with an ordinary teenager for exactly one year.

Conservatists don't accept the existence of sweenagers, but they do accept the existence of teenagers. Accepting that teenagers exist but denying that sweenagers exist, however, is objectionably arbitrary. Consider the following argument:

AA1: There's no ontologically significant difference between teenagers and sweenagers.

AA2: If there's no ontologically significant difference between teenagers and sweenagers, then if there are teenagers then there are sweenagers.

AA3: There are no sweenagers.

AA4: Therefore, there are no teenagers. ${ }^{108}$

This argument has the exact same structure as the Argument from Arbitrariness, but no one would be tempted to raise this argument against conservatists. For there's an ontologically significant difference between teenagers and sweenagers: sweenagers have extraordinary

\footnotetext{
${ }^{108}$ Korman 2015: 126.
} 
persistence-conditions and teenagers don't. Sweenagers cease to exist when they reach a certain age - the age of fourteen - whereas teenagers don't cease to exist when they reach the age of 20. At the twenty-year mark, all that happens is that they cease to be teenagers, but they don't cease to exist! Teenagers have ordinary persistence-conditions; sweenagers have extraordinary persistence-conditions. Thus, the debunking argument fails to make a distinction between an object of a certain kind ceasing to exist and an object of a certain kind ceasing to be of that kind. $^{109}$

One can improve the argument by defining a sweenager* as a person between 13 and 14 years old. The argument would then run as follows:

AA1: There's no ontologically significant difference between teenagers and sweenager*s. AA2: If there's no ontologically significant difference between teenagers and sweenager*s, then if there are teenagers then there are sweenager*s.

AA3: There are no sweenager*s.

AA4: Therefore, there are no teenagers. ${ }^{110}$

Now there's indeed no ontologically significant difference between teenagers and sweenager*s. When a sweenager* reaches the age of 14, she doesn't cease to exist any more than a teenager ceases to exist when she reaches the age of 20. However, although AA1 is now true, AA3 is now false. There are sweenager*s, namely every person between the ages of thirteen and fourteen. ${ }^{111}$

Korman's objection to the Argument from Arbitrariness is that there is an ontologically significant difference between ordinary objects and extraordinary objects, and therefore that

\footnotetext{
${ }^{109}$ Korman 2015: 127.

${ }^{110}$ Korman 2015: 127.

${ }^{111}$ Korman 2015: 127-128.
} 
premise AA1 is false. The ontological difference between ordinary and extraordinary objects is that extraordinary objects have extraordinary persistence-conditions and ordinary objects have ordinary persistence-conditions. The mistake is to characterize islands as objects that cease to exist when they are fully submersed in water. Instead, Korman characterizes islands as a piece of land that protrudes from the water and is surrounded by water, but still exists when it's submerged during high tide. The island is still there during high tide but exists under water for a period of time. So it's not that islands cease to exist during high tide and come back into existence during low tide; rather, the land that the island is made up of continues to exist the whole time. ${ }^{112}$

If one finds it uncomfortable to say that an island is still an island when it's submerged during high tide, one can hold that the island ceases to be an island during high tide without it ceasing to exist, since the land the island is made up of continues to exist. Or one can hold that an island continues to be an island during high tide because the island becomes visible again during low tide. Only when a piece of land is submerged for a longer period of time does it cease to be an island. ${ }^{113}$ Regardless of how one characterizes islands, the idea is that being an island is just a temporary phase of a piece of land, which has ordinary persistence-conditions. ${ }^{114}$

By contrast, being an incar is not merely a temporal phase, because part of the definition of an incar is that it's essentially inside a garage. Thus, being inside a garage is not merely a temporal phase, but is an essential property of an incar. ${ }^{115}$

So, islands don't cease to exist when their land is submerged under water whereas incars do cease to exist when they leave a garage. Being an island is a temporary phase whereas being an

\footnotetext{
112 Korman 2015: 128-129.

${ }^{113}$ Korman 2015: 129.

114 Korman 2015: 129.

${ }^{115}$ Korman 2015: 129.
} 
incar is not. Therefore, there's an ontologically significant difference between islands and incars, and therefore AA1 is false. ${ }^{116}$

One response is that it's arbitrary to distinguish between kinds that are mere phases and kinds that are not. For example, it's arbitrary to say that an island is a mere phase whereas a piece of land is not. Those objects that belong to kinds that are mere phases can cease to be the object they are without ceasing to exist, whereas those objects that belong to kinds that are not mere phases cannot cease to be the object they are without ceasing to exist. Since it's arbitrary to assign objects to kinds that are mere phases or kinds that are not mere phases, it's arbitrary to say that islands exist while incars don't exist. ${ }^{117}$

Korman's reply to this objection is to say that he doesn't need a principle for classifying some kinds as mere phases and others as not being mere phases. We just know that some things can cease to belong to a kind without ceasing to exist, for example, puppies cease to be puppies once they grow up, but they don't cease to exist! If you were to disagree with these intuitions, the problem is not an arbitrariness problem but rather a problem of disagreement. And disagreement without argument is not an objection. ${ }^{118}$

Nevertheless, it seems to me that a piece of land is a phase term as well. The atoms the land is made up of are constantly changing and it isn't clear which borderline atoms belong to the land and which don't. Moreover, the soil itself is always changing as well. Water and wind are constantly eroding and reshaping the land in such a way that the piece of land at any one time is exceedingly likely to be different from other times. If true, then not only is there something arbitrary about distinguishing kinds that are mere phases from kinds that are not mere phases, but it's also hard to say precisely what a phase is. Furthermore, given that the matter of composite

\footnotetext{
${ }^{116}$ Korman 2015: 129.

${ }^{117}$ Korman 2015: 130.

${ }^{118}$ Korman 2015: 131.
} 
objects is constantly changing in a similar fashion to how pieces of land are constantly changing, it seems that being a composite object itself is a phase term as well.

Another worry I have is that eliminativists focus their attention on the ontological difference between islands and incars rather than on ordinary objects in general. This is problematic because it might not be possible to generalize the argument to include all ordinary objects. The reason eliminativists focus on the ontological difference between islands and incars is because they seem to have similar persistence-conditions, since islands allegedly cease to exist when they are fully submerged in water and incars cease to exist when they leave a garage. But not all ordinary objects are like islands; in fact, most ordinary objects are not like islands. Stones do not cease to exist when we move them, nor do they cease to exist when we drop them in a pool of water. Neither do tables, stars, planets, tables, desks, people, dogs, or cats. So even if we grant that the Argument from Arbitrariness is true, it might not generalize to all ordinary objects. Thus, eliminativists must either come up with an argument for how the Argument from Arbitrariness generalizes to include all ordinary objects, or they must restrict their conclusions to some objects only.

Lastly, perhaps eliminativists are confusing incars with incar*s, where an incar* is just a car that's currently inside a garage. If that's the case, then the argument runs as follows:

AA1: There's no ontologically significant difference between islands and incar*s. AA2: If there's no ontologically significant difference between islands and incar*s, then if there are islands then there are incar*s.

AA3: There are no incar*s.

AA4: Therefore, there are no islands. ${ }^{119}$

\footnotetext{
${ }^{119}$ Korman 2015: 125.
} 
Now AA1 is true; there's no ontologically significant difference between islands and incar*s, since incar*s are just like islands in the sense that their constitutive matter continues to exist; the piece of land still exists (albeit under water) and the matter the car is made up of continues to exist (albeit outside a garage). The island and incar* may disappear for a little while, or they might cease to be islands or incar*s for a while, but they don't cease to exist while under water or outside a garage. ${ }^{120}$ However, although AA1 is now true, AA3 is now false. If an incar* is just a car inside a garage, then there are incar*s, namely all those cars currently in garages. ${ }^{121}$

\section{EXTRAORDINARY LIBERAL MODAL PROFILES}

The second objection to the Argument from Arbitrariness is the objection from Extraordinary Liberal Modal Profiles. This argument also claims that there's a significant ontological difference between ordinary and extraordinary objects. The difference becomes apparent if we restructure the Argument from Arbitrariness in terms of pages and 'monewments'. Imagine that the Washington Monument is being demolished and later an exact replica is constructed somewhere else out of new materials. Although controversial, Korman claims that monuments are not the kinds of thing that can survive a complete non-piecemeal replacement of their parts, where a non-piecemeal replacement is a replacement which happens not gradually but rather more quickly and completely. Moreover, the new Washington monument is numerically distinct from the old one. The old Washington Monument doesn't exist anymore. However, if there's an object, (call it a monewment), that survived the demolition, then this would be an object with extraordinary liberal persistence-conditions. ${ }^{122}$ The argument runs as follows:

AA1: There's no ontologically significant difference between pages and monewments.

AA2: If there's no ontologically significant difference between pages and monewments, then if there are pages, then there are monewments.

\footnotetext{
${ }^{120}$ Korman 2015: 129-130.

${ }^{121}$ Korman 2015: 130.

122 Korman 2015:131.
} 
AA3: There are no are monewments.

AA4: Therefore, there are no pages. ${ }^{123}$

This argument has the exact same structure as the Argument from Arbitrariness, but no one would be tempted to raise this argument against conservatists, for there's an ontologically significant difference between pages and monewments; monewments have extraordinary persistence-conditions and pages don't. Pages, such as the pages of this thesis sitting on my desk, have very similar liberal persistence-conditions to monewments. Imagine I spill some coffee on one of the pages, put it through a paper shredder, and print it out again. The original page ceased to exist when I put it through the paper shredder, but it came back into existence in a new embodiment when I printed it out again. ${ }^{124}$

Eliminativists claim there are no monewments (and conservatists would agree there are no monewments). But eliminativists, unlike conservatists, claim that since there are no monewments, there are no pages either, for both can survive a complete and non-piecemeal replacement of their parts. If this is true, then there's no ontologically significant difference between pages and monewments. So if there are no monewments, then there are no pages either. $^{125}$

Korman argues that AA1 is false; there is an ontologically significant difference between pages and monewments. He argues pages don't cease to exist whereas monewments do cease to exist, because pages cannot survive a complete and non-piecemeal replacement of their parts while monewments can (by definition). What happened when I spilled coffee on the page of my thesis and put it through the shredder, is that that page is now gone - it doesn't exist anymore. The new page I printed now plays the role of the old page, namely being a page in my thesis. Say it was

\footnotetext{
${ }^{123}$ Korman 2015: 132. The argument is due to Ginet 1985: 220-221.

${ }^{124}$ Korman 2015: 131-132.

${ }^{125}$ Korman 2015: 132.
} 
the fifth page of thesis. Now, there's no one object that's picked out by the 'the fifth page'. 'The fifth page' is a role and not an object. ${ }^{126}$

Apart from being a role, 'the fifth page' is also a type. Like roles, types are abstract, but unlike roles, types can have multiple tokens. The object that's picked out by 'the fifth page' is a token. When I spilled coffee on the page and printed out a new one, all I have done is destroy one token and bring into existence a new token. The type didn't cease to exist; only the token did. ${ }^{127}$ Neither roles, nor types, nor the piece of paper that tokens the type and plays the role is an object that's able to survive the non-piecemeal replacement of their parts. Since monewments can survive the non-piecemeal replacement of their parts, AA1 is false - there's an ontologically significant difference between pages and monewments. ${ }^{128}$

Korman appeals to roles, where a role is the function or purpose that something has in a certain situation. He also appeals to types and tokens, where a token is the occupier of a role. But if tokens are the occupiers of roles, then it's redundant to appeal to roles, because tokens can explain why the page that had coffee spilled on it is not the same page as the new page. They are different tokens of the same type. Nevertheless, the distinction between roles, tokens, and types doesn't affect the overall structure of the argument but is merely a distinction Korman did not set out clearly.

\subsection{THE ONTOLOGICAL CONCEPTUALIST'S RESPONSE}

I argue that there is an ontologically significant different between ordinary objects and extraordinary objects by appealing to Ontological Conceptualism. According to Ontological Conceptualism, the difference is that ordinary objects are conceptualized objects while extraordinary objects are not conceptualized. Therefore, AA1 is false.

\footnotetext{
${ }^{126}$ Korman 2015: 132.

${ }^{127}$ Korman 2015: 132.

${ }^{128}$ Korman 2015: 132.
} 
Eliminativists claim that islands and incars are of the same, (or similar) kinds in the sense that both are objects that cease to exist when their constituent matter undergoes a change. However, phrasing it in terms of coming into existence and ceasing to exist is misleading. Islands, incars, teenagers, and sweenagers don't cease to exist when they become submerged, leave a garage, or reach a certain age. Instead their constituent matter is not picked out by their respective concepts any longer. The world itself doesn't change in an ontologically significant way, but what constituent matter is picked out by those concepts does change. So an island doesn't cease to exist when submerged, but its constituent matter is not picked out by the concept ISLAND any longer. Similarly, incars don't cease to exist when they leave a garage, but instead their constituent matter doesn't fall under the concept INCAR anymore. Similarly, teenagers don't cease to exist when they turn twenty years old, but instead their constituent matter is not categorized as a teenager anymore, that is, it's not picked out by our concept TEENAGER anymore, and sweenagers don't cease to exist when they turn 14, but instead their constituent matter doesn't fall under the concept SWEENAGER any longer.

Specifically, incars and sweenagers were never conceptualized in the first place (apart from in philosophical discussions), so they never existed in the first place. But assuming they do fall under those concepts, they did not cease to exist when leaving the garage or when turning 14 years old. Rather, they are merely not picked out by our (philosophical) concepts.

So Korman's objection to the Argument from Arbitrariness is misguided. Korman argues that the Argument from Arbitrariness has the same structure as the argument about teenagers and sweenagers. He argues that teenagers have ordinary persistence-conditions whereas sweenagers have extraordinary persistence-conditions. According to Korman, sweenagers would cease to exist when they reach the age of 14, whereas teenagers don't cease to exist when they reach the age of 20 for all that happens when a teenager reaches the twenty-year mark is that they cease to be teenagers; not that they cease to exist. So there's an ontologically significant difference between teenagers and sweenagers. But if all persistence-conditions are grounded in concepts as 
the Ontological Conceptualist holds, then sweenagers don't cease to exist when they reach a certain age either. All that happens is that the person picked out by the concept SWEENAGER is not picked out by that concept anymore in the same way that a person picked out by the concept TEENAGER is not picked out by that concept anymore. So there isn't an ontologically significant difference between the two. What is different between teenagers and sweenagers is that the concepts are different and our use of the concepts that pick out these two objects is different. So eliminativism as described by Korman is wrong; neither sweenagers nor incars cease to exist, instead they merely cease to be of that kind. And moreover, our use of those two concepts is different, because we use the concept TEENAGER in ordinary life while we don't ordinarily use the concept SWEENAGER. For that reason, we take teenagers (and all other ordinary objects) to exist while we don't take sweenagers (and all other extraordinary objects) to exist. But this isn't because the world doesn't contain sweenagers while it does contain teenagers; rather it's because teenagers are conceptualized objects, and thus exist, while sweenagers are not conceptualized, and thus don't exist.

The same holds for islands and incars. Firstly, the distinction between islands and incars in terms of ordinary or extraordinary persistence-conditions is misguided. For neither cease to exist when submerged or when leaving a garage. All that happens is that they cease to fall under their respective concepts. Secondly, our use of those two concepts is different, because we use the concept ISLAND in ordinary life whereas we don't use the concept INCAR. And for that reason, we take islands to exist while we don't take incars to exist. But again, this isn't because the world doesn't contain incars while it does contain islands, but because islands are conceptualized objects whereas incars are not.

Accordingly, it's not arbitrary to admit islands in our ontology while excluding incars. It's not arbitrary because there's a systematic explanation for why ordinary objects exist and extraordinary objects don't exist. The explanation is that ordinary objects are conceptualized objects, and thus exist (albeit mind-dependently) whereas extraordinary objects are not conceptualized and thus don't exist. 
The Argument from Arbitrariness assumes that the modal profiles of objects - both ordinary objects and extraordinary objects - are inherent in the objects themselves. Once this assumption has been undermined, like the Ontological Conceptualist attempts to do, the argument holds no force. For if modal profiles of objects are grounded in the concepts we have of those objects, then we cannot use those modal profiles as a mind-independent explanation for why we should admit some objects but not others in our ontology.

So I agree that the Argument from Arbitrariness goes wrong because it fails to make a distinction between an object of a certain kind ceasing to exist and an object of a certain kind ceasing to be of that kind. I even agree with Korman's objection that the ontological difference between ordinary and extraordinary objects is that extraordinary objects truly have extraordinary persistence-conditions that ordinary objects don't have. But rather than locating these extraordinary persistence-conditions in the objects themselves, I locate them in the concepts we use to describe those extraordinary objects. But, since we don't usually use those extraordinary concepts outside the philosophy room, these extraordinary concepts don't pick out any objects, and therefore, they don't exist. 


\section{CHAPTER 3 THE OVERDETERMINATION ARGUMENT}

\subsection{EXPLANATION OF THE ARGUMENT}

The third argument for eliminativism is the Overdetermination Argument. Sometimes it seems that an effect has two intimately related causes. For example, some events seem to be caused by both a physical and a mental property, a physical and mental event, a macroscopic object and a microscopic object, an object and the event involving that object, or an object and a fact involving that object. The effect $e$ is overdetermined if it's caused by these two causes together. 129 Regarding ordinary objects, which are made up of atoms, both the object and the atoms cause effect. If an effect is caused by an object and the atoms it's made up of, then that effect is overdetermined. But effects cannot be overdetermined. Therefore, ordinary objects don't exist. ${ }^{130}$ The idea is that ordinary objects don't exist because they don't cause anything over and above the atoms they are made up of. All causal work has already been explained by the atoms, and therefore, accepting objects in addition to those atoms would be causally redundant. Since for an ordinary object to exist is to have causal powers, ${ }^{131}$ objects which don't have causal powers don't exist. Ordinary objects don't have any causal powers over and above their parts, so they are causally redundant and therefore we should eliminate them from our ontology. ${ }^{132}$ The argument runs as follows:

OA1: Every event caused by a baseball is caused by atoms arranged baseball-wise.

OA2: No event caused by atoms arranged baseball-wise is caused by a baseball.

OA3: Therefore, no events are caused by baseballs.

\footnotetext{
${ }^{129}$ Sider 2003: 719. I sometimes speak of effects being overdetermined by objects while at other times speaking of effects being overdetermined by events. Even though there's an important distinction between these two ways of articulating the Overdetermination Argument, it won't make much difference for the purpose of this thesis. Also see Brock, Maslen, and Ngai 2013: 72-74.

130 Sider 2003: 720.

${ }^{131}$ See Thomasson 2006: 341; Merricks 2001: 81.

132 Korman 2015: 8; Korman 2016: 24.
} 
OA4: If no events are caused by baseballs, then baseballs don't exist.

OA5: Therefore, baseballs don't exist. ${ }^{133}$

The first premise is plausible because if we were to deny it, we would have to say that baseballs cause things while the atoms they are made up of don't cause things. Assuming that there's a complete causal explanation for physical events in terms of their microphysical constituents, ordinary objects don't cause anything that their parts don't also cause. ${ }^{134}$

The second premise, that no event caused by atoms arranged baseball-wise is caused by a baseball, can be defended with the following argument:

OA6: If an event is caused by a baseball and by atoms arranged baseball-wise, then the event is overdetermined by the baseball and atoms arranged baseball-wise.

OA7: No event is overdetermined by a baseball and atoms arranged baseball-wise.

OA2: Therefore, no event caused by atoms arranged baseball-wise is caused by a baseball. ${ }^{135}$

An event $e$ is overdetermined by an object $o 1$ and $o 2$ when:

(i) $o 1$ causes $e$.

(ii) $o 2$ causes $e$.

(iii) $o 1$ is not causally relevant to $o 2$ 's causing $e$.

(iv) $o 2$ is not causally relevant to $o 1$ 's causing $e$.

\footnotetext{
${ }^{133}$ Korman 2015: 8, 191; Korman 2016: 24.

${ }^{134}$ Korman 2015: 8-9; Korman 2016: 24 . See Merricks 2001: 61-66 for a defence of OA1.

${ }^{135}$ Korman 2015: 8; Korman 2016: 25.
} 
(v) $o 1$ is not identical, or reducible to, $o 2 .{ }^{136}$

To be causally relevant is just to play a role in a complete causal explanation. Thus, if $o 1$ were to be causally relevant to $o 2$ 's causing $e$, then this means that in a complete causal explanation of how $o 2$ causes $e, o 1$ plays a role in that explanation. It could play a role in that causal explanation in a variety of ways. For example, $o 1$ could play a role by causing $o 2$ to cause $e$, it could play a role by being caused by $o 2$ to cause $e$, or by causing $e$ together with $o 2 .{ }^{137}$

If overdetermination is the satisfaction of these five conditions, then OA6 is true. For example, if the breaking of a window is caused by a baseball and its constituent atoms, then the first two conditions are met, i.e. $o 1$ (the baseball) causes the breaking of the window, and $o 2$ (the atoms) causes the breaking of the window. Furthermore, the third and fourth conditions are met as well since the baseball (o1) is not causally relevant to the atoms causing the breaking of the window and the atoms (o2) are not causally relevant to the baseball (o1) causing the breaking of the window either. For baseballs don't cause their atoms to break windows nor do atoms cause baseballs to break windows. The fifth condition is met if one believes that baseballs are not identical to their constituent atoms.

Someone who endorses the Composition as Identity thesis avoids the argument, for they would argue that the baseball is identical to the atoms arranged baseball-wise. However, this thesis assumes that the Composition as Identity thesis is false, so I won't focus on objections directed at OA6.

The fourth premise of the Overdetermination Argument, that if no events are caused by baseballs, then baseballs don't exist, is supported by Ockham's Razor. If baseballs don't cause anything, and if they are not reducible to the atoms arranged baseball-wise, then we shouldn't

\footnotetext{
${ }^{136}$ Korman 2015: 192; Korman 2016: 25.

${ }^{137}$ Korman 2015: 193; Korman 2016: 25.
} 
admit them into our ontology and instead eliminate them. OA4 is also supported by the Eleatic Principle, which states that everything that exist must have causal powers. If we assume that baseballs don't have causal powers because they cannot have causal powers, then OA4 follows. $^{138}$

\subsection{OBJECTIONS TO THE OVERDETERMINATION ARGUMENT}

I discuss four objections to the Overdetermination Argument. The first objection is that since there are unproblematic cases of overdetermination, such as object-event overdetermination, overdetermination in terms of objects and their parts is unproblematic as well. So OA7 is false. Merricks responds to this objection and argues that object-event overdetermination is indeed unproblematic, but there are important differences between object-event and object-part overdetermination. The second objection to $\mathrm{OA} 7$ is that overdetermination is only problematic when the two causes that caused the event are sufficiently independent from one another. Since ordinary objects and their parts are not independent from each other, there's no problematic overdetermination. The third objection against OA7 is that overdetermination is only problematic when both causes exist, e.g. both ordinary objects and the atoms they are made up of exist. If both causes do indeed exist, then there's problematic overdetermination. However, Merricks argues that we don't have reason to believe that ordinary objects exist. If ordinary objects don't exist, then there's no overdetermination between ordinary objects and the atoms that make them up. Merricks' argument, called the Epistemic Argument, has been replied to by Korman who argues one of the premises of the Epistemic Argument is false. Next, I present a recent response by Bernstein, who argues that the distinction between problematic and unproblematic overdetermination doesn't undermine eliminativism, but also argues that this distinction doesn't support conservatism. The fourth objection is a recent argument by Le Bihan, who argues that eliminativism about ordinary objects entails eliminativism about the physical particles that ordinary objects are made up of. Lastly, I set out how the Ontological Conservatist can respond to these objections and replies.

\footnotetext{
${ }^{138}$ Korman 2015: 9.
} 


\section{OBJECTION 1: OBJECT-EVENT AND OBJECT-PART OVERDETERMINATION}

The first objection is to claim OA7 is false. The idea is that there are similar cases of unproblematic overdetermination. For example, the atoms of a baseball cause a window to shatter when someone throws a baseball through a window and at the same time the event of those atoms hitting the window also causes the window to shatter. This sort of object-event overdetermination is unproblematic, so object-part overdetermination involving objects and their parts is similarly unproblematic. ${ }^{139}$ So conservatists can argue that overdetermination of ordinary objects and their parts is not the problematic kind of overdetermination.

\section{MERRICKS' RESPONSE TO OBJECT-EVENT AND OBJECT-PART OVERDETERMINATION}

Merricks' response to this objection is that object-event overdetermination is indeed unproblematic, but there's a disanalogy between object-event overdetermination and object-part overdetermination. Object-event overdetermination is unproblematic because the object causing the event - the baseball causing the window to shatter - can be analysed in terms of the event causing the effect. For what it is for a baseball to cause the window to shatter just is to play a role in the window shattering event. Likewise, what it is for a baseball to cause the window to shatter just is for its parts to cause the shattering of the window. But in the case of object-part overdetermination, the baseball causing the window to shatter cannot be analysed in terms of the baseball's parts causing the window to shatter. For the kind of causation involved in eventcausation and object-causation is relevantly different.

\footnotetext{
${ }^{139}$ Korman 2015: 194; Merricks, T. (2001). Objects and Persons. New York: University Press: 67-72.
} 
Events and objects are categorically different. The kind of causation involved in event-causation is only analogically related to object-causation because they fall into different ontological categories. Although object-causation can be analysed in terms of event-causation, they are still two distinct kinds of causation, and therefore object-event overdetermination is unproblematic. By contrast, the kind of causation involved in object-part causation is not analogically related; the baseball and its parts do the same kind of causal work. Therefore, we cannot analyse the baseball shattering the window in terms of its parts shattering the window. Analysing the baseball causing the window to shatter in terms of its parts causing the window to shatter would be circular and therefore should be abandoned. ${ }^{140}$ Thus, once we make a distinction between cases of overdetermination where one overdeterminer can be analysed in terms of the other, and those cases of overdetermination where one overdeterminer cannot be analysed in terms of the other, we see that object-event overdetermination is unproblematic whereas object-part overdetermination is problematic. ${ }^{141}$

\section{OBJECTION 2: INDEPENDENT CAUSES}

The second objection also claims that OA7 is false. The idea is that there's a difference between problematic and unproblematic overdetermination in terms of the independence of the two causes that allegedly overdetermine the effect. Overdetermination is problematic when the two causes of the shattering of the window (the baseball and its parts) are independent from each other (in some sense or other). Since baseballs and their parts are not independent from each other in the relevant sense, no problematic overdetermination has occurred. The most commonly discussed sense in which an event is overdetermined by two causes is in terms of counterfactuals. An event is overdetermined if, had the first cause not occurred, the effect still would have occurred and had the second cause not occurred, the effect still would have occurred. Since

\footnotetext{
${ }^{140}$ Merricks 2001: 67-72.

${ }^{141}$ Korman 2015: 194.
} 
either one of the causes would have been sufficient for the effect to occur, the event is overdetermined by both causes. ${ }^{142}$

\section{OBJECTION 3: THE EXISTENCE OF BOTH CAUSES}

The third objection also claims OA7 is false. The idea is that there's a difference between problematic and unproblematic overdetermination in terms of the existence of both causes. In the case of baseballs and their parts, if we have reason to believe that both baseballs and the atoms they are made up of exist, then the shattering of the window would be indeed problematic. ${ }^{143}$ Since both baseballs and their parts exist, the shattering of the window is overdetermined. Thus it's false that no event is overdetermined by baseballs and atoms arranged baseball-wise. ${ }^{144}$

\section{MERRICK'S RESPONSE TO THE EXISTENCE OF BOTH CAUSES (THE EPISTEMIC ARGUMENT)}

Merricks' response to this objection is to claim that we don't have reason to believe baseballs exist. If baseballs don't exist, then there's no overdetermination between objects and their parts, and thus OA7 is true - no event is overdetermined by a baseball and atoms arranged baseballwise. $^{145}$

The idea is that we believe baseballs exist because we can perceive them. But perceiving a baseball is not a good enough reason to believe that the atoms arranged baseball-wise compose a baseball, that is, we are not perceptually justified in believing that atoms arranged baseball-wise compose a baseball. Therefore, we are not perceptually justified in believing baseballs exist. And if there's no good reason to believe that baseballs exist, then there's no good reason to believe

\footnotetext{
${ }^{142}$ Korman 2015: 195. This objection was also discussed in Merricks 2001: 72-79.

${ }^{143}$ Korman 2015: 195.

144 Korman 2015: 195.

${ }^{145}$ Korman 2015: 195.
} 
that they overdetermine events such as the shattering of windows, especially if we already know that the atoms arranged baseball-wise cause the shattering of the window. ${ }^{146}$ The argument, called the Epistemic Argument, runs as follows:

OA8: One should believe that an event is overdetermined by $o 1$ and $o 2$ only if one is justified in believing in $o 1$ and $o 2 .^{147}$

OA9: We are justified in believing baseballs exist only if we are perceptually justified in believing baseballs exist.

OA10: No one is perceptually justified in believing trogs exist.

OA11: We are perceptually justified in believing baseballs exist only if we are perceptually justified in believing trogs exist.

OA12: Therefore, we are not perceptually justified in believing baseballs exist.

OA13: Therefore, we shouldn't believe that events are overdetermined by a baseball and atoms arranged baseball-wise. ${ }^{148}$

The conclusion is not OA7 itself, but merely that we shouldn't deny OA7. The premises are plausible. The eighth premise (OA8) is just obvious; if we're not justified in believing $o 1$ and $o 2$ exist, then we're not justified in believing an event is overdetermined by $o 1$ and $o 2$. The ninth premise (OA9) is plausible since it seems the only reason to believe baseballs exist is our perception of them. There doesn't seem to be an abductive argument for the existence of baseballs. We don't have to posit baseballs in addition to atoms arranged baseball-wise, since atoms arranged baseball-wise already explains any causal work. ${ }^{149}$ The tenth premise (OA10) is plausible since seeing a trunk and a dog is not the same as seeing a trog. Perhaps seeing a trunk and a dog together with an argument showing that trunks and dogs compose trogs is justification for believing trogs exist, but the mere perception of trunks and dogs isn't. The eleventh premise

\footnotetext{
${ }^{146}$ Korman 2015: 195; Merricks 2001: 72-79.

${ }^{147}$ And 01 is not identical to 02 , and both 01 and o2 occur.

148 Korman 2015: 196. The argument is adapted from Merricks 2001: 72-79.

${ }^{149}$ Korman 2015: 196.
} 
(OA11) is plausible as well. If merely perceiving a trunk and a dog isn't justification enough to believe trogs exist, then merely perceiving some atoms arranged baseball-wise isn't enough justification to believe baseballs exist either. The idea is that our perceptual experience would be the same regardless of whether or not the trunk and dog composes something. Similarly, our perceptual experience would be the same regardless of whether or not the atoms arranged baseball-wise compose something. Our perceptual experience is insensitive to compositional facts. Therefore, we are not justified to take perceptual experience as a justification to believe something composes a further object or not. Particularly, we cannot take perceptual experience as a justification for believing composite objects such as trogs and baseballs exist. ${ }^{150}$

\section{KORMAN'S REPLY TO THE EPISTEMIC ARGUMENT}

Korman argues OA11 of the Epistemic Argument is false; it's false that we are perceptually justified in believing baseballs exist only if we are also perceptually justified in believing trogs exist. For there's an important difference between our justification for believing baseballs exist and believing trogs exist. The difference is in the content of these two beliefs. The content of our experiences of baseballs represents baseballs as baseballs whereas the content of our experiences of trogs don't represent trogs as trogs. In other words, the content of our experiences of baseballs is that there is a baseball while our experiences of trogs doesn't have the content that there is a trog. To illustrate, someone can perceive an undercover cop without perceiving it as an undercover cop if one doesn't know it's an undercover cop. Similarly, someone could perceive a trog without perceiving it as a trog. ${ }^{151}$ Korman formally sets out the argument as follows:

EA1: We have experiences with the content there is a baseball.

EA2: If we have experiences with the content there is a baseball, then (absent defeaters) we are justified in forming a direct perceptual belief that there are baseballs.

\footnotetext{
${ }^{150}$ Korman 2015: 196-197.

${ }^{151}$ Korman 2015: 198-199.
} 
EA3: So, (absent defeaters) we are justified in forming a direct perceptual belief that there are baseballs. ${ }^{152}$

The first premise is plausible. Although the debate on perceptual content is by no means settled, EA1 is plausible. The second premise is supported by the principle of foundational justification which states that having experiences with a certain content justifies the belief in what the content represents as existing. Therefore, absent defeaters, we are justified in forming the direct perceptual belief that baseballs exist. ${ }^{153}$

\section{RESPONSES TO KORMAN}

The first response to Korman's reply to the Epistemic Argument is to deny perceptual contents are rich. The contents of perception don't include information about kinds, composition, or coinstantiation. Instead, perceptual contents only include lower-level qualities such as shape, colour, size, etc. If perceptual contents are sparse in this way, then EA1 is false. ${ }^{154}$

However, I assume perceptual contents are rich, so I don't consider objections to this reply. I assume our perceptual experience of objects represents objects as belonging to a certain kind, our perceptual experiences represent objects as being composed (or not) of parts, and they represent the qualities belonging to that object as being co-instantiated by a single object. In saying that perceptual contents represent objects in that way, I am not saying, however, that objects actually belong to a certain kind, are composed of parts, or that their qualities are co-instantiated by a single object. ${ }^{155}$

\footnotetext{
152 Korman 2015: 199.

${ }^{153}$ Korman 2015: 199.

${ }^{154}$ Korman 2015: 199. Proponents of this view include Byrne 2005 and 2009, Tye 1995, Price 2009, Dretske 1995, and Martin, 1992. Also see Siegel and Byrne 2016.

${ }^{155}$ See Siegel 2017; Peacocke 1992; Siewert 1998; Nanay 2011; Block 2014 for arguments that the contents of perceptual experience are rich.
} 
The second response to Korman's reply to the Epistemic Argument is that although we don't have experiences as of trogs, this doesn't imply that it isn't possible for anyone to have such experiences. For example, it's possible that a community of creatures - call them troglodytes evolved in such a way that they have trogs in their perceptual contents just like we have baseballs in our perceptual contents. ${ }^{156}$ If true, then we should reformulate the argument for OA12 as follows:

OA10’: Troglodytes are not perceptually justified in believing trogs exist.

OA11': We are perceptually justified in believing baseballs exist only if troglodytes are perceptually justified in believing trogs exist.

OA12': Therefore, we are not perceptually justified in believing baseballs exist. ${ }^{157}$

Korman agrees that troglodytes are possible and therefore he has no objection to OD11'. However, he now objects to AO10' that troglodytes aren't perceptually justified in believing trogs exist. For troglodytes are justified in believing trogs exist for the same reason we are justified in believing baseballs exist. ${ }^{158}$

The third response to Korman's reply to the Epistemic Argument is to accept EA2, that (absent defeaters) we are justified in forming a direct perceptual belief that baseballs exist, but to hold that there are defeaters, and therefore EA2 is false. Korman doesn't think there are defeaters. However, as I outlined in chapter 1, there's a good case to be made that there are defeaters, and thus that EA2 is false after all. ${ }^{159}$

\footnotetext{
${ }^{156}$ Korman 2015: 200.

${ }^{157}$ Korman 2015: 200.

${ }^{158}$ Korman 2015: 200.

${ }^{159}$ Korman 2015: 201.
} 


\section{BERNSTEIN: OVERDETERMINATION UNDERDETERMINED}

Bernstein responds to the objections levelled against OA7. Conservatists distinguish between problematic and unproblematic overdetermination, and use this distinction to argue that the Overdetermination Argument undermines eliminativism. Bernstein argues that the distinction between problematic and unproblematic overdetermination does not undermine eliminativism, but it doesn't support conservatism either. Bernstein provides a comprehensive overview of what it means for something to be overdetermined. She distinguishes between four different types of overdetermination and examines whether they actually constitute overdetermination, and if so, whether they are unproblematic overdetermination. ${ }^{160}$

Causal overdetermination is an objection to nonreductive theories of objects, such as conservatism. ${ }^{161}$ A nonreductive theory of objects claims that both ordinary objects and their parts/atoms ${ }^{162}$ have causal powers, and for that reason ordinary objects and their atoms exist. In response, nonreductive theorists argue that the kind of overdetermination their theories are committed to are different to the problematic cases of overdetermination such as those involving multiple rock throwers, and for that reason overdetermination is unproblematic. In other words, nonreductionists admit there's causal overdetermination but unproblematic overdetermination. To streamline the discussion, I frame the argument in terms of conservatism as opposed to nonreductive theories. ${ }^{163}$

Merricks objects to conservatism because the effects that ordinary objects cause is systematically overdetermined by the atoms that they are made up of. There are two lines of defence conservatists can take, either deny object-part overdetermination occurs or accept

\footnotetext{
160 Bernstein 2016: 34.

${ }^{161}$ The way Bernstein defines a nonreductive theory is that the macroscopic object qua macroscopic object is causally efficacious while the microscopic parts qua microscopic parts are also causally efficacious. On this construal, many conservatist positions would be categorized as a nonreductive theory.

${ }^{162}$ Given I have used the term 'atoms' throughout this thesis, I often use this term instead of 'parts', for the purpose of this thesis they can be used interchangeably. Nothing should hinge on this distinction though.

163 Bernstein 2016: 1.
} 
overdetermination occurs but hold that it isn't the problematic kind of overdetermination. Both lines of defence use the differences between types of causal overdetermination to argue that the type of overdetermination their theories are committed to is not objectionable.

The three important types of overdetermination for the purpose of this thesis are:

- Two rocks overdetermination

- Mereological overdetermination

- Constitutive overdetermination

Two rocks overdetermination is the standard case of overdetermination discussed in metaphysics, e.g. Billy and Suzy each throw a rock at a window, which causes the window to shatter. Either Billy's or Suzy's rock would have shattered the window. Therefore, the two rocks overdetermine the effect. Mereological overdetermination is overdetermination in terms of wholes and their parts. For example, rocks are composed of parts. Both the rock and the atoms arranged rock-wise cause the shattering of the window, so the shattering is overdetermined by the rock and the atoms arranged rock-wise. Constitutive overdetermination is similar to mereological overdetermination. Rocks are made up of matter, i.e. minerals. The sum of minerals materially constitutes, but is not identical to, the rock. Both the rock and the sum of minerals cause the shattering of the window. So the shattering is overdetermined by the rock and the sum of minerals. ${ }^{164}$

In the technical sense, 'overdetermination' means 'causal redundancy'. In another sense, 'overdetermination' is a pejorative term for problematic causal redundancy. So there's a distinction between problematic and unproblematic overdetermination. However, without an account of what this distinction consists of, it's unclear how this distinction helps

${ }^{164}$ Bernstein 2016: 19. 
conservatists. ${ }^{165}$ Therefore, it's important to explain the distinction between these types of overdetermination and state what overdetermination 'in the pejorative sense' means. Bernstein does this by looking at some problems associated with overdetermination. Subsequently, she discusses how, if at all, this distinction solves those problems. ${ }^{166}$

Bernstein's definition of overdetermination is similar to the one stated earlier. She takes overdetermination to be as follows: causes $c 1$ and $c 2$ overdetermine an effect $e$ iff (i) both causes are distinct, (ii) both causes occur, and (iii) both causes are each sufficient to cause $e .{ }^{167}$ Four terms in this definition need explaining:

1. What it is for causes to be distinct.

2. What it is for causes to occur.

3. What it is to be sufficient to cause something else.

4. What it is for an effect $e$ to be the same as it would have been if only one cause had been present. ${ }^{168}$

The first term is distinctness. There are several types of distinctness: numerical distinctness (two causes are non-identical), analytical distinctness (the existence of one cause doesn't entail the existence of the other cause), modal distinctness (it's possible for there to be one cause without the other cause), and mereological distinctness (no overlap of their parts).

Numerical distinctness is the most general kind of distinctness. It means that the two causes are non-identical. The other kinds of distinctness all imply numerical distinctness. ${ }^{169}$ We often treat different types of overdetermination differently because we use different kinds of distinctness. For example, we treat the two rocks case differently to the mereological/constitutive

\footnotetext{
165 Bernstein 2016: 20.

${ }^{166}$ Bernstein 2016: 20.

${ }^{167}$ Bernstein 2016: 20.

${ }^{168}$ Bernstein 2016: 21.

${ }^{169}$ Bernstein 2016: 21.
} 
overdetermination cases because the two rocks case involves numerical, mereological, modal, and analytic distinctness, whereas the mereological/constitutive overdetermination merely involves numerical distinctness. ${ }^{170}$ Numerically distinct overdetermination cases are widespread, since it occurs every time an object and its atoms/parts cause an effect. ${ }^{171}$ Since widespread overdetermination is an objection to conservatism, conservatists restrict the notion of overdetermination to exclude cases that are merely numerically distinct. ${ }^{172}$

The second term is what it is for causes to occur. The Overdetermination Argument claims that to overdetermine an effect, two causes must occur. It's easy to see why both causes occur in the two rocks case, since Billy's and Suzy's rocks exist independently. It's not so easy to see in mereological/constitutive overdetermination. For it isn't clear what it means to say that both the rock and their atoms occur. Mereological/constitutive overdetermination occurs because they posit an extra object in addition to the parts/atoms. Conservatists who posit an extra object in addition to the parts/atoms, must explain how ordinary objects have causal powers over and above the causal powers of their parts/atoms. Assuming that to exist is to have causal powers, positing an extra object in addition leads to mereological/constitutive overdetermination. ${ }^{173}$

The third notion is what it is to be sufficient to cause something. There are different types of causation which lead to different types of overdetermination. Causation could be the transfer of energy from one thing to another; two causes overdetermine an effect when each quantity transferred is sufficient to cause the effect. Causation could be counterfactual dependency. It could be lawful regularities, where multiple coincident regularities result in overdetermination. Opponents of mereological overdetermination often assume the type of causation in question is energy transfer, and object that the amount of energy transferred is not doubled in

\footnotetext{
${ }^{170}$ Bernstein 2016: 21.

171 Bernstein 2016: 21.

172 Bernstein 2016: 21-22.

173 Bernstein 2016: 22.
} 
mereological/constitutive overdetermination, i.e. the object and the atoms don't separately transfer energy. This objection is undermined by adopting a different account of causation. ${ }^{174}$

The fourth notion is what it is for an effect to be the same as it would have been had only one cause been present. In the two rocks case, removing one cause changes the way the effect occurs, e.g. if only Suzy had thrown a rock, there would have only been half the force. Suzy throwing a rock by herself causes a different effect to Suzy and Billy throwing a rock together. In constitutive/mereological overdetermination cases, removing one cause doesn't change the way the effect occurs. It's impossible to remove atoms from an object, so constitutive/mereological overdetermination is not about removing one cause, but is about the relationship between causes; the relationship between objects and their parts/atoms. With constitutive/mereological overdetermination, the relationship between objects and its parts/atoms makes it a case of overdetermination. ${ }^{175}$

Having clarified the terms, we can evaluate whether conservatism can deny overdetermination in the technical sense and evaluate which of the types of overdetermination deserve the pejorative label. ${ }^{176}$ Two lines of defence: deniers deny their views are committed to overdetermination in the technical sense because their causes are too intimately connected. Deniers must explain how to avoid overdetermination in the technical sense while keeping their theoretical posits. ${ }^{177} \mathrm{By}$ contrast, accepters admit overdetermination in the technical sense but claim it's unproblematic overdetermination. The acceptor must explain the problems with overdetermination and how to avoid these problems. ${ }^{178}$ Bernstein argues against deniers and acceptors. She argues conservatists are committed to overdetermination in the technical sense and it's problematic overdetermination. ${ }^{179}$

\footnotetext{
${ }^{174}$ Bernstein 2016: 22-23.

${ }^{175}$ Bernstein 2016: 23-24

${ }^{176}$ Bernstein 2016: 24.

177 Bernstein 2016: 24.

${ }^{178}$ Bernstein 2016: 24.

${ }^{179}$ Bernstein 2016: 24.
} 
Bernstein focuses the rest of her article on mental/physical overdetermination, but in footnote 18 on page 25 she states her suggestions generalize to conservatism about ordinary objects. ${ }^{180}$ So the following is my attempt to apply her suggestions to conservatism about ordinary objects.

Nonreductionist views about the mental and physical are views that hold the mental qua mental has causal powers. Applying this to ordinary objects, ordinary objects qua ordinary objects, e.g. baseballs qua baseballs, have causal powers. Similarly, to mental/physical views, which usually accept closure (the physical world is causally closed), distinctness (the mental and physical are distinct), and efficacy (the mental qua mental has causal powers), conservatism about ordinary objects can also accept these three claims if we reformulate them in terms of ordinary objects and their parts. Conservatists would then accept the following claims:

1. Closure: The physical world is causally closed; there's a complete causal explanation for physical events in terms of the parts/atoms that make up ordinary objects.

2. Distinctness: Ordinary object are distinct from their parts/atoms (composition as identity is false).

3. Efficacy: Ordinary objects qua ordinary objects have causal powers.

So baseballs and their atoms are distinct, both have causal powers, and both are part of the physical world, i.e. there are no non-physical emergent properties. Conservatists cannot deny widespread redundancy in the technical sense without giving up one of these claims. To deny causal overdetermination, conservatists must either deny there are multiple causes or deny the sufficiency of one cause. If they deny there are multiple causes, then this violates Efficacy since it means ordinary objects qua ordinary objects don't have causal powers. If they deny the sufficiency of one of the causes, this violates either Efficacy or Closure. Denying sufficiency of one of the causes can be done in two ways. First, by denying causal potential, and second, by denying follow-through. Causal potential is the potential of a property to cause things, while

\footnotetext{
${ }^{180}$ Bernstein 2016: 25.
} 
follow-through is the completion of the causal process, i.e. from cause to effect. For example, rocks have causal potential whereas ghost rocks don't. Rocks thrown so weakly they never reach the window, don't have follow-through whereas rocks thrown hard enough to shatter the window do have follow-through. To deny the causal potential of ordinary objects violates Efficacy, and denying atoms don't have causal potential violates Closure. To deny follow-through of ordinary objects violates Efficacy and denying follow-through of the parts violates Closure. Therefore, conservatists cannot deny overdetermination without giving up Efficacy or Closure. Nor can they deny Distinctness since conservatists claim that ordinary objects and their atoms exist. Thus, conservatists cannot deny widespread overdetermination in the technical sense. ${ }^{181}$

Moreover, conservatists who accept overdetermination in the technical sense but deny it's problematic overdetermination fail as well. For one objection is that in the two rocks case removing one rock makes a difference to how the effect occurs, while the mereological/constitutive overdetermination cases don't involve such a difference. Removing the ordinary object from the atoms (if it were possible) doesn't make a difference to how the effect occurs. It doesn't change the way the window shatters, since the atoms still cause the same effect that the ordinary object would have caused. ${ }^{182}$ This difference is the reason why overdetermination is problematic for conservatists.

In the two rocks case, the explanation for how removing one rock makes a difference to how the effect occurs is pretty straightforward. We can give a causally satisfying explanation in terms of where the extra causation 'comes from' and where the extra causation 'goes'; the extra causation comes from the second rock and the second rock causes the window to shatter with double the force. So it's not mysterious where the extra cause goes either. The two rocks case is causally satisfying: "there is a precise account of the causal powers of both rocks, and of the individual contribution of each rock to the shattering of the window." ${ }^{183}$ Conservatists must give a similarly causally satisfying explanation of the exact causal contribution of ordinary objects minus the

\footnotetext{
${ }^{181}$ Bernstein 2016: 25-28.

182 Bernstein 2016: 30.

183 Bernstein 2016: 30.
} 
causal contribution of their atoms. According to Bernstein, conservatists have no such explanation. $^{184}$

More importantly, conservatists cannot give a causally satisfying explanation without giving up one of their theoretical posits, i.e. Closure, Distinctness, and Efficacy. The more similar mereological/constitutive overdetermination is to the two rocks case, the further conservatists move away from their theoretical posits. With respect to where the extra causal powers of ordinary objects come from, causal powers of ordinary objects too closely related to the causal powers of atoms threaten nonreductionism. Take for example subset strategists who endorse Distinctness whilst also claiming the causal powers of ordinary objects are a proper subset of the atoms the object is made up of. Subset strategists can give an explanation of where the causal powers came from. However, this violates Efficacy, since now the causal powers of ordinary objects just are the causal powers of the atoms. Subset strategists do indeed avoid problematic overdetermination, but only because they avoid overdetermination in the technical sense, since there's only one set of causal powers to start with. ${ }^{185}$

Likewise, constitution theorists who view the relation between ordinary objects and its atoms like the statue and the clay; there's some overlap regarding some physical properties, but differ in terms of their modal and relational properties. With respect to where the extra causal powers of ordinary objects come from, causal powers of their atoms too closely related to the causal powers of those atoms, threaten nonreductionism. That is, constitution theorists endorse Distinctness while also holding that the causal powers of ordinary objects overlap with the causal powers of their atoms. Thus, constitution theorists can give an explanation of where the causal powers came from. However, this violates Efficacy, since now there's only one set of causally efficacious properties. Constitution theorists do indeed avoid problematic overdetermination, but

\footnotetext{
${ }^{184}$ Bernstein 2016: 30.

185 Bernstein 2016: 31.
} 
only because they avoid overdetermination in the technical sense, since there's only one set of causal powers to start with. ${ }^{186}$

Theorists like subset theorists and constitution theorists do indeed avoid causal overdetermination, but they are not nonreductive in the relevant sense, because these views endorse Distinctness by claiming ordinary objects and their atoms are not identical; not by claiming that the causal powers of ordinary objects are distinct from the causal powers of their atoms. Subset theorists and constitution theorists hold that there's only one set of causal powers which ordinary objects and their atoms share. Since ordinary objects themselves are not the source for why ordinary objects qua ordinary objects are causally efficacious, the shared causal powers don't uphold Efficacy. ${ }^{187}$

Conversely, the less similar mereological/constitutive overdetermination is to two rocks, the more irrelevant ordinary objects are to the causing of certain effects. With respect to where the extra causation goes, in the two rocks case it's quite clear that both rocks contribute a specific amount of energy to the shattering of the window, that is, the forces of each individual rock are additive. Additivity is just the idea that if we double the causation, we double the force of the effect. So there's no mystery where the extra causation goes. However, the causal powers of ordinary objects and their atoms are not additive in this sense. The extra causal powers of the ordinary object doesn't contribute an extra specific amount of energy to the shattering of the window over and above the causal powers of the atoms. ${ }^{188}$

On the one hand, if it is clear what the causal contribution of ordinary objects is, then this violates Closure, since if the causal powers of ordinary objects contribute a specific amount of energy to the shattering of the window, then it's rather mysterious where this extra energy goes. On the other hand, if it isn't clear what the causal contribution of ordinary objects is, then this

\footnotetext{
${ }^{186}$ Bernstein 2016: 31.

${ }^{187}$ Bernstein 2016: 31-32.

${ }^{188}$ Bernstein 2016: 32.
} 
would violate Efficacy, since then it isn't clear how ordinary objects qua ordinary objects cause anything. That is, it isn't clear what this causation consists of. ${ }^{189}$ Here, the problem is that mereological and constitutive overdetermination are not enough like the two rocks case. Where the two rocks case is casually satisfying in the sense that it's clear where the extra causation comes from and where it goes, mereological and constitutive overdetermination is causally unsatisfying in the sense that it isn't clear where the extra causation comes from and where it goes. The differences between the two rocks case and mereological/constitutive overdetermination reinforce this tension as opposed to dissolving it. ${ }^{190}$

Taking all of the above into account, the distinction between problematic and unproblematic overdetermination doesn't undermine eliminativism, and more importantly, it doesn't support conservatism.

\section{OBJECTION 4: LE BIHAN: NO PHYSICAL PARTICLES FOR A DISPOSITIONAL MONIST}

The fourth objection to the Overdetermination Argument is proposed by Le Bihan, who argues that if one is to endorse nihilism about ordinary objects, then one must also endorse nihilism about mereological atoms. This is a problem for eliminativists since they posit mereological atoms as the explanatory force for everything that ordinary objects supposedly cause.

Le Bihan takes mereological atoms to be the fundamental physical particles described by physics, such as quarks and electrons, but he leaves open the possibility that physics is wrong about what these fundamental physical particles actually are. Le Bihan argues that if someone

\footnotetext{
189 Bernstein 2016: 32.

190 Bernstein 2016: 32.
} 
endorses nihilism about ordinary objects, then they should also endorse nihilism about fundamental physical particles (or mereological atoms). ${ }^{191}$

Three assumptions are made. Firstly, dispositional monism is assumed. Dispositional monism is the view that all properties are dispositional, that is, that they have a causal essence. Specifically, it holds that both macrophysical objects, such as baseballs and other ordinary objects, and microphysical objects, such as fundamental particles, have causal properties. Secondly, it's assumed that the composition as identity thesis is false. Thirdly, it's assumed that parts are more fundamental than the whole they make up. That is, if baseballs and their parts exist, then the parts are more fundamental than the baseball. ${ }^{192}$

Nihilism about composite objects usually takes those objects we call ordinary objects to be an arrangement of atoms, usually in the form of fundamental physical particles. Ordinary composite objects don't exist; only the atoms arranged x-wise exist. Thus, nihilists about ordinary objects argue ordinary objects don't exist because the fundamental particles which ground what we call ordinary objects exist. ${ }^{193}$ Merricks proposed an argument for nihilism about composite objects. Le Bihan shows that this argument can be used in the same way to establish nihilism about physical particles if we assume dispositional monism about properties. In other words, a dispositional monist shouldn't believe physical particles exist. ${ }^{194}$

Merricks argues that a baseball is at best a mere overdeterminer, because whatever a baseball causes is already explained by atoms arranged baseball-wise. Baseballs causally overdetermine their effects since atoms arranged baseball-wise also cause the effect. ${ }^{195}$ Assuming composition is not identity and assuming the whole is less fundamental than the parts, baseballs are overdeterminers and shouldn't be included in our ontology. Similarly, Le Bihan argues that if

\footnotetext{
${ }^{191}$ Le Bihan, B. (2015). No physical particles for a dispositional monist. Philosophical Papers 44/2: 207-208.

192 Le Bihan 2015: 207, 214-215.

${ }^{193}$ Le Bihan 2015: 208.

${ }^{194}$ Le Bihan 2015: 209.

${ }^{195}$ Le Bihan 2015: 214.
} 
physical particles have causal properties, then they themselves are overdeterminers. "If physical properties are causal $[\ldots]$ then it is usually supposed that this causal aspect of properties confers a causal aspect to the object instantiating the properties itself. But then, this is the very same situation as for the baseball: if real, the object is an overdeterminer of the causal physical properties it instantiates. ${ }^{\text {196 }}$ For example, electrons are particles which have different properties, such as charge, spin, inertial mass, energy, etc. These properties are dispositional, which means they have causal properties. For example, the property of having a mass causes electrons to behave in a certain way when located in a gravitational field. One could describe electrons fully just in terms of their properties. Electrons causally overdetermine their effects since whatever an electron causes is already accounted for by the causal properties of the electron. ${ }^{197}$ Therefore, dispositional monists shouldn't believe that fundamental physical particles, such as electrons, exist. Therefore, the dispositional monist shouldn't believe physical particles exist. ${ }^{198}$

Merricks argues that the parts of an object are more fundamental that the objects they make up. This claim is important for Merricks' argument, so for the analogy to work, Le Bihan must show that the causal properties of fundamental physical particles are more fundamental than the objects instantiating those properties. The causal properties of fundamental particles are more fundamental than the objects instantiating those causal properties because of the causal nature of causal properties. The reason objects are thought to be causal is because they instantiate causal properties. The term 'because' could mean that causal properties are more fundamental than objects or it could mean that causal properties are identical to objects. Since the Composition as Identity Thesis is assumed to be false, causal properties are not identical to objects. Therefore, causal properties are more fundamental than objects. Since both causal properties and the object instantiating those properties exist, the effect is overdetermined by the causal properties and the object instantiating it. And since causal properties are more fundamental than the object instantiating them, by Merricks' reasoning, we should eliminate objects from our ontology. ${ }^{199}$

\footnotetext{
${ }^{196}$ Le Bihan 2015: 215-216.

${ }^{197}$ Le Bihan 2015: 216.

${ }^{198}$ Le Bihan 2015: 216.

${ }^{199}$ Le Bihan 2015: 216-217.
} 


\subsection{ONTOLOGICAL CONCEPTUALISM}

I argue that Conservatist Minimal Realist views about ordinary objects, such as Ontological Conceptualism, can address the Overdetermination Argument and the objections and responses proposed in this chapter

The idea behind the Overdetermination Argument is that ordinary objects don't have any causal powers over and above their parts. I argue this is false; ordinary objects do have causal powers over and above their parts. Events are not overdetermined by baseballs and atoms arranged baseball-wise, because baseballs, as conceptualized objects, cause things that mere atoms arranged baseball-wise don't. For example, baseballs as conceptualized objects cause emotional reactions to signed baseballs, they increase in value by signature, or any other psychological effects. These psychological effects are not caused by the atoms arranged baseball-wise but instead are caused by the associations we have with atoms arranged baseball-wise. Therefore, conceptualized objects causes things that mere atoms arranged x-wise don't.

Moreover, for something to be real is to have (non-redundant) causal powers. This is a widely endorsed view and I won't defend it here. So according to Ontological Conceptualists, baseballs are real because, as conceptualized object, they cause things that mere atoms arranged baseballwise don't. So ordinary objects as conceptualized objects are real, and exist, because they have causal powers.

One worry for Ontological Conceptualism is that it seems incompatible with the claim that there's a complete causal explanation for physical events in terms of their constituent atoms. However, it there can be a complete causal explanation for physical events in terms of their constituent atoms whilst holding that conceptualized objects also have causal powers over mental events which are not explained in terms of their constituent atoms. Take for example the 
associations we have with signed baseballs. The atoms arranged baseball-wise by themselves do not cause the increase in value of baseballs (even taking into account the atoms associated with the signature). Instead it the mental associations with the concept BASEBALL that causes the increase in value. Personally, I think that mental events cause physical events as well, and it might be problematic to explain mental to physical causation, but this is not a problem exclusive for Ontological Conceptualism but is a problem for any view that holds that the mental can influence the physical.

Another worry is that Ontological Conceptualism seems to imply that ordinary objects have emergent properties. If emergent properties are defined as causally efficacious properties that cannot be explained in terms of atoms arranged $x$-wise, then Ontological Conceptualism is indeed wedded to the idea of emergent properties. However, if that's the case, then I just bite the bullet and admit there are causally efficacious properties that cannot be explained in terms of atoms arranged $\mathrm{x}$-wise. For although they might not be able to be explained in terms of the atoms, they can still be explained by appealing to psychology and neurological processes. So there's a satisfying causal explanation, but this explanation appeals to psychological and neurological processes as well as the atoms arranged $\mathrm{x}$-wise.

Regarding Korman's reply to the Epistemic Argument, I agree that troglodytes are perceptually justified in believing trogs exist. Therefore, OA12' is false, and we are perceptually justified in believing baseballs exist after all. Since OA12' is false, OA12 is false as well (since it's the same premise), and therefore the conclusion (OA13) is false. That is, it's false that we shouldn't believe that any events are overdetermined by a baseball and atoms arranged baseball-wise.

Moreover, I agree that (absent defeaters) we are justified in forming a perceptual belief that baseballs exist. However, I argue there are such defeaters, such as the ones talked about in the debunking argument. Nevertheless, the Ontological Conceptualist argues that those defeaters are irrelevant because Ontological Conceptualism adopts a view of objects on which objects are conceptualized. Conceptualized objects are partially mind-independent and partially mind- 
dependent. They are partially constituted by the mind-independent physical world, which is interpreted in one way or another, giving rise to the conceptualized objects we perceive. These conceptualized objects include the CCK-facts. Conceptual knowledge (including CCK-facts) is not part of the atoms arranged $\mathrm{x}$-wise, but are imposed on the atoms arranged $\mathrm{x}$-wise by us. However, the Ontological Conceptualist argues that our concept OBJECT refers to both the minddependent and mind-independent aspect, the term 'object' refers to what we take objects to be. Thus, I agree with Korman that no event is overdetermined by a baseball and atoms arranged baseball-wise, I do so for different reasons.

Moreover, Merricks argues tour visual experience would be exactly the same if ordinary objects didn't exist, since we would still experience the atoms arranged x-wise. I argue this claim is false. Our visual experience would not be exactly the same. There's an important difference between perceiving atoms arranged $\mathrm{x}$-wise and perceiving ordinary objects. For atoms arranged $\mathrm{x}$-wise don't include conceptual information and/or background knowledge. Ontological Conceptualists claim conceptual knowledge influences how and what we perceive. So, in perceiving an ordinary object we perceive something more than merely the atoms arranged $\mathrm{x}$ wise.

Regarding Le Bihan, who argues that if one were to endorse nihilism about ordinary objects, then one must also endorse nihilism about physical particles. Again, the reasoning discussed above applies here. The reason we don't think that the causal powers of atoms in addition to the atoms themselves overdetermine the effects is because we don't usually conceptualize the causal powers of atoms as the cause of those effects. We don't even conceptualize the atoms arranged $\mathrm{X}$-wise as the cause of those effect. Perhaps if we did conceptualize the atoms arranged $\mathrm{x}$-wise as the cause of those effects, then the atoms arranged $\mathrm{x}$-wise might overdetermined their effects if the causal powers of those atoms caused the effect as well. However, then it must be shown that we conceptualize the causal powers of atoms as the cause of those effects as opposed to conceptualizing the atoms arranged x-wise as the cause of the effects. Perhaps there's an argument to be made for this. However, it's much more likely that we neither conceptualize the 
causal powers of the atoms nor do no we conceptualize the atoms arranged x-wise as the cause of the effect. Instead, we conceptualize ordinary objects as being the cause of the effects.

To conclude, I hope to have shown that Minimal Realist views, such as Ontological

Conceptualism can address the Overdetermination Arguments and can answer the objections and responses that were proposed. 


\section{CHAPTER 4 THE ARGUMENT FROM VAGUENESS}

\subsection{EXPLANATION OF THE ARGUMENT}

The fourth argument for eliminativism is the Argument from Vagueness. The idea behind this argument is that composition is either restricted or unrestricted; either every plurality of objects composes a further object, or none of them compose a further object. Since not every plurality of objects composes something, no pluralities of objects composes something. ${ }^{200}$ The argument runs as follows:

AV1: If some pluralities of objects compose something and others don't, then it's possible for there to be a sorites series for composition.

AV2: Any such sorites series must contain either an exact cut-off or borderline cases of composition.

AV3: There cannot be exact cut-offs in such sorites series.

AV4: There cannot be borderline cases of composition.

AV5: Therefore, either every plurality of objects composes something or none of them do.

AV6: Not every plurality of objects composes something.

AV7: Therefore, no pluralities of objects composes something. ${ }^{201}$

A sorites series is a series of cases starting from a case where composition doesn't occur to a case where composition does occur. The intermediate cases are similar in all relevant respects.

\footnotetext{
${ }^{200}$ Korman 2015: 160-161. I set aside views which make a principled restriction, such as van Inwagen who makes an exception for composite organisms (van Inwagen 1990: 181-97) and Merricks who makes an exception for persons (Merricks 2001).

${ }^{201}$ Korman 2015: 161.
} 
Take for example the construction of a table. At the beginning of the construction process, the unassembled pieces of wood don't compose a table, but at the end of the construction process they do. The different phases in the construction process, from unassembled pieces of wood to the construction of a table, is a sorites series. ${ }^{202}$

The first premise is plausible since if the unassembled pieces of wood don't compose something while the assembled pieces of wood do compose something, then it's possible for there to be a sorites series for the composition of tables. ${ }^{203}$ The second premise is trivial since any sorites series must involve some transition from uncomposed to composed object, and this transition will or will not contain an exact point where this occurs. ${ }^{204}$ The third premise is plausible, since if some pluralities compose an object while others don't, then there must be an explanation for why that is. ${ }^{205}$ The problem, however, is that the differences between the intermediate cases in the sorites series are too similar to another to explain why some pluralities compose an object while others don't. ${ }^{206}$ The fourth premise is more problematic. At first glance it seems obvious that it's possible for there to be borderline cases of composition in the same way there are borderline cases of baldness or redness. However, borderline cases of baldness and redness on the one hand, and borderline cases of composition on the other, differ in one important respect. Cases of composition are intimately related to questions about what objects exist and how many objects exist, while cases of baldness and redness don't. If composition is vague then existence is vague as well, because if some plurality of objects composes a further object, then it is vague whether this further object exists, and thus influences how many objects exist. ${ }^{207}$ But existence (arguably) cannot be vague since it's possible to specify the number of objects in 'numerical sentences' in a completely precise language. ${ }^{208}$ Since such sentences don't contain vague

\footnotetext{
202 Korman 2015: 7; Korman 2016: 11.

${ }^{203}$ Korman 2015: 161.

${ }^{204}$ Korman 2015: 7, 161-162.

${ }^{205}$ Cf. Markosian 1998.

${ }^{206}$ Korman 2015: 7-8; Korman 2016: 11. See also Sider 2001: 123-124, 130-132 and Kurtsal Steen 2014 for why there cannot be an exact cut-off point in sorites series.

${ }^{207}$ Korman 2016: 12.

${ }^{208}$ A 'numerical sentence' is a sentence which states that for some number $n$, there are exactly $n$ things. See Korman 2015: 162.
} 
language, it cannot be vague how many objects exist. ${ }^{209}$ If there are borderline cases of composition, then it is vague how many objects exist. Therefore, there cannot be borderline cases of composition. ${ }^{210}$ The fifth premise follows from the first four. ${ }^{211}$ The sixth premise is plausible since it seems true that not every plurality composes something. For example, my nose and the Eiffel Tower don't compose a further object. The conclusion then follows from the first six premises.

The phenomenon of vagueness often appears in the case of vague objects, vague predicates, and in sorites series. When the object itself is vague, it has imprecise boundaries; for example, Mount Kilimanjaro is a vague object because it doesn't have precise boundaries. Likewise, the boundaries of all objects are imprecise, and therefore, all objects are vague. When an object has vague predicates, it's indeterminate whether a particular predicate applies to the object. For example, baldness is an indeterminate vague predicate, since it doesn't specify how many hairs a man can have to be classified as bald. Although not all predicates are vague in this way, many of them are. Vagueness also appears in sorites series, which are generated by appealing to vague objects or by appealing to vague predicates. ${ }^{212}$

There are three main views on the nature of vagueness: the Ontic view, the Epistemic view, and the Supervaluationist view. On the Ontic view, vagueness exists, and the world contains lots of it. Mount Kilimanjaro is a vague object, because it doesn't have precise boundaries. Baldness is a vague predicate, because it is indeterminate whether this predicate applies to a man with 100 hairs. Similarly, in the sorites series some of the premises are neither true nor false. On the Ontic view, sentences such as 'Tom is bald' or 'Mount Kilimanjaro is tall' are neither true nor false. ${ }^{213}$

\footnotetext{
${ }^{209}$ Korman 2015: 12-13.

${ }^{210}$ Korman 2015: 8; Korman 2016: 12.

${ }^{211}$ Again, if we set aside those views which make a principled restriction.

${ }^{212}$ Benovsky 2011: 97-98.

${ }^{213}$ Benovsky 2011: 99.
} 
On the Epistemic view, vagueness is due to our ignorance. On this view objects do have determinate boundaries, but we don't know where these boundaries are. Similarly, baldness is a determinate predicate, but we don't know when this predicate applies to a man with 100 hairs. And in the sorites series, there's an exact cut-off point where the uncomposed object turns into a composite object, but we don't know where this exact cut-off point is. So the world is not vague; it has perfectly determinable boundaries, but we are ignorant about these boundaries. ${ }^{214}$ Epistemicism often locates the vagueness in our language, and thus is a semantic phenomenon. $^{215}$

On the Supervaluationist view, vagueness is due to the imprecisions of our language or concepts. On this account vagueness is a linguistic, semantic, or conceptual phenomenon. The mindindependent world is not vague, but the words or concepts we use to describe the mindindependent world are vague. On this view, Mount Kilimanjaro seems like a vague object because the word concept 'Mount Kilimanjaro' doesn't have a precise meaning. Similarly, the predicate baldness seems like a vague predicate because doesn't have a precise meaning. And in the sorites series, it seems there are no exact cut-offs, because the words that pick out the objects in question don't have a precise meaning. ${ }^{216}$

Propositions that involve such indeterminacy are said to lack an exact truth-value. However, many propositions similar to the indeterminate cases do have exact truth-values. The idea is to treat vagueness as semantic indecision; there are many precise candidates that can be the referent of 'Mount Kilimanjaro' or 'baldness', but we haven't decided which of these precise candidates they refer to. If we decide to precisify the boundaries of Mount Kilimanjaro, then only one of these candidates would be the referent of 'Mount Kilimanjaro'. These precisified candidates are called precisifications. So propositions are true or false, but only under a certain precisification. ${ }^{217}$ Propositions that are not precisified lack truth-values; they are neither true nor

\footnotetext{
214 Benovsky 2011: 99.

${ }^{215}$ Kurtsal Steen 2014: 131; Merricks 2017: 5.

${ }^{216}$ Benovsky 2011: 99-100.

217 Benovsky 2011: 100.
} 
false. Unprecisified propositions can be super-true or super-false if they are true or false under all admissible precisifications. ${ }^{218}$ So in the sorites series, one of the intermediate cases. ${ }^{219}$

\subsection{OBJECTIONS TO THE ARGUMENT FROM VAGUENESS}

In the next section, I discuss four objections to the Argument from Vagueness. The first objection is the epistemicist objection that there are exact cut-offs in sorites series and therefore AV3 is false. A recent response to this objection is proposed by Kurtsal Steen, who argues the epistemicist objection doesn't succeed since epistemicism entails that 'almost-bicycles' exist, which are objects just like ordinary bicycles except they are not quite bicycles. If almost-bicycles exist, then there are no exact cut-offs in sorites series. The second objection is that there can be borderline cases of composition, and accepting this commits one to existential indeterminacy. This can be done in two ways. First, one can deny an expression in a numerical sentence must be vague if it's indeterminate which objects exist. Second, one can deny no expression in numerical sentences is vague. The third objection is recently proposed by Merricks and argues that if vagueness is a feature of language, then there cannot be vagueness in the absence of language. But there is vagueness in the absence of language. Since epistemicists and supervaluationists argue vagueness is a feature of language, epistemicism and supervaluationism are false. The fourth objection is proposed by Wasserman, who argues borderline cases result from indeterministic metaphysical laws and thus denies that there cannot be borderline cases of composition, but also denies there cannot be exact cut-offs in sorites series.

\section{OBJECTION 1: DENYING AV3 AND ACCEPTING THERE ARE EXACT CUT-OFFS}

The first objection to the Argument from Vagueness is the Epistemicist objection which claims there are exact cut-offs but we don't know where this exact cut-off is located. Epistemicists thus

\footnotetext{
218 Benovsky 2011: 101.

${ }^{219}$ Benovsky 2011: 101.
} 
deny AV3 that there cannot be exact cut-offs in sorites series. ${ }^{220}$ Epistemicists often locate vagueness in our language. They argue there are exact cut-offs in sorites series, but these exactcut offs are located in the kind terms we use. ${ }^{221}$

\section{KURTSAL STEEN'S RESPONSE TO DENYING AV3}

Kurtsal Steen proposes a response to this objection, and argues there cannot be exact cut-offs in sorites series about composition. ${ }^{222}$ If exact cut-offs are located in the kind terms we use, then the epistemic vagueness of those kind terms requires that vague objects exist. For example, vagueness surrounding kind terms such as 'bicycle' requires that objects that can be described as 'almost-bicycles' must exist even though they are not in the extension of the kind term 'bicycle'. If 'almost-bicycles' exist, then this leads to permissivism. ${ }^{223}$ She concludes that, even if epistemicism is true, it doesn't follow that the only existing objects are ordinary objects. ${ }^{224}$

The idea is that small differences matter. Epistemicists claim one hair makes the difference between being bald and not being bald. The indeterminacy regarding whether a predicate applies to an object is not ontological but instead is due to our ignorance. So it's determinately true or false whether someone is bald, but we don't know (and cannot know) which it is. ${ }^{25}$

Epistemicists claim there are multiple candidate meanings for different predicates. For example, there are multiple candidate meanings for the predicate being bald, and one of these meanings is

\footnotetext{
${ }^{220}$ Korman 2015: 164.

${ }^{221}$ Kurtsal Steen 2014: 131; Merricks 2017: 5.

222 Kurtsal Steen 2014): 130.

${ }^{223}$ Kurtsal Steen 2014: 131.

${ }^{224}$ Kurtsal Steen frames her argument in terms of unrestricted composition, but the argument can be adapted to nihilism/eliminativism about composition In Kurtsal Steen's formulation of the argument, she uses AV6 as a premise to argue for AV7. By using not-AV7, one can reach the conclusion not-AV6 that no pluralities of objects compose something.

${ }^{225}$ Kurtsal Steen 2014: 133.
} 
the meaning. However, we don't know, and cannot know, which meaning this the meaning, because the different candidate meanings are indiscriminably similar to each other. ${ }^{226}$

Epistemicists can hold that the only existing objects are those falling under sortal concepts. Since sortal concepts have determinate extensions (according to the epistemicist), objects are only vague in the epistemic sense. Imagine some bicycle parts in a garage. These bicycle parts are loosely attached to one another in such a way that it's indeterminate whether they compose a bicycle. According to epistemicism, the number of bicycles in that garage is either determinately one or determinately zero, ${ }^{227}$ since there's a determinate meaning of 'bicycle'. Since there's a determinate meaning of 'bicycle', it's also determinate what falls under it, that is, it's determinate what the extension of 'bicycle' is. So it's determinate whether or not the bicycle parts in the garage fall under it. But since there are multiple candidate meanings and thus also multiple candidate extensions of 'bicycle' which are indiscriminably similar to one another, we don't know - and cannot know - whether what is in the garage is in the extension of 'bicycle'. 228

According to epistemicism, 'bicycle' has multiple candidate extensions. The extension of 'bicycle' would be different if we had attached a different meaning to it. However, only one of those extensions is the extension, and all (and only) bicycles are in it. The other extensions of 'bicycle' (all the extensions apart from the extension) also have members that fall under those extensions. Since those candidate members are indiscriminably similar to the members falling under the correct extension, most of them are also bicycles. So some bicycles are members of extensions other than the extension. This isn't problematic, but what is problematic is that some non-bicycles are members of those extensions that are not the extension. If that's true, then there exist non-bicycles which are indiscriminably similar to actual bicycles. Kurtsal Steen calls these non-bicycles 'almost-bicycles'. When we take the loosely attached bicycle, and firmly attach one part of it (while the rest is still loosely attached), we have created an almost-bicycle. ${ }^{229}$

\footnotetext{
${ }^{226}$ Kurtsal Steen 2014: 133.

227 Kurtsal Steen 2014: 133.

${ }^{228}$ Kurtsal Steen 2014: 134.

${ }^{229}$ Kurtsal Steen 2014: 134.
} 
To say an almost-bicycle is in a candidate extension of 'bicycle', of which we can say it is indiscriminable from the actual extension of 'bicycle', almost-bicycles must exist, since otherwise we couldn't say of $i t$ that it's in a candidate extension. So, epistemicism entails that almost-bicycles exist. If epistemicism entails that almost-bicycles exist, then epistemicism entails that there cannot be exact cut-offs in sorites series about bicycles, and thus cannot restrict composition to ordinary objects. ${ }^{230}$

\section{OBJECTION 2: THERE CAN BE CASES OF BORDERLINE COMPOSITION}

The second objection to the Argument from Vagueness is that there can be borderline cases of composition and accept commitment to existential indeterminacy. There are two ways to argue for this. First, one can deny that an expression in a numerical sentence must be vague if it's indeterminate which objects exist. Secondly, one can deny no expression in numerical sentences are vague.

Consider the following argument for AV4 of the Argument from Vagueness:

AV8: If there are borderline cases of composition, then it is indeterminate which objects exist.

AV9: If it is indeterminate which objects exist, then some expression in some numerical sentence must be vague.

AV10: No expression in any numerical sentence is vague.

AV4: Therefore, there cannot be borderline cases of composition.

${ }^{230}$ Kurtsal Steen 2014: 134. 
The eight premise is plausible since if it's true that the pieces of wood don't compose anything at the beginning of the assembly process and that they do compose something at the end of the assembly process, then somewhere in of the assembly process, it's indeterminate whether the pieces of wood compose something. If that's true, then it's indeterminate which objects exist at that time. ${ }^{231}$ The ninth premise is plausible because if it's indeterminate whether there exists something in addition to the pieces of wood, then it's indeterminate how many objects there are. Therefore, it would neither be determinately true nor determinately false that there exist exactly $n$ objects. Since the source of the indeterminacy regarding how many objects exist is (presumably) vagueness, there must be some expression in the sentence causing the vagueness. ${ }^{232}$ The tenth premise is plausible as well. No expression in any numerical sentence is vague since for an expression to be vague, that expression must be able to be precisified in multiple ways. But since all the expressions are already precise, they cannot be vague. ${ }^{233}$

Korman provides a variety of arguments directed at AV8, AV9, and AV10. Instead of repeating these arguments, I focus on Korman's response and two recent responses to AV3 and AV4.

\section{THERE CAN BE CASES OF BORDERLINE COMPOSITION I}

Firstly, one could deny there cannot be borderline cases of composition (AV4) by denying an expression in a numerical sentence must be vague if it's indeterminate which objects exist (AV9) and accept there's indeterminacy with respect to which objects exist. ${ }^{234}$

The argument for AV9 runs as follows:

\footnotetext{
${ }^{231}$ Korman 2015: 162.

${ }^{232}$ Korman 2015: 162-163.

${ }^{233}$ Korman 2015: 163. See also Evans 1978.

${ }^{234}$ Korman 2015: 172.
} 
AV11: If it is indeterminate which objects exist, then some numerical sentence lacks a determinate truth-value.

AV12: If a numerical sentence lacks a determinate truth-value, then it must lack a determinate truth-value as a result of vagueness.

AV13: If a sentence lacks a determinate truth-value as a result of vagueness, then some expression in that sentence must be vague.

AV9: Therefore, if it is indeterminate which objects exist, then some expression in some numerical sentence must be vague. ${ }^{235}$

AV11 is plausible since indeterminacy about which objects exist sometimes leads to indeterminacy about how many objects exist. If true, then a numerical sentence lacks a determinate truth-value. ${ }^{236}$ AV12 is more controversial, but the idea is that the source of indeterminacy for truth-values of numerical sentences is vagueness. Other sources of indeterminacy include future contingents, truth in fiction, and reference failure (underspecification), however, Korman argues vagueness is the most likely culprit when it comes to the indeterminacy of numerical sentences. ${ }^{237}$ Lastly, the idea behind AV13 is that vagueness in a sentence is inherited from a subsentence. ${ }^{238}$

Existential indeterminacy has been criticized by many as incoherent since it implies there are vague objects. But there cannot be vague objects; something either exists or it doesn't. However, Korman takes existential indeterminacy to mean that "it's indeterminate what there is, but that's not to say that there is something such that it's indeterminate whether it is. "239 Framed this way, existential indeterminacy is coherent.

\footnotetext{
${ }^{235}$ Korman 2015: 173.

${ }^{236}$ Korman 2015: 173.

${ }^{237}$ See Korman 2015 Ch. 4.4.2, 8.1.1, and 8.3.4 for arguments.

${ }^{238}$ Korman 2015: 173-174.

${ }^{239}$ Korman 2015: 172.
} 


\section{THERE CAN BE BORDERLINE CASES OF COMPOSITION II}

Secondly, one can deny there cannot be borderline cases of composition (AV4) and accept commitment to existential determinacy by denying no expression in numerical sentences are vague (AV10). The argument for AV10 runs as follows:

AV14: An expression is vague only if it has multiple admissible precisifications.

AV15: No expression in any numerical sentence has multiple admissible precisifications.

AV10: Therefore, no expression in any numerical sentence is vague. ${ }^{240}$

An expression has multiple admissible precisifications when there's a range of candidate meanings for that expression which meets three conditions: precision, multiplicity, and admissibility. Precision is the condition where each of the candidate meanings for an expression has a determinate intension. So it's determinate what's in its extension and what's not in its extension. Multiplicity is the condition that the candidate meanings for an expression don't all have the same intension. Admissibility is the condition that none of the candidate meanings for an expression definitely is the meaning of that expression and none of them definitely aren't. So an expression has multiple admissible precisifications, which all have different intensions, where none of the candidate meanings have been selected as the meaning of that expression. ${ }^{241}$

AV14 is an expression of a semantic account of vagueness. According to this account, vagueness-related indeterminacy of an expression results from semantically vague terms which have multiple possible meanings. So vagueness-related indeterminacy is a matter of semantic indecision. ${ }^{242}$ The multiple possible meanings for a term are often called precisifications. So on this view, there's no vagueness in the mind-independent world, and is instead due to semantic

\footnotetext{
${ }^{240}$ Korman 2015: 174.

${ }^{241}$ Korman 2015: 174.

${ }^{242}$ Korman: 2015: 174; Lewis 1986: 244 fn.32; Sider 2001: 126-127.
} 
indecision. ${ }^{243}$ AV15 is plausible as well since expressions in numerical sentences intuitively have determinate meanings. ${ }^{244}$

According to Korman, there exists vagueness-related indeterminacy that's not due to semantic indecision but instead is due to ontic vagueness, that is, vagueness in the mind-independent world. For example, when Bob is losing one hair from his already pretty bald head, it's indeterminate whether that particular hair is part of him. The term 'Bob' doesn't have multiple admissible precisifications, since it's unclear what they would be. The only options are that there's an object that has precise boundaries exactly where Bob is, which definitely has that one hair as a part, and there's another object which also has precise boundaries exactly where Bob is, which definitely doesn't have that one hair as a part. Korman doesn't think any of those objects exist, and even if he did, he doesn't think they are admissible precisifications; 'Bob' doesn't refer to any precisely bounded object. Instead, there's an object with imprecise boundaries, and 'Bob' refers to that object. ${ }^{245}$ Likewise, the property being bald is picked out by the word 'bald', but doesn't have multiple admissible precisifications, since it's unclear what they would be. There are such properties as having fewer than exactly 9,999 hairs, having fewer than exactly 9,998 hairs, etc. But 'bald' doesn't refer to any of them. The term 'bald' doesn't refer to any precisely stipulated property. Instead, there's a vague property, being bald, and 'bald' refers to that property. ${ }^{246}$

\section{OBJECTION 3: MERRICKS'OBJECTION}

The third objection to the Argument from Vagueness is proposed by Merricks, who argues against AV3 and AV4. He argues if vagueness is a property of language, then there cannot be vagueness without language. Epistemicists and supervaluationists claim vagueness is a property

\footnotetext{
${ }^{243}$ Korman 2015: 174-175.

${ }^{244}$ Korman 2015: 175.

${ }^{245}$ Korman 2015: 176.

${ }^{246}$ Korman 2015: 176.
} 
of language. But there's vagueness in the absence language. Therefore, epistemicism and supervaluationism are false. ${ }^{247}$

Epistemicists claim vagueness results from not knowing the extensions of certain predicates. Without language it would be impossible to be ignorant about it. Therefore, vagueness is not possible without language. Supervaluationism claims vagueness results from a predicate or property having multiple precisifications some of which - but not all - are satisfied by an object. Without language it would be impossible for there to be predicates, and if there were no predicates, then it would be impossible for those predicates to have precisifications. Therefore, vagueness is not possible without language. ${ }^{248}$

Merricks initially sets out the argument as follows:

P1: Possibly, there's the stock series in the absence of language. ${ }^{249}$

P2: For all possible worlds, if there's the stock series in a possible world, then there's vagueness regarding the predicate 'is a heap' at that possible world. ${ }^{250}$

P3: Therefore, possibly, there's vagueness in the absence of language. ${ }^{251}$

P4: Therefore, it's false that all vagueness is a property of language. ${ }^{252}$

The first premise is plausible. A stock series is a series of granite slabs: on the first there's a single grain of sand, on the second there are two grains of sand, etc., which are stacked up in the shape of a heap. Before people existed, and thus before there was language, there were many

\footnotetext{
${ }^{247}$ Merricks 2017: 1-2. Merricks speaks of both language and thought, but for readability I merely talk about language.

${ }^{248}$ Merricks 2017: 6.

${ }^{249}$ Merricks 2017: 8.

${ }^{250}$ Merricks 2017: 11.

${ }^{251}$ Merricks 2017: 15.

252 Merricks 2017: 15.
} 
objects, such as atoms, grains of sand, stars, planets, etc. Therefore, it's possible grains of sand existed before there was language. Therefore, it's possible for grains of sand to exist without language. Likewise for all ordinary objects; it's possible for ordinary objects to exist without language. $^{253}$

The second premise is plausible as well. There's a well-known distinction between sentences being true in and at possible worlds. A sentence is true in a possible world if it's necessarily the case that if possible world obtains, then that sentence is true. A sentence is true at a possible world when the actual truth-conditions (the truth-conditions of sentences in the world that actually obtains (i.e. our world)) are indeed satisfied in that possible world. ${ }^{254}$

For example, take the sentence 'There are no sentences', and stipulate that in a possible world that obtains, there are no sentences in that world. So if this possible world obtains, then there are no sentences. So the sentence 'There are no sentences' cannot be true (or false) since sentences that don't exist cannot be true (or false). Therefore, that sentence is not true in that possible world. By contrast, the sentence 'There are no sentences' is true at that possible world, since that sentence is true iff there are no sentences. The actual truth-conditions of 'There are no sentences' are satisfied iff there are no sentences. If the aforementioned possible world obtains, then there are indeed no sentences, so the actual truth-conditions of that sentence are satisfied. Therefore, the truth-conditions of 'There are no sentences' are satisfied in that possible world, and thus the sentence is true at that possible world. ${ }^{255}$

Merricks introduces another distinction between predicates applying to objects in and at possible worlds. A predicate applies to an object in a possible world if it's necessarily the case that if that possible world obtains, then that predicate applies to that object. A predicate applies to an object at a possible world when it's necessarily the case that if that possible world obtains, then that

\footnotetext{
${ }^{253}$ Merricks 2017: 7.

254 Merricks 2017: 8.

255 Merricks 2017: 8.
} 
object satisfies the actual application-conditions (the application-conditions in the world that actually obtains, i.e. our world) in that possible world. ${ }^{256}$

Take the predicate 'is a heap' and stipulate that in a possible world that obtains, there are no heaps in that world. So, if this possible world obtains, then there are no heaps. So the predicate 'is a heap' doesn't apply to anything, since predicates that don't exist cannot apply to anything. Therefore, that predicate doesn't apply to any object in that possible world. ${ }^{257}$ By contrast, the predicate 'is a heap' is true at that possible world. For if that possible world obtains, the final step in the stock series still exists, so there exists an object that is composed of 100,000 grains of sand in the shape of a heap. Since a predicate applies to an object at a possible world when it's necessarily the case that if that possible world obtains, then that object satisfies the actual application-conditions, and since this possible world satisfies the actual application-conditions of the predicate 'is a heap', those application-conditions apply to the 100,000 grains of sand stacked up on that slab of granite. Therefore, the predicate 'is a heap' applies to that object at this possible world. ${ }^{258}$

Vagueness about predicates arises when that predicate exists, has application-conditions, and it's indeterminate whether that predicate satisfies those application-conditions. Vagueness about predicates thus arises in a possible world when it's necessarily the case that if that possible world obtains, then that predicate exists, has application-conditions, and it's indeterminate whether that predicate satisfies those application-conditions. ${ }^{259}$ Epistemicists and supervaluationists claim there's no vagueness in any possible world unless that vagueness is a feature of language in that world. Therefore, in any possible world without language there is no vagueness. ${ }^{260}$

\footnotetext{
${ }^{256}$ Merricks 2017: 9.

${ }^{257}$ Merricks 2017: 9.

258 Merricks 2017: 9.

259 Merricks 2017: 10.

${ }^{260}$ Merricks 2017: 10.
} 
However, vagueness about predicates can still arise at possible worlds even in possible worlds without language. Let's stipulate again that in a certain possible world that obtains, there are no heaps in that world. If that possible world obtains, then it's necessarily the case that it's indeterminate whether or not the predicate 'is a heap' satisfies the actual application-conditions (the application-conditions in the world that actually obtains, i.e. our world). Since it's indeterminate whether the predicate 'is a heap' satisfies the actual application-conditions, there's vagueness at that possible world, even if there were no language in that possible world. ${ }^{261}$

Thus P2 is plausible. If vagueness exists at all, the predicate 'is a heap' seems like a good example of it. If there's vagueness regarding the predicate 'is a heap', then the stock series guarantees this vagueness. Furthermore, this explanation shows that the predicate 'is a heap' is vague at a possible world even when there's no language in that world, and thus supports $\mathrm{P} 2 .^{262}$

P1 and P2 of the argument imply that it's possible for there to be possible worlds without language in that world while at the same time there's vagueness regarding the application of the predicate 'is a heap' at that world. So far the argument has not undermined epistemicism or supervaluationism since this result is consistent with the claim that there's no language while at the same time there is vagueness. ${ }^{263}$

However, take a possible world that includes a stock series and no language. The first case of the stock series consists of a single grain of sand on a slab of granite, called 'case1'. The second case of the stock series consists of two grains of sand on a slab of granite called 'case2', etc. Note that 'case2' consists of an object composed of two grains of sand. Thus 'case100K' consists of an object composed of a hundred thousand grains of sand. ${ }^{264}$ The predicate 'is a heap' clearly applies to case $100 \mathrm{~K}$ at $\mathrm{W}$, since this case satisfies our application-conditions in $\mathrm{W}$. So if $\mathrm{W}$ obtains, then there is a heap, case $100 \mathrm{~K}$, since an entity which satisfies our application-conditions

\footnotetext{
${ }^{261}$ Merricks 2017: 10-11.

262 Merricks 2017: 11.

${ }^{263}$ Merricks 2017: 11-12.

${ }^{264}$ Merricks 2017: 12.
} 
does so only if that entity is in fact a heap. Therefore, there are heaps in the world that actually obtains. $^{265}$

However, case $100 \mathrm{~K}$ is not the first instance of a heap in the stock series in W. Let's stipulate that case1000 is the first case of a heap in $\mathrm{W}$ and add that each subsequent case is also a heap in $\mathrm{W}$. Then the predicate 'is a heap' picks out case1000 and each subsequent case at W. Furthermore, lets stipulate that each of the cases that came before case 1000 is not a heap in $\mathrm{W}$, and thus that the predicate 'is a heap' doesn't pick out any of those cases at W. If we assume this, then there's no vagueness at $\mathrm{W}$, or at least there's no vagueness in this stock series, nor is there vagueness regarding the predicate 'is a heap. ${ }^{266}$ So $\mathrm{P} 2$ for all possible worlds, if there's the stock series in a possible world, then there's vagueness regarding the predicate 'is a heap' at that possible world, is false. $^{267}$

But P2 is true, so perhaps we weren't justified in stipulating that case1000 and subsequent cases are heaps in W, and perhaps we weren't justified in stipulating that all the cases that came before are not heaps in W. However, if we were to stipulate instead that case1001 and subsequent cases are a heap in $\mathrm{W}$, we would run into the same problems as above; case1000 cannot be the first case, case999 cannot be the first case, all the way down to case $1 .{ }^{268}$

Merricks argues that the best way to defend P2 is claiming that it's vague in $\mathrm{W}$ whether a certain case is a heap in the stock series. To defend P2, one must hold that "for all possible worlds, if the stock series occurs in a possible world, then, for some case in that series, it's vague in that possible world whether that case is a heap." 269 Because "for all possible worlds, if the stock series occurs in a possible world, then, for some case in that series, it's vague in that possible world whether that case is a heap; so it's vague whether that case satisfies the actual application-

\footnotetext{
265 Merricks 2017: 12.

${ }^{266}$ Merricks 2017: 13.

${ }^{267}$ Merricks 2017: 11.

${ }^{268}$ Merricks 2017: 13-14.

${ }^{269}$ Merricks 2017: 14.
} 
conditions of the predicate 'is a heap' in that possible world; so it's vague at that possible world whether the predicate 'is a heap' applies to that case; so [P2] is true.",270

Therefore, Merricks concludes that the only non-epistemic way of formulating the second premise is:

P2*: For all possible worlds, if there's the stock series in a possible world, then, for some case in that series, it's vague in that possible world whether that case is a heap.

The argument then run as follows:

P1: Possibly, there's the stock series in the absence of language.

P2*: For all possible worlds, if there's the stock series in a possible world, then, for some case in that series, it's vague in that possible world whether that case is a heap.

P3: Therefore, possibly, there's vagueness in the absence of language. ${ }^{271}$

And if it's possible for there to be vagueness without language, then it's false that vagueness is a property of language. Since epistemicists and supervaluationists claim vagueness is a property of language, and since Merricks' argument shows there is vagueness without language, vagueness cannot be a property of language. Therefore, epistemicism and supervaluationism are false. ${ }^{272}$

\section{OBJECTION 4: WASSERMAN'S OBJECTION}

\footnotetext{
${ }^{270}$ Merricks 2017: 14-15.

${ }^{271}$ Merricks 2017: 15

${ }^{272}$ Merricks 2017: 15.
} 
Wasserman proposes a novel account that claims borderline cases result from indeterministic metaphysical laws. According to this account vagueness consists in the indeterminacy of the laws of metaphysics. The idea is that Wasserman's account, called the Law-based Theory of Vagueness, denies AV4 that there cannot be borderline cases of composition and denies AV3 that there cannot be exact cut-offs in sorites series. Wasserman's conclusion is that there's nothing that explains why in two adjacent cases in the sorites series one case composes a further object while the other case doesn't. The reason that there's nothing that explains this, is because of the indeterminacy of the metaphysical laws. To be clear, on the Law-based Theory of Vagueness, there is an exact cut-off between two adjacent cases, but nothing determines why this exact cut-off is where it is as opposed to it being somewhere else.

Wasserman contrasts the indeterminacy of the laws of metaphysics with the indeterminacy of the laws of nature. He takes laws of nature to be generalizations about what causes what, where the 'what' are the natural phenomena the laws of nature are concerned with, and 'causation' is the source of change or rest. For example, according to Newton's law of motion, objects in motion stay in motion, and objects at rest stay at rest, unless acted on by a force. Stated this way, Newton's law of motion is merely a generalization; it's a description of patterns in the natural world. A generalization becomes a theory, when it explains why objects in motion stay in motion and objects at rest stay at rest unless acted on by a force. Newton's law of motion is a theory because it states that objects in motion stay in motion, and objects at rest stay at rest, because they are not acted on by a force. The term 'because' is a causal explanation. Since Newton's law is a causal explanation, the generalizations constitute a theory; a theory that explains natural phenomena. $^{273}$

Similarly, Wasserman argues the laws of metaphysics are generalizations; they are descriptions of patterns that occur within metaphysics. But whereas the laws of nature are generalizations

\footnotetext{
${ }^{273}$ Wasserman, R. (2017). Vagueness and the laws of metaphysics. Philosophy and Phenomenological Research XCV/1: 66-67.
} 
about what causes what, the laws of metaphysics are generalization about what grounds what, where the 'what' here is everything, and the grounding relation is a "non-causal generative relation that imposes a hierarchal structure on reality."274 Take for example wholes and their parts. The existence and properties of the whole are grounded in the existence and properties of their parts. If true, then wholes can be explained by their parts. The grounding relation explains metaphysical phenomena in the same way that the causal relation explains natural phenomena. ${ }^{275}$

Assume the laws of nature are indeterministic; i.e., the initial state of the universe together with the laws of nature don't uniquely determine subsequent events. For example, Nitrogen-13 (henceforth just nitrogen) has a half-life of just under 10 minutes (henceforth just 10 minutes). The half-time of a reaction is the time needed for a concentration to decrease to half the original concentration. So a concentration of nitrogen takes 10 minutes to decrease by half. However, because the laws of nature are indeterministic, this is usually put in terms of probabilities. Thus, to say nitrogen has a half-life of 10 minutes is to say it has a $50 \%$ chance of decaying within 10 minutes after it has been created. So the initial state of the universe together with the laws of nature don't determine whether the nitrogen atom still exists in 10 minutes. ${ }^{276}$

To say the laws of nature are indeterministic is not to say that some events are uncaused. Determinism requires necessitation, so if something determines something else then it's physically impossible for the first to occur without the second one to occur. Causation, by contrast, doesn't require necessitation. For example, radioactivity may cause the decay of an atom, but it doesn't determine when it decays. ${ }^{277}$

Following the analogy between the laws of nature and the laws of metaphysics, if the laws of nature are indeterminate, then the laws of metaphysics are indeterminate as well. Whereas

\footnotetext{
${ }^{274}$ Wasserman 2017: 67. See also Schaffer 2016; Wilson (ms); and Trogdon (forthcoming) for three related accounts of the similarity between grounding and causation. Cf. Koslicki 2016 and Bernstein 2016 for criticism. ${ }^{275}$ Wasserman 2017: 67-68.

${ }^{276}$ Wasserman 2017: 69-70.

${ }^{277}$ Wasserman 2017: 70.
} 
indeterminism about the laws of nature involves the initial state of the universe, indeterminism about the laws of metaphysics involves the totality of fundamental facts. Thus, if the laws of metaphysics are indeterminate, then the totality of fundamental facts together with the laws of metaphysics don't determine the non-fundamental facts that are grounded in the fundamental facts. ${ }^{278}$ For example, suppose some atoms are arranged cloud-wise. If the laws of metaphysics are indeterministic, then the fact that some atoms are arranged cloud-wise doesn't determine the fact that those atoms compose a cloud. The former facts don't determine the latter facts, because it's possible that metaphysical laws determine that the atoms arranged cloud-wise compose something, but not that they compose a cloud. Thus, indeterminacy results from indeterminacy about when something counts as a cloud. Alternatively, the former facts don't determine the latter facts because it's possible that compositional laws are indeterministic. Thus, indeterminacy results from indeterminacy about when something composes some thing or whether it composes anything. These two examples are cases of metaphysical indeterminacy; examples where the totality of fundamental facts together with the laws of metaphysics don't determine the nonfundamental facts. ${ }^{279}$

Take the example of the bald man discussed earlier in this chapter. Suppose Bob has a hundred hairs on his head. The totality of facts together with the laws of metaphysics don't determine whether Bob is bald. Bob having a thousand hairs on his head is a borderline case of baldness where it's indeterminate whether the totality of fundamental facts together with the laws of metaphysics describe Bob as bald or not. ${ }^{280}$

The law-based theory of vagueness denies AV4 that there cannot be borderline cases of composition. To solve the problem of vagueness in terms of the sorites series, the law-based theory of vagueness can, and does, also deny AV3 that there cannot be exact cut-offs in sorites series. The idea is that there's nothing that explains why in two adjacent cases in the sorites

\footnotetext{
${ }^{278}$ Wasserman 2017: 70.

${ }^{279}$ Wasserman 2017: 70-71.

${ }^{280}$ Wasserman 2017: 76.
} 
series one case composes a further object while the other case doesn't. The reason that there's nothing that explains this, is because of the indeterminacy of the metaphysical laws.

To explain, contrast the case of baldness with the case of the decay of a nitrogen atom, which is placed in a container at a particular time $t$. Nitrogen doesn't instantaneously decay, so it won't decay at the time we place it in the container. Assuming one nanosecond cannot make a difference, then for any time $n$, if that nitrogen atom hasn't decayed by that time, it doesn't decay by $n+1$ nanosecond either. Therefore, using mathematical induction, the nitrogen atom never decays. ${ }^{281}$ Suppose we open the container after 600,000,000,000 nanoseconds (10 minutes, which is the half-life of nitrogen) and find it has decayed. Then, the conclusion that that the nitrogen atom never decays, is false. Therefore, one of the intermediate cases in the sorites series is false. But none of the intermediate cases are good candidates, since the nitrogen atom didn't undergo any intrinsic or extrinsic changes in the nanosecond just before it decayed. What does change are the probabilities, which are statistically described by the laws of radioactive decay; those laws merely state it's slightly more likely that the atom has decayed. The difference, however, is so small that the chances of that atom decaying at any one time is virtually identical to the chances of that atom decaying one nanosecond later. What vindicates the fact that the nitrogen atom decays at this particular moment as opposed to any other moment, is that nothing does; one nanosecond doesn't make a difference, so nothing vindicates the fact that the nitrogen atom decays when it does, as opposed to it decaying earlier or later. There simply is no causal explanation. There might still be other causes for the decay of a nitrogen atom, e.g. nitrogen atoms decay because they are radioactive, but there's no explanation for why it decayed when it $\operatorname{did}^{282}$

Applying this to Bob, who is losing his hair one at a time, starting with a million hairs and ending with zero hair. By the same reasoning, Bob with a million hairs is not bald, so he isn't bald with a million hairs minus one either. Continuing this, we reach the conclusion that Bob with zero hair is not bald either. Since a man with zero hairs is obviously bald, the conclusion is

\footnotetext{
${ }^{281}$ Wasserman 2017: 79.

${ }^{282}$ Wasserman 2017: 80.
} 
false. Therefore, one of the intermediate cases in the sorites series must be false. Since any adjacent cases, say Bob with 999 hairs and Bob with 1000 hairs, are virtually identical, what makes it the case that the exact cut-off appears where it does is that nothing makes it the case that in one case Bob is bald while in the adjacent second case he $i s$ bald. That is, there's no explanation for why someone is bald in one case but not in the other, and again the reason for why there's no explanation is because of the indeterminacy of the metaphysical laws. ${ }^{283}$

To be clear, on the law-based theory of vagueness, "there is an [exact cut-off] where Bob goes from being non-bald to being bald, but nothing determines why this [exact cut-off] is where it is, rather than somewhere else. Of course, there might still be grounds for baldness. And there might still be non-contrastive metaphysical explanations for why certain people are bald, even when they are on the borderline (e.g., 'they're bald because they don't have much hair'). But there is no explanation for why a particular individual becomes bald at one point, rather than a little bit earlier or a little bit later.,284

Applying this to ordinary objects, e.g. the pieces of wood that are supposed to compose a table, the idea is that there's nothing that explains why in one case the pieces of wood compose a table while in the other case they don't. The reason why there's nothing that explains this, is because of the indeterminacy of the metaphysical laws. To be clear, it's not the case that there's no fact of the matter whether two objects compose a further object. But rather, there $i$ s a fact of the matter whether two objects compose a further object, although this further fact isn't determined by the totality of fundamental facts together with the laws of metaphysics.

\subsection{ONTOLOGICAL CONCEPTUALISM}

\footnotetext{
${ }^{283}$ Wasserman 2017: 78, 80-81.

${ }^{284}$ Wasserman 2017: 81-82.
} 
I argue that Conservatist Minimal Realist views about ordinary objects, such as Ontological Conceptualism, can address the Argument from Vagueness and the objections and responses proposed in this chapter.

The Ontological Conceptualist endorses a semantic view of vagueness. On this view, vagueness is due to imprecisions of our concepts. The mind-independent world isn't vague, but the concepts we use to describe the mind-independent world are vague. Concepts are vague because they are influenced by our conceptual knowledge and the categorization process. Concepts are not rigid categories governed by a set of necessary and sufficient conditions, but are instead flexible; they differ from person to person and can change over time.

Regarding AV3 that there cannot be exact cut-offs in sorites series, Ontological Conceptualists argue that there can be exact cut-offs, but any cut-offs are specified by $u s$, and are thus not located in the mind-independent world. Instead, they depend on our use of our concepts. There might not seem to be any exact cut-offs, because sometimes it's unclear which objects fall under our concepts. For example, in the case of the assembly of a table, our concept TABLE doesn't specify whether any particular case in the sorites series falls under it. It might be determine that the parts of a table don't fall under our concept TABLE when they in different locations, and it might be determinate that the parts of a table do fall under our concept when they are firmly connected to one another (in the appropriate way). But it might not be determinate whether they fall under our concept when they are so loosely connected that it's unclear whether they fall under our concept.

Regarding Kurtsal Steen's ingenious argument, I agree with epistemicists that the only existing objects are those falling under our concepts. However, I argue that epistemicists are wrong to claim that one of the multiple candidate meanings for predicates or concepts is the meaning of that predicate or concept. For this presupposes the sort of essentialist thinking I deny. Concepts do not have one set of necessary and sufficient conditions which supposedly picks out an object; they do not have determinate extensions. Instead, our concepts are determined by our knowledge 
and perceptions, which differs from person to person and at different times within a person's life. Thus, our concepts are not static in the way the epistemicist takes them to be.

Regarding Merricks' argument, Ontological Conceptualists argue against P1 of Merricks' argument. That is, it isn't possible for there to be a stock series if there were no language. To see this, let's first distinguish between a sorites series and a stock series. A sorites series is a series of cases starting from a case where composition doesn't occur to a case where composition does occur. A sorites series is thus about when composition occurs. A stock series, by contrast, takes for granted that composition occurs. It takes for granted that there already are such objects as grains of sand, hydrogen atoms, planets, and stars. If it's true that grains of sand exist, then it's true that stock series are possible even in the absence of language. However, this assumes that composite objects already exist; a claim that both eliminativists and Ontological Conceptualists deny. Merricks does touch on this objection, but he writes that those who endorse this objection are wedded to the claim that being a heap, a star, or a planet, or more generally, being an ordinary object, must essentially, at least partly, depend on our language. ${ }^{285}$ But this is exactly what the Ontological Conceptualist claims; the existence of ordinary objects partly depend on the concepts we have and use.

Regarding Wasserman's argument, I think it's plausible to claim that metaphysical laws are indeterministic, both in terms of indeterminacy about whether something counts as the object it $i s$, and in terms of whether something composes something at all.

At first glance it seems that ordinary objects exist determinately because our conceptualizations of entities determine which objects exist. Conceptualized objects are grounded in their parts together with the concepts we have of those objects. So, in a sense, if we take the parts and the concepts to be the fundamental facts, then, taken together, they determine which objects exist.

\footnotetext{
${ }^{285}$ Merricks 2017: 17-18.
} 
Suppose the laws of metaphysics are indeed indeterministic. This means that the totality of fundamental facts together with the laws of metaphysics don't determine non-fundamental facts. Suppose the totality of fundamental facts merely includes atoms arranged $\mathrm{x}$-wise, and suppose that the metaphysical law in question is the law that the existence and properties of a whole are grounded in the existence and properties of its parts. If so, then atoms arranged x-wise, together with the law that wholes are grounded in their parts, don't determine non-fundamental facts. For example, suppose the totality of fundamental facts includes atoms arranged cloud-wise. Then atoms arranged cloud-wise, together with the metaphysical law that wholes are grounded in their parts, don't determine the non-fundamental fact that those atoms arranged cloud-wise count as a cloud, or indeed that they compose anything at all. Something more is needed if we want to go from mere atoms arranged cloud-wise to clouds. Thus, if the (relevant) fundamental facts merely include atoms arranged $\mathrm{x}$-wise, then ordinary objects, such as clouds, don't exist.

Alternatively, if the totality of fundamental facts includes atoms arranged $\mathrm{x}$-wise, and also includes psychological facts, such as which concepts we possess and the content of those concepts, then it would determine the non-fundamental facts about ordinary objects. For example, suppose the totality of fundamental facts includes all those physical and psychological fundamental facts relevant for the composition of ordinary objects. Then together with the metaphysical law that wholes are grounded in their parts, this would determine whether the atoms arranged cloud-wise count as a cloud and indeed it would determine that those atoms compose a cloud. Thus, if the (relevant) fundamental facts include both physical and psychological fundamental facts, then together with the laws of metaphysics, they determine that ordinary objects, such as clouds, exist.

The question, then, is whether we should include psychological facts in the totality of fundamental facts. I don't have time or space here to discuss the relationship between psychological and physical (neurological) facts, but if one holds that psychological states are (somehow) caused by neurological states, then it's possible, at least in theory, to say that neurological states are included in the totality of fundamental facts. If one includes neurological 
states in the totality of fundamental facts, then it's plausible that those fundamental facts $d o$ determine non-fundamental facts.

However, brain processes are often taken to be indeterministic, in the sense that processes in the brain don't determine behaviour in a deterministic way. If brain processes are indeterministic, then what those brain processes give rise to - e.g. conceptualized objects - is indeterministic as well. The idea is that the sensory information from our environment and conceptual knowledge don't combine in a deterministic way to give rise to conceptualized objects. Instead, they are probabilistic and stochastic, which means they have a random probability distribution that can be analysed statistically but cannot be predicted in a deterministic way. ${ }^{286}$

To conclude, Ontological Conceptualists endorse AV3 and deny AV4. There can be borderline cases of composition, which means either AV9 and/or AV10 must be false. The easiest way for Ontological Conceptualists to deny AV4, in my opinion, is to deny AV10 that no expression in any numerical sentence is vague. For the concepts used in such numerical sentences are often vague, and as a result the expression containing those vague concepts would be vague as well. So, expressions in numerical sentences can be vague.

${ }^{286}$ Barrett, Mendenhall, and Barsalou 2015: 98. 


\section{CHAPTER 5 ARGUMENT FROM MATERIAL CONSTITUTION}

\subsection{EXPLANATION OF THE ARGUMENT}

The fifth argument for eliminativism is the Argument from Material Constitution. The idea is that ordinary objects are made up of the matter that constitutes them. For example, a statue (Athena) is made up of a lump of clay (Lumpy). The relationship between ordinary objects and that what constitutes them leads to a tension between our intuitions about the identity of objects and our intuitions about the persistence-conditions of objects. Our intuitions about the identity between the clay and the statue on the one hand, and the persistence-conditions of the clay and the statue on the other hand, are in tension, because we usually regard the clay and statue as identical (albeit belonging to difference kinds), but at the same time they have different persistence-conditions and therefore cannot be identical. The eliminativist's solution is to simply eliminate the ordinary objects that give rise to the tension. ${ }^{287}$

Let's stipulate that Athena is a statue made up of a lump of clay called Lumpy. Furthermore, assume that both Lumpy and Athena come into existence at the same time and cease to exist at the same time. Lastly, define coincident objects as objects that share all their parts at the same time. The argument runs as follows: ${ }^{288}$

MC1: Athena (if it exists) has different properties from Lumpy.

MC2: If Athena has different properties from Lumpy, then Athena is not identical to Lumpy.

MC3: If Athena is not identical to Lumpy, then there exist distinct coincident objects.

\footnotetext{
${ }^{287}$ Korman 2015: 9; Korman 2016: 13-14.

${ }^{288}$ See Heller 1990: par.2.4-2.7; van Inwagen 1990: 125-127; Merricks 2001: par.2.3 for arguments from material constitution against ordinary objects.
} 
MC4: There cannot exist distinct coincident objects. ${ }^{289}$

MC5: Therefore, Athena doesn't exist. ${ }^{290}$

The first premise is supported by the claim that Athena and the Lumpy have different modal profiles; Lumpy can survive being flattened, but Athena cannot. The first premise is also supported by the claim that Athena and Lumpy have different sortal profiles; Athena has the sortal property of being a statue while Lumpy doesn't. ${ }^{291}$ The second premise follows from Leibniz's Law, i.e. if two objects are identical, they must have exactly the same properties. ${ }^{292}$ The third premise follows from the first two premises. It's plausible that Athena and Lumpy coincide because both are composed of the exact same lump of clay. Therefore, if it's true that Athena is not identical (at least not numerically identical) to Lumpy, then they are coincident objects. ${ }^{293}$ The fourth premise is plausible because it seems implausible that something can compose more than one thing at the same time. It may be true that some things can compose more than one thing across time; for example, when the same Lego blocks compose a castle at one time and a ship at a later time. But it's hard to see how they can compose both at the same time. $^{294}$

Before considering the objections to the Argument from Material Constitution, I want to point out that the conclusion doesn't support eliminativist, since it merely holds that Athena doesn't exist, not that ordinary objects in general don't exist. One arrives at an eliminativist conclusion if all ordinary objects are just like Athena. If ordinary objects in general have different properties from that what they are made up of, and if those ordinary objects are not identical to what they are made up of, and if there cannot be coincident objects, then ordinary objects don't exist.

\footnotetext{
289 'Distinct' here means 'not numerically identical'.

290 Korman 2015: 9-10.

291 Korman 2015: 10.

292 Korman 2015: 10.

293 Korman 2015: 10.

${ }^{294}$ Korman 2015: 10.
} 
Moreover, MC5 doesn't follow from the premises, since the argument leaves open the possibility that Lumpy doesn't exist while Athena does exist. The reasoning behind the claim that Lumpy exists while Athena doesn't, is presumably because Lumpy is more fundamental than Athena, and more fundamental entities should be favoured in our ontology over less fundamental entities.

\subsection{OBJECTIONS TO THE ARGUMENT FROM MATERIAL CONSTITUTION}

Two main objections against the Argument from Material Constitution are monist objections and Pluralist Objections. According to monist objections, Athena is identical to Lumpy. Korman sets out several monist and pluralist objections, but I focus on the ones that have recently been replied to. The monist objection I consider is the Inconstancy Objection and provide a recent response by Barker and Jago. According to Pluralist objections, Athena is distinct from Lumpy. The argument against the Pluralist Objection is the Grounding Problem, which is the problem of what grounds the differences between Athena and Lumpy. I discuss four replies to the Grounding Problem.

\section{MONIST OBJECTION: THE INCONSTANCY OBJECTION}

Monist objections argue that MC1 is false: Athena doesn't have different properties from Lumpy. $\mathrm{MC} 1$ is supported by several arguments. The argument for $\mathrm{MC} 1$ runs as follows:

MC6: Athena (if it exists) is unable to survive flattening.

MC7: Lumpy is able to survive flattening.

MC1: Therefore, Athena (if it exists) has different properties from Lumpy. 
The Inconstancy Objection claims the argument is invalid because Lumpy's properties and Athena's properties are different. The idea is that the property of being able to survive flattening in MC6 is not the same property as the one in MC7 because de re modal attributions like the properties expressed in MC6 and MC7 are inconstant; that is, they express different properties in different contexts ${ }^{295}$. If the properties expressed in MC6 and MC7 are not identical, then the conclusion doesn't follow, and therefore we cannot conclude that Athena has different properties from Lumpy. MC1 is thus false. ${ }^{296}$

\section{BARKER AND JAGO'S RESPONSE TO THE INCONSTANCY OBJECTION}

One response to the Inconstancy Objection is that the property can survive flattening is not context sensitive in the way monists require. Korman gives a detailed overview of the different replies to the Inconstancy Objection. ${ }^{297}$ Instead of repeating the existing responses, I focus on a recent response proposed by Barker and Jago. ${ }^{298}$

Barker and Jago respond to the Inconstancy Objection and argue that modal analyses of material constitution fail. They argue that material constitution is an asymmetrical relation; the lump of clay constitutes the statue while the statue doesn't constitute the lump of clay. Granting that material constitution is asymmetrical, ${ }^{299}$ 'materially constitutes' must be an inconstant predicate. 'Materially constitutes' picks out a different property in the context of ' $a$ materially constitutes $b$ ' and ' $b$ materially constitutes $a$ '. If 'materially constitutes' picks out a different property in these two instances, then it's not contradictory to claim that ' $a=b$ ', ' $a$ materially constitutes $b$ ', and ' $b$ doesn't materially constitute $a$ '. Therefore, it's not contradictory to claim that 'Athena is

\footnotetext{
${ }^{295}$ Also called Abelardian predicates.

296 Korman 2015: 207-208.

297 See Korman 2015: 207-209.

298 Baker 2007.

${ }^{299}$ Barker and Jago give a further argument for the asymmetrical relation based on 'recipe-making', but for now I just grant the asymmetry.
} 
Lumpy', 'Lumpy materially constitutes Athena', and 'Athena doesn't materially constitute Lumpy'. ${ }^{300}$

However, modal analyses of material constitution, that are supposed to support the claim that 'materially constitutes' is an inconstant property, fail because they give the wrong results for certain judgments involving material constitution. ${ }^{301}$ Three modal analysis are discussed; in terms of persistence-conditions/destruction-conditions, essential parts, and favourable circumstances.

The destruction analysis of material constitution claims that " $a$ materially constitutes $b$ at time $t$ iff (i) $a$ spatially coincides with $b$ at $t$ and (ii) $a$ could be a substratum of $b$ 's total destruction., ${ }^{302}$ In other words, Lumpy constitutes Athena at a certain time $t$ if and only if Lumpy spatially coincides with Athena at that time and Lumpy could be a substratum of Athena's total destruction. This modal analysis correctly states that Lumpy materially constitutes Athena, since Lumpy can survive being flattened, which would destroy the statue. This modal analysis also correctly states that Athena doesn't materially constitute Lumpy, because the statue cannot survive being flattened, which would not destroy Lumpy. ${ }^{303}$

The essential parts analysis of material constitution claims that " $a$ materially constitutes $b$ at $t$ iff (i) $a$ spatially coincides with $b$ at $t$; (ii) something is an essential part of $a$ at $t$, no part of which is an essential part of $b$ at $t$; and (iii) all essential parts of $b$ at $t$ have a part that is essential to $a$ at t. ${ }^{, 304}$ This means that (i) the collection of atoms and Lumpy are spatially coincident. Now (ii), some of the atoms located at $l$ at a time $t$ is an essential part of the collection of atoms, since without these atoms, the collection of atoms isn't the same collection of atoms. At the same time, these atoms are not essential to Lumpy, since we can destroy those atoms without destroying

\footnotetext{
${ }^{300}$ Barker and Jago 2014: 3.

${ }^{301}$ Barker and Jago 2014: 7. These modal analyses support the claim that 'materially constitutes' is an inconstant property assuming counterpart theory is true.

${ }^{302}$ Barker and Jago 2014: 5.

${ }^{303}$ Barker and Jago 2014: 5.

${ }^{304}$ Barker and Jago 2014: 6.
} 
Lumpy. Lumpy would be damaged, since it's now missing a portion of its atoms, but Lumpy would still exist. Now (iii) take any essential part of the Lumpy, e.g. the right half of it, which is made up of a certain collection of atoms, all of which are essential to the collection of atoms. So (i), (ii), and (iii) are all met. The essential parts analysis of material constitution correctly states that the collection of atoms materially constitutes Lumpy, and it correctly states that the collection of atoms materially constitutes Athena. ${ }^{305}$

The favourable circumstances analysis of material constitution claims that is that in appropriate circumstances a collection of clay atoms is spatially coincident with a statue, whereas collections of clay atoms in general don't have to be spatially coincident with statues. Circumstances are statue-favourable when every property that must be exemplified for something to be a statue, other than primary kind properties such a being a collection of clay atoms, being a statue, etc. is in fact exemplified. This includes the collection of atoms having an appropriate form for a statue. The favourable circumstances analysis of material constitution then holds that the collection of clay atoms materially constitutes the statue because the collection of clay atoms necessitates the existence of a spatially coincident statue in statue-favourable circumstances, whereas collections of clay atoms in general don't have to be spatially coincident with statues. ${ }^{306}$

These three modal analyses of material constitution fail because they give the wrong results for certain judgments regarding material constitution. Imagine, like the monist would, that the statue, the lump of clay, and the clay atoms (collectively), are one object. This object can be referred to using certain descriptive phrases such as 'the lump of clay that's also a statue', 'the statue that's also a lump of clay', 'the thing that's both a lump of clay and a collection of clay atoms', etc. Since these phrases are all suitable for picking out the statue, monists must have something to say about the following judgments: ${ }^{307}$

\footnotetext{
${ }^{305}$ Barker and Jago 2014: 6.

${ }^{306}$ Barker and Jago 2014: 6-7.

${ }^{307}$ Barker and Jago 2014: 7-8.
} 
(1) The thing that's both a collection of atoms and a lump of clay materially constitutes the statue.

(2) The thing that's both a collection of atoms and a statue materially constitutes the lump of clay.

(3) The lump of clay materially constitutes the thing that's both a collection of atoms and a statue. $^{308}$

These three judgments concern the one-to-one relation of material constitution. On the monist view, (1) is true while (2) and (3) are false. However, the three modal analyses discussed above give the wrong results for (2) and (3).

The destruction analysis of material constitution gives the wrong result for (3). Consider the thing that's both a collection of atoms and a statue. The atoms spatially coincide with the lump of clay. Now suppose we flatten the lump of clay thereby destroying the statue. This would be a total destruction of the statue, for completely altering the shape of a statue destroys that statue. If the statue is destroyed, then the thing that's both a collection of atoms and a statue doesn't exist anymore. But the lump of clay does survive being flattened, and therefore can survive the destruction of the thing that's both a collection of atoms and a statue. Therefore, the destruction analysis of material constitution says that (3) is true, but (3) is not true, and therefore, the destruction analysis of material constitution cannot be the correct analysis of material constitution judgments. ${ }^{309}$

Similarly, the destruction analysis of material constitution gives the wrong result for (2). Suppose that the lump of clay is hollowed out while preserving both the overall outside form of the statue and the quantity of clay (perhaps by viewing it in the same way as a balloon being blown up; the shape and material is the same but it's just a blown-up version of the statue). And suppose that the art community considers this a modification of the original statue as opposed to

\footnotetext{
308 Barker and Jago 2014: 8.

${ }^{309}$ Barker and Jago 2014: 8-9.
} 
a new statue. Now there's no solid lump of clay, although the quantity of clay remains, since solid lumps of clay cannot be hollowed out lumps of clay. In this case, both the statue and the collection of atoms survive the destruction of the solid lump of clay, since again, the total destruction of the solid lump of clay doesn't require the annihilation of its matter. Therefore, the destruction analysis of material constitution would say that (2) is true, but (2) is not true, and therefore, the destruction analysis of material constitution cannot be the correct analysis of material constitution judgments. ${ }^{310}$

The essential parts analysis of material constitution also gives the wrong result for (2). Take the thing that's both a collection of atoms and a statue. We first must establish what the essential part is of the thing that's both a collection of atoms and a statue. Since every portion of the collection of atoms is essential to that collection of atoms, it follows, on the monist view, that that portion of the collection of atoms is essential to the thing that's both a collection of atoms and a statue. Similarly, every part that's essential to the statue is also essential to the thing that's both a collection of atoms and a statue. Since the collection of atoms materially constitutes the lump of clay, then by monist standards together with the essential parts analysis of material constitution, it follows that (i) the collection of atoms has an essential part $p$, no part of which is essential to the lump of clay; and that (ii) all essential parts of the lump of clay have a part that's essential to the collection of atoms. This would imply that $p$ is essential to the thing that's both a collection of atoms and a statue, and all essential parts of the lump of clay have a part that's essential to the thing that's both a collection of atoms and a statue. And the thing that's both a collection of atoms and a statue clearly spatially coincides with the lump of clay. Therefore, the essential parts analysis of material constitution would say that (2) is true, but (2) is not true, and therefore, the essential parts analysis of material constitution cannot be the correct analysis of material constitution judgments. ${ }^{311}$

The favourable circumstances analysis of material constitution also gives the wrong result for (2). Since the collection of atoms materially constitutes the lump of clay, it follows from the

\footnotetext{
${ }^{310}$ Barker and Jago 2014: 9.

${ }^{311}$ Barker and Jago 2014: 9.
} 
favourable circumstances analysis that there are circumstances $C^{*}$ (favourable to lumps of clay such as ours) such that: (4) It is necessarily the case that for any $x$ that's essentially a collection of atoms and in circumstances $C^{*}$, there is a $y$ that's essentially a lump of clay and spatially coincident with $x$.

On the inconstancy account, everything that's essentially a collection of atoms and a statue is thereby essentially a collection of atoms. Imagine a thing $x$, which both a collection of atoms and a statue, is in circumstances $C^{*}$. That thing is essentially a collection of atoms and therefore, from (4), there's a $y$ that's essentially a lump of clay and spatially coincident with $x$. So, it's necessary that anything that's essentially both a collection of atoms and a statue are, in circumstances $C^{*}$, spatially coincident with something that's essentially a lump of clay. Moreover, the thing that's both a collection of atoms and a statue could exist without being materially coincident with the lump of clay, e.g. when the statue is constituted by a hollow lump of clay rather than a solid lump of clay. Therefore, the favourable circumstances analysis of material constitution would say that (2) is true, but (2) is not true, and therefore, the favourable circumstances analysis of material constitution cannot be the correct analysis of material constitution judgments. ${ }^{312}$

The three different analyses of material constitution, combined with monism, all give the wrong results for (2) and/or (3).

\section{THE PLURALIST OBJECTION}

The Pluralist Objection claims that Athena is numerically distinct from Lumpy and thus denies MC4. Pluralists argue there are two interpretations of sentences such as 'Lumpy is Athena'. On the first interpretation, the 'is' in 'Athena is Lumpy' is the 'is'-of-identity, while on the second interpretation it's the 'is'-of-constitution. On the first interpretation 'Athena is Lumpy' is true if

\footnotetext{
312 Barker and Jago 2014:9-10.
} 
Athena is numerically identical to Lumpy. On the second interpretation, 'Athena is Lumpy' is true if Athena constitutes Lumpy (or if Lumpy constitutes Athena). Thus, according to pluralists, 'Athena is Lumpy' is false on the 'is'-of-identity interpretation, but true on the 'is'-ofconstitution interpretation. The reason why we usually think that 'Athena is Lumpy' is true is because we hear the second interpretation, that is, we hear the 'is' as an 'is'-of-constitution instead of the 'is'-of-identity. ${ }^{313}$

\section{THE GROUNDING PROBLEM}

The response to the Pluralist Objection is the Grounding Problem. The idea is that if one accepts that Athena and Lumpy are distinct objects, then there must be certain differences between the two. But Athena and Lumpy are located in the same place and they are made up of the same parts. This gives rise to the grounding problem: Athena and Lumpy share the same parts, but Lumpy can survive being flattened while Athena cannot. So, pluralists need to explain what makes it the case that Athena and Lumpy have different persistence-conditions. That is, they need to explain what grounds these differences; in virtue of what do Athena and Lumpy have different modal profiles. ${ }^{314}$ The argument runs as follows:

GP1: If Athena and Lumpy differ modally, then there must be some difference between them that explains their modal differences.

GP2: There's no difference between them that explains their modal differences.

GP3: Therefore, Athena and Lumpy don't differ modally. ${ }^{315}$

GP4: If Athena and Lumpy don't differ modally, then Athena is identical to Lumpy. GP5: Therefore, Athena is identical to Lumpy

\footnotetext{
${ }^{313}$ Korman 2015: 210.

${ }^{314}$ Korman: 2015: 212; Jago 2016: 1-2.

${ }^{315}$ Korman 2015: 212.
} 
Assuming modal differences are not brute, pluralists cannot undermine the Grounding Problem by denying GP1. Neither can they deny GP3, since the reason that Athena and Lumpy are different is because they differ modally. This leaves them to deny the second premise, that there's no difference between them that can explain their modal differences. ${ }^{316}$

\section{REPLIES TO THE GROUNDING PROBLEM}

To deny GP2, pluralists must point to a difference between Athena and Lumpy that explains their modal differences. In this section I set out four replies and state how they are supposed to solve the Grounding Problem. The Sortal Reply claims that Athena and Lumpy are different because they fall under different sortals. The Spatial Arrangements Reply claims the differences are grounded in the way their parts are arranged. A recent reply by Jago claims that the differences are grounded in the identity of objects. Another recent reply by Campdelacrue claims that the differences are grounded in the primary kind an object belongs to.

\section{REPLY 1: THE SORTAL REPLY}

The first reply to the Grounding Problem is the Sortal Reply. The difference between Athena and Lumpy that explains their modal differences is that they fall under different sortals. Sortals specify the essence of an object, the number of things of that kind (since counting requires knowing which objects are the same and which ones are different), and the persistenceconditions of an object. ${ }^{317}$ Thus, the difference between Athena and Lumpy is that Athena falls under the sortal statue and Lumpy falls under the sortal clay - lumps of clay and statues are

\footnotetext{
${ }^{316}$ Korman 2015: 212.

317 Grandy 2016.
} 
different sortals, which explains why they have different modal profiles; it's why Lumpy can survive being flattened while Athena cannot survive being flattened. ${ }^{318}$

One response to this reply is that the sortal differences also need to be explained, that is, why it is that Athena falls under the sortal statue while Lumpy falls under the sortal clay. ${ }^{319}$ Intuitively, something falls under a sortal because it satisfies certain criteria. However, given Athena and Lumpy are co-located and metaphysically indistinguishable, it doesn't explain why they fall under different sortals. The only difference seems to be their modal profiles, but pluralists cannot appeal to modal profiles to explain the differences in modal profiles, since that would be circular. $^{320}$

\section{REPLY 2: THE SPATIAL ARRANGEMENTS REPLY}

The second reply to the Grounding Problem is Korman's Spatial Arrangements Reply. Korman argues that Athena and Lumpy are grounded in their parts and the way in which those parts are arranged. ${ }^{321}$ An object is Athena-shaped if it's shaped in one of the shapes that Athena can take while an object is Lumpy-shaped if it's shaped in one of the many forms lumps of clay can take. Note that being Athena-shaped and Lumpy-shaped are determinable properties involving shape and are not modal properties. Now some objects are collectively Athena-shaped, that is, some objects jointly occupy the region in which the Athena-shape is found, and some objects are collectively Lumpy-shaped in that they jointly occupy the region in which the Lumpy-shape is found. ${ }^{322}$ The parts of Athena are then the parts arranged Athena-shaped and the parts of Lumpy are the parts arranged Lumpy-shaped (instead of talking about atoms or simples arranged x-wise, Korman talks about parts being arranged x-shaped). ${ }^{323}$

\footnotetext{
${ }^{318}$ Korman 2015: 212; Jago 2016: 4.

${ }^{319}$ Korman 2015: 212; Jago 2016: 4.

${ }^{320}$ Korman 2015: 212-213.

${ }^{321}$ See Skiles 2015 par.3.1 for a defence.

322 Korman 2015: 213-214.

${ }^{323}$ Korman 2015: 213-214.
} 
The idea is that Athena is grounded in the parts being collectively Athena-shaped while Lumpy is grounded in the parts being collectively Lumpy-shaped. This is the difference between Athena and Lumpy that determines what it is for Athena or Lumpy to exist. Moreover, this difference can provide a solution to the Grounding Problem, since it can ground the modal differences. The reason Athena cannot survive flattening is because what it is for Athena to exist is to be Athenashaped, and a flattened Athena is not Athena-shaped anymore. Similarly, the reason Lumpy can survive flattening is because what it is for Lumpy to exist is to be Lumpy-shaped, and a flattened lump of clay is still Lumpy-shaped. ${ }^{324}$

\section{REPLY 3: JAGO'S ESSENTIAL BUNDLE THEORY}

The third reply to the Grounding Problem is Jago's Essential Bundle Theory. The Essential Bundle Theory claims that ordinary objects are "suitably closed, consistent mereological sums of non-modal, non-sortal property instances, all of which share the same spatiotemporal region." ${ }^{, 325}$ For something to be suitably closed means, roughly, that if an object has properties that entail other properties, then that object has those entailed properties as well. For example, an object that has the properties of being red also has the property of being coloured. For something to be a consistent mereological sum just means that an object cannot contain contradictory properties, e.g. it cannot contain both being red and not being red. Lastly, mereological sums don't contain non-modal or non-sortal properties, because modal and sortal properties are analysed in terms of the bundles they belong to. ${ }^{326}$ Another feature of the essential bundle theory is that it doesn't analyse the possession of properties in terms of the bundles they belong to. Instead, the properties that belong to the bundle specify the essence of material objects. The essence of a material object is a bundle of properties and that object is identified with its essence. ${ }^{327}$

\footnotetext{
${ }^{324}$ Korman 2015: 214.

325 Jago 2016: 13.

326 Jago 2016: 13.

327 Jago 2016: 13.
} 
Jago's response to the Grounding Problem is to argue that objects themselves ground their possession of modal, kind, and sortal properties. So, modal, kind, and sortal properties are not primitive. Instead, objects are bundles of property instances, where each of those properties are essential properties of those objects. So, part of Athena's bundle is the functional property of being in a particular shape. The properties in the bundle ground the modal, kind, and sortal properties. So, the essential functional properties of Athena ground Athena's modal properties. Since being in a particular shape is one of Athena's essential properties, it grounds its modal property of being unable to be flattened, whereas the lump of clay that Lumpy is made up of doesn't have the essential properties that ground the modal property of being unable to be flattened. ${ }^{328}$ The idea is that since part of Athena's essence is to be in a particular shape, any persistence-conditions incompatible with being in that shape are incompatible with Athena. So, if we were to flatten Athena, Athena wouldn't be in that shape anymore and thus would cease to exist. $^{329}$

Although essences aren't inherently modal, they do have modal consequences, since an object that's essentially an F could not have not been an F. And anything that's entailed by being an F is de re necessary of that thing. And conversely, anything that's excluded by being an F lacks that thing necessarily. For example, if Athena is essentially unable to be flattened, then it cannot be flattened without Athena ceasing to exist. ${ }^{330}$ Similarly, since being unable to be flattened is not part of Lumpy's essence, it also lacks modal properties such as being necessarily flattened. So Lumpy won't cease to exist when flattened. ${ }^{331}$ Similarly for sortal properties. Athena is a statue because part of Athena's essence is the sortal property being a statue. Lumpy, by contrast, might be shaped in the particular shape Athena is shaped in, but doesn't have being a statue as part of its essence, and therefore is not a statue. Both persistence-conditions and sortal properties are thus grounded in the differences in essence.

\section{REPLY 4: CAMPDELACRUE}

328 Jago 2016: 16 .

329 Jago 2016: 16-17.

330 Jago 2016: 17.

331 Jago 2016: 17. 
The fourth reply to the Grounding Problem is recently proposed by Campdelacreu. ${ }^{332}$ The idea is that objects can be coincident while still being distinct objects by appealing to a constitution relation on which of object is constituted by another. ${ }^{333}$ Campdelacreu's response is based on Baker's account of coincident objects and his constitution relation. For Baker, there are two ideas related to the constitution relation: the idea of a primary kind and the idea of favourable circumstances. The primary kind of an object determines what an object is and determines its identity, existence, and persistence-conditions. For example, being a statue or being a lump of clay are primary kind properties. The idea of favourable circumstances is that for any primary kind property, such as being a statue, the favourable circumstances are those circumstances in which something can be a statue. Those favourable circumstances are necessary, but not sufficient, for something to be a statue. When another primary kind, such as being a lump of clay, is in those statue-favourable circumstances, then it constitutes a statue. ${ }^{334}$

After discussing some objections to the idea of favourable circumstances, Campdelacreu proposes an alternative account based on Baker's account of the constitution relation that keeps the idea of primary kinds without appealing to the idea of favourable circumstances. Instead of appealing to favourable circumstances, Camdelacreu appeals to the idea of coming-intoexistence-conditions based on the kind an object belongs to. Coming-into-existence-conditions are relative to the kind an object belongs to. For example, there are different coming-intoexistence-conditions for statues and lumps of clay because they belong to different kinds. ${ }^{335}$ Exactly what these coming-into-existence-conditions refer to must be left to the experts, but they might include existence of certain atoms arranged in a certain way. They might refer to the existence of certain material components that have certain inner-boundary properties (such as shape, structure, colour, weight, etc.), or they might refer to the existence of the environment the

332 Campdelacreu 2015.

332 Campdelacrue 2015: 9.

333 Campdelacreu 2015: 2.

${ }^{335}$ Campdelacreu 2015: 10. 
material component must be in for a new object to come into existence. ${ }^{336}$ The material component of an object of a certain kind is the material object of a different kind. So, the material component of a lump of clay is the material object of a statue that comes into existence in virtue of the lump of clay. Moreover, the lump of clay determines the material properties (such as shape, colour, weight, mass etc.) of the statue. ${ }^{337}$

For example, the material component of a statue can be a particular lump of clay. When that lump of clay has certain inner-boundary properties and if it's located in a particular environment, then that statue that's coincident with the lump of clay comes into existence. The inner-boundary properties of the lump of clay include the way the atoms are arranged, while the environment may include the person making this lump of clay into a statue. Furthermore, the lump of clay determines the material properties of the statue, such as the shape, height, and weight, because the piece of clay has those material properties. ${ }^{338}$

So, the idea is that Athena belongs to the primary kind statue and Lumpy belongs to the primary kind lump of clay. Athena and Lumpy are coincident at that time and Lumpy has the innerboundary properties and is located in the right environment as stipulated by the coming-intoexistence-conditions for statues, since Athena was created from the lump of clay by someone. Lumpy determines the material properties of Athena while they are coincident. That is, Athena has a certain shape, height, and weight because Lumpy has those properties. Moreover, when the lump of clay has those inner-boundary properties and is located in the right environment as stipulated by the coming-into-existence-conditions for statues, the statue that's coincident with it comes into existence. By contrast, Lumpy could have existed without being coincident with any statues, since the artist who made Athena might not have decided to make a statue out of the lump of clay. ${ }^{339}$

\footnotetext{
${ }^{336}$ Campdelacreu 2015: 10.

${ }^{337}$ Campdelacreu 2015: 10-11.

${ }^{338}$ Campdelacreu 2015: 12.

${ }^{339}$ Campdelacreu 2015: 13.
} 
Therefore, constitution relation between Athena and Lumpy can explain the modal differences between Athena and Lumpy and thus GP2 of the Grounding Problem is false. Moreover, on Campdelacreu's account, there can exist distinct coincident objects, and thus MC4 is false as well.

\subsection{ONTOLOGICAL CONCEPTUALISM}

I argue that Conservatist Minimal Realist views about ordinary objects, such as Ontological Conceptualism, can address the Argument from Material Constitution and the objections and responses proposed in this chapter. Ontological conceptualism denies MC4 that there cannot exist coincident objects, and accepts MC3 that there exist distinct coincident objects.

It may seem that Lumpy is identical to Athena since they are located in the exact same space and share all of their parts. Despite this, as conceptualized objects Athena and Lumpy are not identical. For Athena is conceptualized as a statue whereas Lumpy is conceptualized as a lump of clay. Their location and parts might be identical, but their conceptualizations are different. And since objects are individuated by their concepts, they are two numerically distinct objects.

The argument for MC4, that there cannot exist coincident objects, is that it seems implausible that something can compose more than one thing at the same time. However, on an Ontological Conceptualist view it's not implausible something composes more than one thing at the same time. For it's plausible that something can be conceptualized as more than one thing. It's quite natural to say that the same atoms arranged x-wise can be conceptualized in different ways. For example, a plant can be conceptualized as a weed or a flower depending on the perceiver's categorization. A plant can be conceptualized as a weed when its presence isn't welcome, when it takes over your garden and you want to get rid of it. A plant can also be conceptualized as a flower when its presence is welcome and we are purposely trying to cultivate them. The idea is 
that there's nothing in the material constitution of plants that makes them a weed or a flower, but instead it's the way we conceptualize it that makes it the (conceptualized) object it is.

The other argument for MC4 is if one argues that the statue is distinct from the clay, then one must provide a solution to the Grounding Problem. Again, Ontological Conceptualism provides a coherent solution to the Grounding Problem: our concepts ground the modal differences between the statue and the clay. Since Ontological Conceptualists hold that modal profiles are grounded in our concepts, having different concepts about the same parts explains why Athena and Lumpy are two distinct conceptualized objects. So, Ontological Conceptualists deny GP2 of the Grounding Problem.

One worry about this solution, similar to the sortal solution to the grounding problem discussed above, is that Ontological Conceptualists need to explain why atoms arranged x-wise are conceptualized as a statue in one case and as a piece of clay in the other case. The original objection is aimed at the Sortal Reply to the Grounding Problem, which pointed out that sortal differences also need to be explained, but the problem is that since the only difference between Athena and Lumpy are their modal profiles, pluralists cannot appeal to modal profiles to explain the differences in modal profiles, since that would be circular. This worry might seem to apply to the Ontological Conceptualist. However, unlike the sortalist, the Ontological Conceptualist can explain why the atoms arranged $\mathrm{x}$-wise are can be conceptualized as a statue and as a lump of clay. For they can appeal to different conceptual knowledge, different cultural and social factors, different functions, different psychological and cognitive factors, etc. that influence the concepts we have.

Regarding Campdelacreu, the constitution relation she proposed consists of two elements: the idea of primary kinds and the idea of coming-into-existence-conditions. My issue is not so much with the coming-into-existence-conditions but rather with the idea of primary kinds. The idea of primary kinds underlies the constitution relation, and without it his idea of coming-intoexistence-conditions won't work either. Campdelacreu doesn't explicitly state that she takes 
kinds to be intrinsic to objects, although she probably assumed this is the case. To be charitable, I take him to be neutral on this topic, since she can be interpreted both ways. She merely says that the primary kind of an object determines what this object fundamentally is; primary kinds are essential to objects and determine their identity, existence, and persistence-conditions. So far so good. The Ontological Conceptualist can agree with this. Ontological Conceptualists can also claim that the primary kind of an object determines what that object is, and can also claim that kinds determine the identity, existence, and persistence-conditions of that object, although she would hold that the primary kind of an object is not found intrinsically in objects themselves but is rather grounded in concepts that pick out objects. What the Ontological Conceptualist cannot claim though is that there's a mind-independent fact about which of the kind properties are primary kind properties. Any kind property that's taken to be a primary kind is either a decision we've made, e.g. we decided that the property being a statue is important in the case of statues whereas being a lump of clay is the important kind property of lumps of clay, or we didn't so much decide which kind properties are primary kind properties so much as the properties we take as important to being a statue or being a lump of clay feature highly in the concepts we have of statues and lumps of clay. Concepts determinate what objects are; concepts, which include knowledge about which objects fall under what kinds, determines what objects are; the kinds themselves don't determine what objects are. Campdelacreu argues that coming-into-existenceconditions are grounded on the kind objects belong to. If I am right in claiming that the kind an object belongs to is a property of the concept we have of that object, the coming-into-existenceconditions are also grounded in the concepts we have. Hence, it's not the case that what objects exist are grounded in the primary kinds an object belongs to, but rather what objects exist are grounded in our concepts. Thus, according to the Ontological Conceptualist, it's still the case that there are coincident objects, but the reason is not because they belong to different primary kinds, but instead is because coincident objects are those objects that occupy the same space at the same time but have different concepts associated with them.

To conclude, Minimal Realist views such as Ontological Conceptualism can address the Argument from Material Constitution and the objections and responses that have been proposed in this chapter. 


\section{CHAPTER 6 PROBLEM OF THE MANY}

\subsection{EXPLANATION OF THE ARGUMENT}

The sixth argument for eliminativism is the problem of the many. The idea behind it is that if we were to say that there's one desk in an office, then we are forced to say that there are countless desks in that office. Since it's not the case that there are countless objects in the office, there are no objects in the office. For example, there's a single desk in my office. This desk is constituted of a piece of wood with exact boundaries demarcating the desk from its surroundings. So, there's not a single atom separate from the others. Call this piece of wood with its exact boundaries Woodrow. Now take another object that consists of all the same parts Woodrow is made up of except for one atom named Molly. Let's call this new object Woodrow-minus. The Problem of the Many is that when we admit that there's one object, Woodrow, then we must also admit countless other objects, e.g. Woodrow-minus, Woodrow-minus2, etc. ${ }^{340}$ The argument runs as follows:

PM1: Woodrow is a desk iff Woodrow-minus is a desk.

PM2: If Woodrow is a desk iff Woodrow-minus is a desk, then it's not the case that there's exactly one desk in the office.

PM3: There's at most one desk in the office.

PM4: Therefore, there's no desk in the office. ${ }^{341}$

The first premise is plausible since Woodrow-minus seems to be a desk, since it has everything for it to be a desk: it has a flat top, it has some drawers, it's used to study or work at, etc. Having one less atom doesn't change its status from desk to non-desk. Therefore, it would be arbitrary to

\footnotetext{
${ }^{340}$ Korman 2015: 10-11.

${ }^{341}$ Korman 2015: 11.
} 
call Woodrow a desk but not Woodrow-minus. ${ }^{342}$ The second premise is plausible, since if Woodrow is a desk iff Woodrow-minus is a desk, then either both are desks or neither of them are. If both are desks, then there's more than one desk in the office, and if neither of them are desks then there are no desks in the office. Either way, it would not be the case that there's exactly one desk in the office. ${ }^{343}$ The third premise is plausible, since intuitively there's only one desk in the office. ${ }^{344}$

\subsection{OBJECTIONS TO THE PROBLEM OF THE MANY}

In this section I set out two objections to the Problem of the Many. The first objection, labelled Constitutionalism, denies PM2 and PM2', The third objection, called Manyism, denies PM3 that there's at most one desk in the office. I then discuss two responses to Manyism. The first response to Manyism appeals to supervaluationism and claims that once we precisify the relevant terms involved, PM3 is true. The second response to Manyism appeals to Almost-Identity and claims that since Woodrow and Woodrow-minus overlap significantly, they are one object. Next, I discuss a recent reply to Almost-Identity proposed by Sutton who argues that mereological overlap and functional overlap come apart, and when they do, functional overlap is more important. Since Woodrow and Woodrow-minus significantly overlap in their functions, they are one object and thus PM3 is true.

\section{OBJECTION 1: CONSTITUTIONALISM}

The first objection to the Problem of the Many is set out by Korman, who argues that PM2 and PM2' are false while PM3 is true. There's exactly one desk in the office, call it Desky. PM2 is false, because Desky is indeed constituted by Woodrow, but Woodrow is not itself a desk. Nor is Woodrow-minus or Woodrow-plus a desk, because pieces of wood are not desks. And it's false

\footnotetext{
${ }^{342}$ Korman 2015: 11.

${ }^{343}$ Korman 2015: 11.

${ }^{344}$ Korman 2015: 11.
} 
that, if Woodrow-plus is a desk iff Woodrow-minus is a desk, then it's not the case that there's exactly one desk in the office, because Desky is indeed constituted by a piece of wood, but it's indeterminate whether Molly is part of the piece of wood that constitutes Desky. So PM2', is false as well. The idea is that neither Woodrow, Woodrow-minus, Woodrow-plus, nor any other pieces of wood in the office are Desky, and nor are they desks. ${ }^{345}$

\section{OBJECTION 2: MANYISM}

The second objection to the Problem of the Many denies PM3 that there's at most one desk in the office. This objection admits there are many desks in the office, since there will be a desk composed of all the atoms that compose Woodrow, but there will also be a desk composed of all of Woodrow's atoms minus one atom, minus two atoms, minus three atoms, etc. Thus, there will be as many desks as there are atoms in Woodrow. And the same goes for every other object. Therefore, this leads to manyism, the view that whenever there's an object that belongs to a certain kind, there are countless other objects of that kind in the same location as that object. ${ }^{346}$

\section{RESPONSE 1 TO MANYISM: SUPERVALUATIONISM}

The first response to Manyism that it's extremely implausible. One attempt proposed by Lewis to explain away the implausibility appeals to supervaluationism. Supervaluationism takes into account the precisifications of the terms involved. On a supervaluationist reading, a sentence is true if it's true on every precisification of the terms. For example, the meaning of the term 'desk' in PM3 has many precisifications, e.g. desk1, desk2, desk3, etc. each of which applies to exactly

\footnotetext{
${ }^{345}$ Korman 2015: 222. For responses to Constitutionalism in terms of the Problem of the Many see Korman 2015: 223-224.

${ }^{346}$ Korman 2015: 220.
} 
one of the many candidate desks in the office. Since each of the precisifications applies to exactly one of the candidate desks, PM3 is true. ${ }^{347}$

\section{RESPONSE 2 TO MANYISM: ALMOST IDENTITY}

The second response to Manyism is another attempt by Lewis to explain away the implausibility of Manyism by appealing to almost-identity. The reason PM3 seems true is because the desks are 'almost-identical'. This attempt appeals to mereological overlap, i.e. by appealing to the parts that two or more objects share. According to Lewis, identity is not an all-or-nothing relation, but should instead be thought of as a continuum. On one end of the continuum, there's no mereological overlap at all, and thus there's no identity, while on the other end of the continuum, there's complete mereological overlap, and thus there's strict identity. When there's a lot of mereological overlap, there's 'almost-identity'. So, Woodrow and Woodrow-minus or Woodrow and Woodrow-plus are 'almost-identical' since they mereologically overlap significantly. Almost-identity can be used to show why there's only one desk while at the same time strict identity can be used to show that there's still a sense in which there are many desks. ${ }^{348}$

\section{REPLY TO ALMOST-IDENTITY}

One reply to Almost-Identity is proposed by Sutton, who argues against Lewis' idea of mereological overlap. Sutton argues that functional overlap is more important than mereological overlap. Mereological overlap may track functional overlap often, but they do come apart at times. And when they come apart, it turns out that functional overlap is more important than mereological overlap when it comes to questions regarding the number of members of a kind that

\footnotetext{
${ }^{347}$ Korman 2015: 220; Lewis 1986: 172-175. For replies to supervaluationism in terms of the Problem of the Many see Korman 2015: 220-222.

${ }^{348}$ Lewis 1999: 177-179; Sutton 2015: 45-47.
} 
exists. ${ }^{349}$ The idea is that since Woodrow and Woodrow-minus significantly overlap in their function, they should be considered as one object. So PM3 is true.

For example, imagine a duplex house with super thick walls; the shared wall is so thick it makes up $95 \%$ of the duplex. Although the living space in each of the houses is really small (it makes up only $5 \%$ combined), each of the houses still has a living room, bathroom, bedroom, etc. The two houses share most of their parts, and thus if we count by mereological overlap, the duplex is only one house. But it seems that there are two houses. If we were to count by functional overlap, there are two houses, since each house has a function as a house that doesn't overlap. So mereological overlap and functional overlap sometimes come apart, and moreover, functional overlap seems to give the correct answer here. ${ }^{350}$

Since the case described above shows that mereological and functional overlap can come apart, and moreover that functional overlap is more important, we should use functional overlap to solve the problem of the many. Sutton's proposal is:

"Functional Almost-Identity: Candidates $x$ and $y$ for kind-K are almost identical Ks if their token K-functions significantly overlap as a result of mereological overlap. If they are almost identical, then we count them as one K." 351 Applied to the duplex case, the two candidate houses "for the kind house are almost identical if their token house-functions significantly overlap as a result of mereological overlap. If they are almost identical, then we count them as one house. ${ }^{\text {"352 }}$ Since the function of a house is to live in it, the two house candidates don't functionally overlap, and therefore, we should count them as two houses - not one. ${ }^{353}$ Applied to the original case about the desks, where the function of a desk is to study/work at. Since the Woodrow-minus and Woodrow-plus do functionally overlap, we should count them as one desk.

\footnotetext{
${ }^{349}$ Sutton 2015: 46.

${ }^{350}$ Sutton 2015: 47.

${ }^{351}$ Sutton 2015: 48.

${ }^{352}$ Sutton 2015: 48.

${ }^{353}$ Sutton 2015: 48.
} 
Many ordinary kinds are already defined functionally, so this approach would work very well for those functional kinds. But many ordinary kinds are not usually defined functionally. In those cases, one could use the mereological approach or translate them into functional terms. Since mereological overlap usually tracks functional overlap, we could use either approach. For example, a non-functional kind such as a mass of matter can be defined by the parts it has, if one takes that the function of a mass of matter is to have its parts essentially. So, we would track the same thing regardless of the approach we use; we just look to see how much the parts of the candidate masses overlap. Moreover, it seems that we could define many non-functional kinds in functional terms anyway, for example, artefacts, biological organisms, fundamental particles, etc. since they all seem to have certain functional features. Artefacts have a certain purpose, biological organisms have parts that interrelate to serve functions such as growth, digestion, etc., and fundamental particles are often defined in terms of what they do. Overall, functionally defined objects are found everywhere, and using functional overlap to count those objects shows us what the essence of those objects are. Even if we had to use mereological overlap as a back-up plan, we wouldn't even need it that often. ${ }^{354}$

\subsection{ONTOLOGICAL CONCEPTUALISM}

I argue that Conservatist Minimal Realist views about ordinary objects, such as Ontological Conceptualism, can answer the Problem of the Many and the objections and responses proposed in this chapter. I argue PM1 is false. It is not true that Woodrow is a desk iff Woodrow-minus is a desk. Composition is not determined by the atoms that make up objects. Composite objects, such as ordinary objects, are not determined by other composite objects. But this is exactly what PM1 attempts to do. It claims that Woodrow is a composite object if and only if another composite object (Woodrow-minus) is a composite object. I argue this is false; composition is determined by the concepts we employ not by the existence of other objects.

\footnotetext{
${ }^{354}$ Sutton 2015: 49-50.
} 
Moreover, the way an object is conceptualized depends on a variety of factors, such as our conceptual knowledge, prior experiences, etc., which don't discriminate between objects that differ in one atom only, for the simple reason that we don't perceive those differences and because this difference isn't useful for us. For example, the concept TREE still functions as it would regardless of whether the concept picks out slightly different atoms. We don't use infinitely many concepts to refer to the almost infinite number of near-identical objects. For practical reasons, one concept will do the job even if it picks out a slightly different object each time. And this makes sense both from psychological/cognitive reasons in that we don't perceive the difference between two objects that differ in one atom, and it makes sense from an evolutionary viewpoint that one atom is not going to make a difference, for adaptive reasons. It also makes sense from a social/cultural viewpoint, since for social or cultural reasons it doesn't matter whether the atoms picked out by our concepts have one atom more or less.

If there is an object where one atom does make a difference, either for psychological, practical, or adaptive reasons, then we would conceptualize that object differently. For example, in in physics, if we were to discover an object made up of two atoms, then gaining or losing one atom would make a difference to what objects exist. Since in this case one atom does make a difference, we would conceptualize that object differently if it gained or lost one atom. But regarding ordinary objects, one atom does not make a difference, and therefore, we don't conceptualize objects differently when they gain or lose one atom. 


\section{CONCLUSION}

In this thesis I have set out the main arguments for eliminativism about ordinary objects and described the main objections to them. The basis for which was Korman's book Ordinary Objects: Nothing out of the ordinary, which I supplemented with some of the recent literature. Korman defined eliminativism as the view that ordinary objects do not exist. I explained that eliminativism is not merely the claim that ordinary objects don't exist, but also entails the claim about us being in error about the existence of ordinary objects, and the claim that we should stop talking about ordinary objects. Thus, the arguments for eliminativism he described in his book are not so much arguments for eliminativism per se, but rather, they are arguments for the claim that ordinary objects do not exist. For that reason, I framed the debate in terms of Minimal Realism and Minimal Anti-Realism. Next, I pointed out that Korman tacitly endorses a view about the nature of ordinary objects, namely that ordinary objects have intrinsic essences. I argued that ordinary objects don't have intrinsic essences, but instead that they are grounded in the concepts we employ. Moreover, I hope to have shown that views that take essences (or identity-conditions) to be grounded in our concepts, and thus endorse a mind-dependent view about ordinary objects, can address the arguments and the proposed objections and responses. 


\section{REFERENCES}

Baker, L.R. (2007). The metaphysics of everyday life. Cambridge: Cambridge University Press.

Barker, S. and Jago, M. (2014). Monism and material constitution. Pacific Philosophical Quarterly 95/1: 189-204.

Barrett, L.F. (2006). Solving the emotion paradox: categorization and the experience of emotion. Personality and Social Psychology Review 10/1: 20-46.

Barrett, L.F. (2009a). The future of psychology: connecting mind to brain. Perspectives on Psychological Science 4/4: 326-339.

Barrett, L.F. (2009b). Variety is the spice of life. Cognition \& Emotion 23/7: 1284-1306.

Barrett, L. F (2011). Constructing emotion. Psychological Topics 3: 359-380.

Barrett, L.F., Mendenhall, C.D., and Barsalou, L.W. (2015). The conceptual act theory: A roadmap. In The Psychological Construction of Emotion. New York: The Guilford Press.

Benacerraf, P. (1973). Mathematical truth. Journal of Philosophy 70/19: 661-679.

Benovsky, J. (2011). Vagueness: A statistical epistemicist approach. Teorema 30/3: 97-111.

Benovsky, J. (2015). From experience to metaphysics: On experience-based intuitions and their role in metaphysics. Nous 49/3: 684-697.

Bernstein, S. (2016). Overdetermination underdetermined. Erkenntnis 81: 17-40.

Biederman, I. (1987). Recognition-by-components: A theory of human image understanding. Psychological Review 94/2: 115-117.

Bird, A. and Tobin, E. (2017). Natural kinds. The Stanford Encyclopedia of Philosophy.

Block, N. (2014). Seeing-as in the light of vision science. Philosophy and Phenomenological Research 89/1: 560-572.

Bloom, P. (1996). Intention, history, and artefact concepts. Cognition 60: 1-29.

Bowers, J. (2016). A teleological answer to the special composition question.

Brock, S., Maslen, C., and Ngai, J. (2013). A puzzle about fictional characters. In Carola Barbero, Maurizio Ferraris, and Alberto Voltolini (eds.), From Fictionalism to Realism. Cambridge: Cambridge Scholars Publishing: 63-86.

Byrne, A. (2005). Perception and conceptual content. In Ernest Sosa \& Matthias Steup (eds.), Contemporary Debates in Epistemology. Blackwell: 231-250.

Byrne, A. (2009). Experience and Content. Philosophical Quarterly 59: 429-451.

Campdelacreu, M. (2015). The constitution relation and Baker's account of it. International Journal of Philosophical Studies 21/1: 1-19.

Dretske, F. (1995). Naturalizing the Mind. Cambridge: MIT Press.

Einheuser, I. (2003). Conventionalism. Dissertation. Massachusetts Institute of Technology. 
Einheuser, I. (2006). Counterconventional conditionals. Philosophical Studies 127/3: 459-482.

Einheuser, I. (2011). Toward a conceptualist solution of the grounding problem. Nous 45/2: 300-314.

Elder, C. (2011). Familiar objects and their shadows. Cambridge: Cambridge University Press.

Evans, G. (1978). Can there be vague objects. Analysis 38/4: 208.

Evnine, S.J. (2016). Review Objects: Nothing out of the ordinary by Daniel Z. Korman. Notre Dame Philosophical Reviews.

Fine, K. (1994). Essence and modality. Philosophical Perspectives 8: 1-16.

FitzPatrick, J.W. (2015). Debunking evolutionary debunking of ethical realism. Philosophical Studies 172/4: 883-904.

Goldstein, E.B (2015). Cognitive psychology: Connecting mind, research, and everyday experience. Cengage Learning.

Goodman, N. (1978). Ways of worldmaking. Hackett Publishing.

Grandy, R.E. (2016). Sortals. The Stanford Encyclopedia of Philosophy.

Heller, M. (1990). The ontology of physical objects: Four-dimensional hunks of matter. Cambridge: Cambridge University Press.

Hirsch, E. (1976). Physical identity. The Philosophical Review 85: 357-389.

Hirsch, E. (1982). The concept of identity. New York: Oxford University Press.

Hricko, J. and Leben, D. (forthcoming). In defense of best-explanation debunking arguments in moral philosophy. Review of Philosophy and Psychology 1-18.

Humberstone, I.L. (1996). Intrinsic/Extrinsic. Synthese 108: 205-267.

Jago, M. (2016). Essence and the grounding problem. In Mark Jago (ed.), Reality Making. Oxford: Oxford University Press: 99-120.

Joyce, R. (2006). The evolution of morality. Cambridge: MIT Press.

Korman, D.Z. (2015). Objects: Nothing out of the ordinary. New York: Oxford University Press.

Korman, D.Z. (2016). Ordinary Objects. The Stanford Encyclopedia of Philosophy.

Korman, D.Z. and Carmichael, C. (2017). In David Rose (ed.), Experimental Metaphysics. London: Bloomsbury Academic: 187-206.

Koslicki, K. (2016). Where grounding and causation part ways: Comments on Jonathan Schaffer. Philosophical Studies 173/1: 101-112.

Kurtsal Steen, I. (2014). Almost-ontology: Why epistemicism cannot help us avoid unrestricted composition or diachronic plenitude. Pacific Philosophical Quarterly 95: 130-139.

Le Bihan, B. (2015). No physical particles for a dispositional monist. Philosophical Papers 44/2: 207232.

Lewis, D. (1986). On the plurality of worlds. New York: Blackwell 
Lindquist, K.A. (2013). Emotions emerge from more basic psychological ingredients: A modern psychological constructionist model. Emotion Review 5/4: 356-368.

Lowe, E.J. (2008). Two notions of being: Entity and essence. Royal Institute of Philosophy Supplement 83/62: 23-48.

Machery, E (2017). Philosophy within its proper bounds. New York: Oxford University Press.

Markosian, N. (1998). Brutal composition. Philosophical Studies 92: 211-249.

Martin, M.G.F. (1992). Perception, concepts, and memory. In Y. Gunther (ed.), Essays in NonConceptual Content. Cambridge: MIT Press: 237-250.

Merricks, T. (2001). Objects and Persons. New York: Oxford University Press.

Merricks, T. (2017). Locating vagueness. Journal of Philosophy 114/5: 221-250.

Nanay, B. (2011). Do we see apples as edible? Pacific Philosophical Quarterly 92/3: 305-322.

Olivero, I. (2016). Review Objects: Nothing out of the ordinary by Daniel Z. Korman. Universa: Reconsioni di filosofia 5/2: 91, 95.

Osborne, R.C. (2016). Debunking rationalist defenses of common-sense ontology: An empirical approach. Review of Philosophy and Psychology 7/1: 197-221.

Peacocke, C. (1979). Deviant causal chains. Midwest Studies in Philosophy 4: 123-155.

Peacocke, C. (1992). A study of concepts. Cambridge: MIT Press.

Price, R. (2009). Aspect-switching and visual phenomenal character. Philosophical Quarterly 59/236: 508-518.

Pust, J. (2017). Intuition. The Stanford Encyclopedia of Philosophy.

Rea, M. (2002). World without design. New York: Oxford University Press.

Rose, D. and Schaffer, J. (2017). Folk mereology is teleological. Nous 51/2: 238-270.

Sanson, D. (forthcoming). Review Objects: Nothing out of the ordinary by Daniel Z. Korman. Australasian Journal of Philosophy

Sattig, T. (2015). The double lives of objects. Oxford: Oxford University Press.

Sider, T. (2001). Four-Dimensionalism. Oxford: Clarendon Press.

Sider, T. (2003). What's so bad about overdetermination. Philosophy and Phenomenological Research LXVII/3: 719-726.

Siegel, S. and Byrne, A. (2016). Rich or thin? In Bence Nanay (ed.), Current Controversies in Philosophy of Perception. Routledge.

Siegel, S. (2017). The rationality of perception. Oxford: Oxford University Press.

Siewert, C. (1998). The significance of consciousness. Princeton: Princeton University Press.

Skiles, A. (2015). Against grounding necessitarianism. Erkenntnis 80/4: 717-751.

Rescorla, M. (2017). Convention. Stanford Encyclopedia of Philosophy. 
Street, S. (2006). A Darwinian dilemma for realist theories of value. Philosophical Studies 127: 109166.

Sutton, C.S. (2015). Almost one, overlap and function. Analysis 75/1: 45-52.

Sytsma, J. and Buckwalter, W. (2016). A companion to experimental philosophy. Oxford: Wiley \& Sons, Ltd.

Thomasson, A. (2006). Metaphysical arguments against ordinary objects. The Philosophical Quarterly 56/224: 340-359.

Thomasson, A. (2007). Ordinary Objects. Oxford: Oxford University Press.

Trogdon, K. (forthcoming). Grounding-mechanical explanation. Philosophical Studies.

Tye, M. (1995). Then Problems of Consciousness. Cambridge: MIT Press.

van Inwagen, P. (1990). Material Beings. Ithaca: Cornell.

Wasserman, R. (2017). Vagueness and the laws of metaphysics. Philosophy and Phenomenological Research XCV/1: 66-89.

Wilson, A. (ms). Metaphysical causation. 
